GAS SLAG REACTION KINETICS

IN 


\title{
GAS SLAG REACTION KINETICS \\ IN \\ SLAG CLEANING OF COPPER SLAGS
}

BY

ELAINE (XIAO MING) CHEN

\author{
A Thesis \\ Submitted to the School of Graduate Studies \\ in Partial Fulfillment of the Requirements \\ for the Degree \\ Master of Engineering
}

McMaster University

(C) Copyright by Elaine (X.M) Chen, January 2005 
Master of Engineering (2005)

McMaster University

Materials Science and Engineering

Hamilton, Ontario

TITLE: Gas Slag Reaction Kinetics in Slag Cleaning of Copper Slags

AUTHOR: Elaine (X.M) Chen, B. Eng. (Northeastern University, China)

SUPERVISOR: Professor K. S. Coley

NUMBER OF PAGES: $x v, 95$ 


\begin{abstract}
The reduction of iron oxide from slag is involved in many processes, such as, bath smelting, EAF steelmaking and copper slag cleaning processes, and it is known to occur via gaseous intermediates. Four possible rate determining steps are involved during the reduction. Among them, these two interfacial chemical reactions, gas slag and gas carbon could ultimately limit the enhancement of these processes.
\end{abstract}

In this work, the gas slag reaction kinetics in slag cleaning of copper slags has been studied. The dissociation rate of $\mathrm{CO}_{2}$ on the surface of liquid copper slags is measured using an isotope exchange method, where the mass transfer in the gas phase was eliminated by using a sufficiently high gas flowrate.

It is found that, for slag of the $\mathrm{Fe}_{\mathrm{x}} \mathrm{O}-\mathrm{SiO}_{2}-\mathrm{Al}_{2} \mathrm{O}_{3}-\mathrm{Cu}_{2} \mathrm{O}$ system, the apparent rate constant remains fixed with $\mathrm{Cu}_{2} \mathrm{O}$ content from 1-10 wt pct at higher oxygen potentials. The rate constant becomes approximately 2 times higher after metallic copper is reduced from the slag, this is due to the suspension of small metal drops on the slag surface.

The effect of temperature in the range from $1200-1450^{\circ} \mathrm{C}$ on the rate constants was also studied. The activation energy was $190 \mathrm{~kJ} /$ mole for slag of composition $60 \mathrm{Fe}_{\mathrm{x}} \mathrm{O}$ $30 \mathrm{SiO}_{2}-10 \mathrm{Al}_{2} \mathrm{O}_{3}$. In the presence of $\mathrm{Cu}$ metal $\sim 10 \%$, the activation energy was reduced to $122 \mathrm{~kJ} /$ mole. 


\section{ACKNOWLEDGEMENTS}

I am greatly indebted to my supervisor, Dr. K.S. Coley for his guidance and encouragement. I can't begin to describe my gratitude for the many learning opportunities that he provided me with.

I am also grateful to Dr. F. Z. Ji. I will always remember with gratitude the many times when he stayed late and assisted in arranging the experimental setup. A sincere note of gratitude is extended to Mansoor Barati for the valuable ideas that he contributed to this work.

I wish to thank the staff of the department of Materials Science and Engineering in the course of this work. The financial support of Center for Chemical Process Metallurgy (CCPM) and NSERC is gratefully acknowledged.

I am also grateful for the support and encouragement of my husband and my parents throughout my graduate study. 


\section{TABLE OF CONTENTS}

List of figures $\quad$ ix

List of tables $\quad$ xii

Symbols and abbreviations $\quad$ xiii

\section{Literature Review}

1.1 Main Reactions in Slag Cleaning Furnaces 3

1.2 Mechanism of Slag Reduction 5

1.3 Possible Rate Determining Steps 7

1.4 Liquid Phase Mass Transfer Control (LPMT) 8

1.5 Gas Diffusion 9

1.6 Gas-Metal and Gas-Carbon Reaction 11

1.6.1 The Model for Gas-Metal Reaction $\quad 11$

1.6.2 The Model for Gas-Carbon Reaction $\quad 13$

1.7 Model for the Gas Slag Reaction 22

1.7.1 Isotope Exchange Method 22

$\begin{array}{ll}\text { 1.7.2 Thermo-Gravimetric Technique } & 27\end{array}$

1.7.3 The Work Done by Utigard et al. 29

1.8 Critical Analysis of the Literature 31

$2{ }^{13} \mathrm{C}$ Isotope Exchange Method

2.1 The Rate-Limiting Step for Isotope Exchange Reaction 34

2.2 The Equation of ${ }^{13} \mathrm{C}$ Method 35

2.3 The Calculation of Parameters in the Equation $\left(\mathrm{CO}_{2}\right.$ Method $) \quad 40$ 


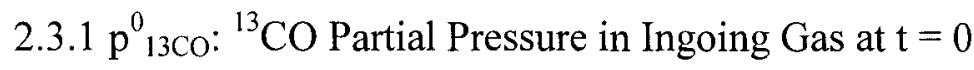

2.3.2 $\mathrm{p}_{13 \mathrm{CO}}$ : the Partial Pressure of ${ }^{13} \mathrm{CO}$ after Isotope Exchange

2.3.3 The Calculation of Partial Pressure of ${ }^{13} \mathrm{CO}$ at Equilibrium

2.4 The Recalculation of Parameters in the Equation (CO Method)

\section{Experimental Work}

3.1 The furnace

3.2 GC and MS

3.3 The Experimental Materials

3.4 The Procedure

3.5 Experimental Errors

\section{Experimental Results}

4.1 Liquid Aluminum Iron Silicates $\quad 57$

$\begin{array}{ll}4.2 & \text { Liquid Copper-Making Slag }\end{array}$

5 Discussion of Experimental Results

5.1 The Effect of $\mathrm{Cu}_{2} \mathrm{O}$ on the Dissociation Rate of $\mathrm{CO}_{2}$

5.1.1 The Site Blockage Model

5.1.2 The Apparent Rate Constants as a Function of $\mathrm{Fe}^{+3} / \mathrm{Fe}^{+2}$ Ratio

5.1.3 The Charge Transfer Model

5.2 The Effect of Metallic $\mathrm{Cu}$ on the Rate Constant

\section{Conclusions}


6.1 Conclusions

6.2 Future Work

References: 


\section{LIST OF FIGURES:}

(1.1) The main reactions in slag cleaning furnace 5

(1.2) The mechanism of slag reduction $\quad 7$

(1.3) Comparison of experimental measurements with rate model 15 predictions for stationary graphite rods

(1.4) Comparison of experimental measurements with rate model 16 predictions for stationary coke rods

(1.5) Slag reduction rate at $1300^{\circ} \mathrm{C}$ as a function of magnetite 19

(1.6) Logarithm of the rate vs inverse of absolute temperature 20

(1.7) The relationship between rate constant and oxygen potentials 25

(1.8) Comparison of the apparent forward rate constants between 26 liquid $\mathrm{CaO}$-saturated calcium ferrites and liquid iron oxide at $1500^{\circ} \mathrm{C}$

(1.9) The dependence of the apparent rate constant on iron oxide 28 content at $1773 \mathrm{~K}$

(3.1) Schematic diagram of the experimental setup 48

(3.2) The temperature profile of the furnace 49

(3.3) The overall view of experimental arrangement 51

(3.4) The furnace and gas train 52

(3.5) The GC and MS 52 
(3.6) The detail arrangement of crucible and blowing tube 54

(4.1) The effect of gas flowrate on the apparent rate constant for slag 58 $60 \mathrm{Fe}_{\mathrm{x}} \mathrm{O}-30 \mathrm{SiO}_{2}-10 \mathrm{~A} \mathrm{l}_{2} \mathrm{O}_{3}$ at $\mathrm{T}=1585 \mathrm{~K}$ and $\mathrm{pCO}_{2} / \mathrm{pCO}=1$

(4.2) The time for achieving equilibrium for slag $60 \mathrm{Fe}_{\mathrm{x}} \mathrm{O}-30 \mathrm{SiO}_{2}-$ $10 \mathrm{~A}_{2} \mathrm{O}_{3}$ at $\mathrm{T}=1585 \mathrm{~K}$ and $\mathrm{pCO}_{2} / \mathrm{pCO}=1$

(4.3) Apparent rate constants $\left(\mathrm{mol} \mathrm{cm} \mathrm{s}^{-2} \mathrm{~atm}^{-1}\right)$ for the dissociation 60 of $\mathrm{CO}_{2}$ on liquid aluminum iron silicates at $1585 \mathrm{~K}$ as a function of the equilibrium $\mathrm{CO}_{2} / \mathrm{CO}$ ratio

(4.4) Apparent rate constants $\left(\mathrm{mol} \mathrm{cm} \mathrm{s}^{-2} \mathrm{~atm}^{-1}\right)$ for the dissociation 61 of $\mathrm{CO}_{2}$ on liquid aluminum iron silicates at $1585 \mathrm{~K}$ and $1723 \mathrm{~K}$ as a function of the equilibrium $\mathrm{CO}_{2} / \mathrm{CO}$ ratio

(4.5) Arrhenius plot of the apparent rate constants for liquid 62 aluminum iron silicates at an equilibrium $\mathrm{CO}_{2} / \mathrm{CO}$ ratio of 1

(4.6) Apparent rate constants $\left(\mathrm{mol} \mathrm{cm} \mathrm{s}^{-1} \mathrm{~atm}^{-1}\right)$ for the dissociation 65 of $\mathrm{CO}_{2}$ on slag of $60 \mathrm{Fe}_{\mathrm{x}} \mathrm{O}-30 \mathrm{SiO}_{2}-10 \mathrm{Al}_{2} \mathrm{O}_{3}$ and $60 \mathrm{Fe}_{\mathrm{x}} \mathrm{O}$ $30 \mathrm{SiO}_{2}-10 \mathrm{Al}_{2} \mathrm{O}_{3}-10 \mathrm{Cu}_{2} \mathrm{O}$ at $1585 \mathrm{~K}$ as a function of the equilibrium $\mathrm{CO}_{2} / \mathrm{CO}$ ratio

(4.7) Apparent rate constants ( $\left.m o l \mathrm{~cm}^{-2} \mathrm{~s}^{-1} \mathrm{~atm}^{-1}\right)$ for the dissociation 66 of $\mathrm{CO}_{2}$ on slag of $60 \mathrm{Fe}_{\mathrm{x}} \mathrm{O}-30 \mathrm{SiO}_{2}-10 \mathrm{Al}_{2} \mathrm{O}_{3}$ and $60 \mathrm{Fe}_{\mathrm{x}} \mathrm{O}$ $30 \mathrm{SiO}_{2}-10 \mathrm{~A}_{2} \mathrm{O}_{3}-10 \mathrm{Cu}_{2} \mathrm{O}$ at $1585 \mathrm{~K}$ and $1723 \mathrm{~K}$ as a function of the equilibrium $\mathrm{CO}_{2} / \mathrm{CO}$ ratio 
(4.8) Arrhenius plot of the apparent rate constants for slag of $60 \mathrm{Fe}_{\mathrm{x}} \mathrm{O}-30 \mathrm{SiO}_{2} 10 \mathrm{Al}_{2} \mathrm{O}_{3}$ and $60 \mathrm{Fe}_{\mathrm{x}} \mathrm{O}-30 \mathrm{SiO}_{2}-10 \mathrm{~A}_{2} \mathrm{O}_{3}-$ $10 \mathrm{Cu}_{2} \mathrm{O}$ at an equilibrium $\mathrm{CO}_{2} / \mathrm{CO}$ ratio of 1

(4.9) Apparent rate constants $\left(\mathrm{mol} \mathrm{cm} \mathrm{s}^{-2} \mathrm{~atm}^{-1}\right)$ for the dissociation 69 of $\mathrm{CO}_{2}$ on slag of different percentages of $\mathrm{Cu}_{2} \mathrm{O}$ based on liquid aluminum iron silicates at $1723 \mathrm{~K}$ as a function of the equilibrium $\mathrm{CO}_{2} / \mathrm{CO}$ ratio

(5.1) The apparent first order rate constants for slag of different 72 percentages of $\mathrm{Cu}_{2} \mathrm{O}$ at $1723 \mathrm{~K}$ as a function of the equilibrium $\mathrm{CO}_{2} / \mathrm{CO}$ ratio

(5.2) The dependence of the apparent rate constants on oxygen potential at $1723 \mathrm{~K}$

(5.3) The effect of metallic copper on the rate constants

(5.4) Dependence of the apparent first order rate constant on oxygen potential

(5.5) The rate constants as a function of temperatures at $\mathrm{pCO}_{2} / \mathrm{pCO}$ $=1$

(5.6) The comparison between the area fraction calculated from equation (5.11) and that assuming all reduced copper distributes in the crucible evenly

(5.7) The change of the radii of the droplets calculated from kinetic measurements with the percentage of reduced metallic copper 


\section{LIST OF TABLES:}

(1.1) The slag and products composition for the continuous smelting systems. 4

$\begin{array}{lll}(1.2) & \text { Surface area. } & 18\end{array}$

$\begin{array}{ll}\text { (1.3) The rate constants for different binary systems. } & 27\end{array}$

(1.4) The comparisons of gas flowrate used in different experiments. 30

$\begin{array}{lll}\text { (4.1) The control of oxygen potentials. } & 68\end{array}$ 


\section{SYMBOLS AND ABBREVIATIONS:}
A Slag surface area
B Oxygen potential $=\mathrm{pCO}_{2} / \mathrm{pCO}$
$\mathrm{D}_{\text {Diff }} \quad$ Diffusivity $\left(\mathrm{cm}^{2} / \mathrm{s}\right)$
$D_{\mathfrak{e}} \quad$ Effective diffusivity
J Reaction rate $\left(\mathrm{mol} \mathrm{cm} \mathrm{s}^{-2} \mathrm{~s}^{-1}\right)$
$\mathrm{k} \quad$ Intrinsic rate constant expressed per unit total pore surface area
k" Reverse rate constant
$\mathrm{k}_{\mathrm{a}} \quad$ The rate constant of ${ }^{13} \mathrm{CO}_{2}$ dissociation
$\mathrm{k}_{\mathrm{Boud}} \quad$ Rate constants for Boudouard reaction
$\mathrm{k}_{\mathrm{C}} \quad$ Rate constants for mass transfer of carbon in the metal
$\mathrm{k}_{\mathrm{f}} \quad$ The rate constant of ${ }^{14} \mathrm{CO}_{2}$ dissociation
$\mathrm{k}_{\text {gas }} \quad$ Rate constants for mass transfer of gas
$\mathrm{k}_{\mathrm{g} / \mathrm{s}} \quad$ Rate constants for gas-slag reaction
$\mathrm{k}_{\mathrm{M} / \mathrm{O}} \quad$ Rate constants for mass transfer of liquid metal oxides
$\mathrm{M}_{\mathrm{FeO}} \quad$ Molecular weight of $\mathrm{FeO}$
$\mathrm{m}_{\mathrm{g}} \quad$ Gas phase mass transfer coefficient
$\mathrm{m}_{\mathrm{s}} \quad$ Mass transfer coefficient $\left(\mathrm{cm} \mathrm{s}^{-1}\right)$
n Number of moles
$N^{\prime} \quad$ Counting rate of the ingoing ${ }^{14} \mathrm{CO}_{2}$ 
${ }^{14} \mathrm{CO}_{2}$ which results from conversion of $\mathrm{CO}$

P

Partial pressure

pct $\mathrm{FeO} \quad \mathrm{FeO}$ content (weight percent) in the slag bulk

pct $\mathrm{FeO}^{\mathrm{e}} \quad \mathrm{FeO}$ content (weight percent) at the slag-gas interface

$\mathrm{P}^{0}{ }_{13 \mathrm{CO}} \quad$ Partial pressure of ${ }^{13} \mathrm{CO}$ in ingoing gas

$\mathrm{P}_{13 \mathrm{CO}} \quad$ Partial pressure of ${ }^{13} \mathrm{CO}$ after isotope exchange

$\left(\mathrm{P}_{13 \mathrm{CO}}\right)_{\mathrm{eq}} \quad$ Partial pressure of ${ }^{13} \mathrm{CO}$ at equilibrium

$\mathrm{P}_{14 \mathrm{CO}} \quad$ Partial pressures of tagged ${ }^{14} \mathrm{CO}_{2}$ after reaction

$\left(\mathrm{P}_{14 \mathrm{CO}}\right)_{\mathrm{eq}} \quad$ Partial pressure of tagged ${ }^{14} \mathrm{CO}_{2}$ at complete isotope equilibrium

$\mathrm{p}^{\mathrm{s}} \quad$ Pressure of the reacting gas at external surface

R Gas constant

$\mathrm{R}_{\text {ref. }} \quad$ Sample ratio of minor to major beam

$\mathrm{R}_{\mathrm{sam}} \quad$ Reference ratio of minor to major beam

S Pore surface per unit mass (specific internal surface area)

$\theta_{\mathrm{i}} \quad$ Fractional coverage of adsorbed species

$\theta_{0} \quad$ Fractional coverage by oxygen

$\dot{V} \quad$ Gas flowrate

z Thickness of the gas halo (millimeter)

$\left(\frac{2}{1}\right)_{i n}^{\infty} \quad$ Natural fraction of ${ }^{13} \mathrm{CO}$ in the ingoing gases 


$\begin{array}{ll}\left(\frac{2}{1}\right)_{o u t}^{C O} & \text { Abundance of }{ }^{13} \mathrm{CO} \text { in the outgoing gases } \\ \left(\frac{2}{1}\right)_{\text {in }}^{c_{\text {co }}} & \text { Abundance of }{ }^{13} \mathrm{CO}_{2} \text { in the ingoing gases } \\ \left(\frac{2}{1}\right)_{\text {out }}^{c c_{2}} & \text { Abundance of }{ }^{13} \mathrm{CO}_{2} \text { in the outgoing gases } \\ \delta & \text { Enrichment }\end{array}$




\section{Chapter 1:}

\section{Literature Review}

In the modern copper making industry, reverberatory furnace matte and electricfurnace matte smelting have been replaced by flash and continuous processes due to the improved use of energy and control of emissions. The extraction of $\mathrm{SO}_{2}$ from low concentration gases produced by the earlier generation of copper smelting furnaces is difficult and very costly. Flash furnaces produce higher concentrations $\mathrm{SO}_{2}$ (for example, $80 \%$ for INCO oxygen flash furnace). [2] However, a new problem occurs with the application of these new technologies, the loss of copper to the slag.

In the non-ferrous industry, more and more attention has been paid to the recovery of valuable metals, such as cobalt, copper and nickel, from the slag. This can be done by using electric slag-cleaning furnaces. [4][5] 
Usually coal or coke is injected into these furnaces to reduce the oxides of iron and copper to $\mathrm{FeO}$ and copper metal. During the reduction of slags, there are four possible rate determining steps, namely, $[1][5][6][7][8][11][12][25]$

1) Mass transfer of metal oxides $\left(\mathrm{Fe}^{2+}, \mathrm{Fe}^{3+}\right.$ and $\left.\mathrm{O}^{2-}\right)$ from the bulk of the slag to the slag-gas interface;

2) Chemical reaction at the slag-gas interface;

3) Mass transfer of $\mathrm{CO}_{2}$ away from the slag-gas interface toward the gas-carbon interface and diffusion of $\mathrm{CO}$ away from the gas-carbon interface to the slag-gas interface;

4) Chemical reaction at the gas-carbon interface;

In this chapter, the reduction mechanism of these metal oxides, the four possible rate determining steps as well as individual models are reviewed (1.4-1.7). The chapter ends with a critical discussion of the existing literature (1.8). The aim of the discussion is to highlight the importance of this study, filling in the gaps in gas slag reaction kinetics relevant to the copper making industry. 


\subsection{The main reactions in slag cleaning furnaces}

In modern copper making processes, due to the extensive oxidation, copper oxide is dissolved in the slag and excess solid magnetite is formed on the slag surface in the matte smelting furnace. [2] The formation of solid $\mathrm{Fe}_{3} \mathrm{O}_{4}$ increases the viscosity of the slag. In addition, the extensive oxidation also leads to the formation of more $\mathrm{Fe}^{3+} . \mathrm{Fe}^{3+}$ is a good network former, which makes slag more viscous, and eventually inhibits matte settling to the bottom. All of these factors result in a larger amount of copper being lost to the slag.

The losses of copper to the slag are in three forms, copper oxide, copper sulphide and metallic copper, as dissolved oxides and as mechanically entrained matte or metal prills, respectively. [42] [44] It has been widely accepted that copper oxide in the slag in contact with metallic copper at high temperature is in the form of $\mathrm{Cu}_{2} \mathrm{O}$. [20] The reduction of cuprous oxides occurs simultaneously with the reduction of iron oxide. [10] With $\mathrm{Fe}^{3+}$ being reduced $\mathrm{Fe}^{2+}$, the viscosity of the slag is decreased. This allows any entrained matte or metal prills settle to the bottom, realizing the separation of slag and matte. In the slag cleaning furnace, the slag typically consists of $\mathrm{Fe}_{x} \mathrm{O}, \mathrm{Cu}_{2} \mathrm{O}, \mathrm{SiO}_{2}$, and $\mathrm{Al}_{2} \mathrm{O}_{3}$, see table 1 . 


\begin{tabular}{|l|l|l|l|l|l|}
\hline \multirow{2}{*}{} & \multicolumn{4}{|l|}{ Composition \% } & \multicolumn{2}{l|}{} \\
\cline { 2 - 6 } & $\mathbf{C u}$ & $\mathbf{F e}$ & $\mathbf{S i O}_{2}$ & $\mathbf{C a O}$ & $\mathbf{A l}_{2} \mathbf{O}_{3}$ \\
\hline Slag in cleaning furnace & 0.5 & $30-40$ & $30-35$ & $5-10$ & $2-5$ \\
\hline Converting furnace slag & 15 & $65-70$ & & $10-20$ & \\
\hline Blister copper & $99-99.5$ & & & & \\
\hline
\end{tabular}

Table (1.1): The slag and products composition for continuous smelting systems. [2]

The main reactions in electric furnaces used for slag cleaning are: [2][4][23]

a. The decomposition of coal hydrocarbons and partial combustion of the resulting products:

$$
\begin{aligned}
\mathrm{C}_{\mathrm{n}} \mathrm{H}_{\mathrm{m}} & \rightarrow \mathrm{nC}+\mathrm{m} / 2 \mathrm{H}_{2} \\
2 \mathrm{C}+\mathrm{O}_{2} & \rightarrow 2 \mathrm{CO} \\
2 \mathrm{H}_{2}+\mathrm{O}_{2} & \rightarrow 2 \mathrm{H}_{2} \mathrm{O}
\end{aligned}
$$

b. The reduction of magnetite and cuprous oxide,

$$
\begin{aligned}
& \mathrm{Fe}_{3} \mathrm{O}_{4(\mathrm{~s})}+\mathrm{CO} \rightarrow 3 \mathrm{FeO}_{(\text {slag })}+\mathrm{CO}_{2} \\
& \mathrm{Fe}_{3} \mathrm{O}_{4(\mathrm{~s})}+\mathrm{H}_{2} \rightarrow 3 \mathrm{FeO}_{(\text {slag })}+\mathrm{H}_{2} \mathrm{O} \\
& \mathrm{Cu}_{2} \mathrm{O}_{\text {(slag) }}+\mathrm{CO} \rightarrow 2[\mathrm{Cu}]_{\text {metal }}+\mathrm{CO}_{2} \\
& \mathrm{Cu}_{2} \mathrm{O}_{\text {(slag) }}+\mathrm{H}_{2} \rightarrow 2[\mathrm{Cu}]_{\text {metal }}+\mathrm{H}_{2} \mathrm{O}
\end{aligned}
$$




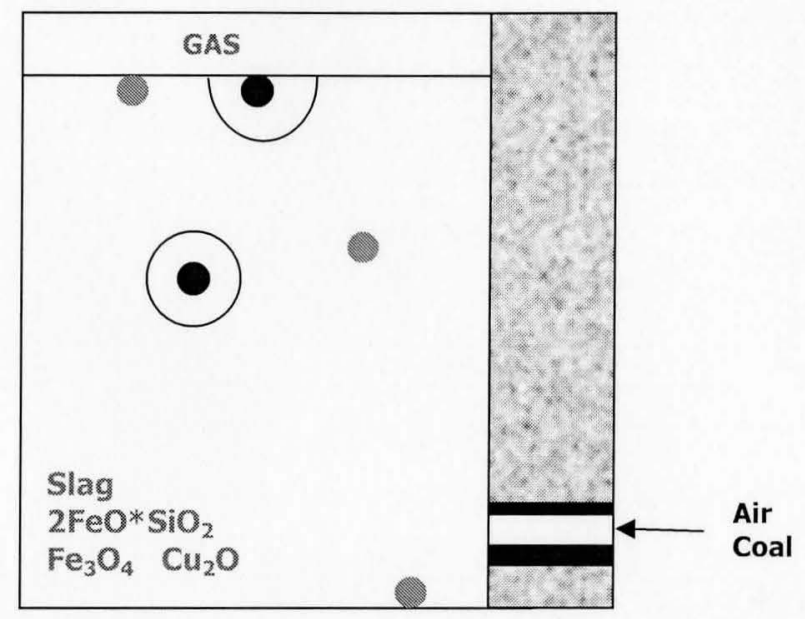

Metallic Cu c

Figure (1.1): The main reactions in slag cleaning furnace.

During the cleaning of the slag, attention should be given to control of the oxygen potential so that no metallic iron is produced, because it will be impossible to separate the reduced metals from each other once the alloy is formed. [3]

\subsection{Mechanism of slag reduction}

The reduction of iron oxides from slag is also important in iron and steel-making. Smelting reduction processes are being developed in some industrialized countries, which can use coal and pulverized ore instead of coke and lumpy ore. [21] In addition, almost 
$50 \%$ of world steel is made in the electrical arc furnace (EAF). These processes involve the reduction of iron oxides from slag, and many studies have been conducted on various aspects of this. [6]-[8], [11] [12], [14]-[19], [25]-[27], [36]. Good agreement has been obtained with regard to the reduction mechanism, although there are numerous discrepancies relating to the rate determining step and magnitude of the rate. [11]

Some researchers have investigated the mechanism of slag reduction relevant to non-ferrous smelting, and they also obtained similar results to their ferrous counterparts. $[4][5][42]$

The consensus is that the reduction of iron oxide proceeds via reducing gases which are produced after the injection of coal into the furnace. The overall reduction reaction can be regarded to proceed by the following steps:

$$
\begin{aligned}
& \mathrm{Fe}_{3} \mathrm{O}_{4}+\mathrm{CO}_{\text {(gas) }}\left(\text { or } \mathrm{H}_{2}\right)=\mathrm{FeO}+\mathrm{CO}_{2} \text { (gas) } \\
&\left.\left(\mathrm{Cu}_{2} \mathrm{O}\right)_{\text {slag }}+\mathrm{CO} \mathrm{H}_{2} \mathrm{O}\right) \\
&\left.\mathrm{CO}_{2 \text { (gas) }} \text { (or } \mathrm{H}_{2}\right)=2[\mathrm{Cu}]_{\text {metal }}+\mathrm{CO}_{2} \text { (gas) } \\
&\left(\text { or } \mathrm{H}_{2} \mathrm{O}\right) \\
& \mathrm{H}_{2} \mathrm{O}_{\text {(gas) }}+\mathrm{C}=2 \mathrm{CO}_{\text {(gas) }} \\
&=\mathrm{CO}_{\text {(gas) }}+\mathrm{H}_{2 \text { (gas) }}
\end{aligned}
$$

Carbon in reaction (1.3) and (1.4) can either present as solid carbon or dissolved in liquid metal. 
Figure 1.2 shows the mechanism of slags reduction in slag cleaning furnaces.

\section{Liquid slag with magnetite}

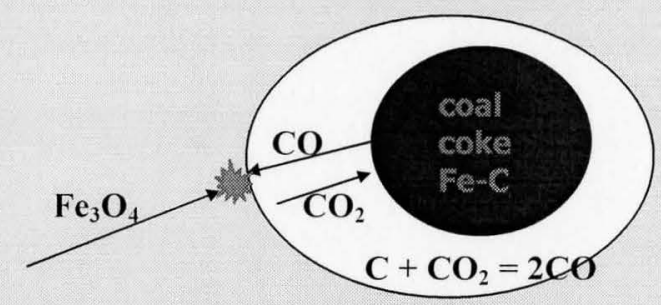

$\mathrm{Cu}_{2} \mathrm{O}+\mathrm{CO}=2 \mathrm{Cu}+\mathrm{CO}_{2}$

$$
\mathrm{Fe}_{3} \mathrm{O}_{4}+\mathrm{CO}=3 \mathrm{FeO}+\mathrm{CO}_{2}
$$

Figure (1.2): The mechanism of slag reduction.

\subsection{Possible rate determining steps}

As mentioned above, the reduction of metal oxides is done by reducing gas, $\mathrm{CO}$ or $\mathrm{H}_{2}$, which is produced by the injection of coal. This is a typical heterogeneous reaction involving liquid slag, solid carbon and gases. By understanding the mechanism of slag reduction, the possible rate-determining steps might be determined, as mentioned before, which are the mass transfer of liquid iron oxides, $\mathrm{CO} / \mathrm{CO}_{2}$ diffusion, and these two interfacial chemical reactions at the slag-gas interface and the gas carbon interface. 
The overall rate constant is expressed by equation (1.5),

$$
k_{0}=\frac{1}{\frac{1}{k_{\text {Boud }}}+\frac{1}{k_{z / s}}+\frac{1}{k_{\text {gas }}}+\frac{1}{k_{M O}}}
$$

where $k_{\text {Boud }}$ and $k_{g / s}$ are rate constants for Boudouard reaction and gas-slag reaction, $k_{\text {gas }}$ and $k_{M O}$ are rate constants for mass transfer of gas and liquid metal oxides.

\subsection{Liquid phase mass transport control (LPMT)}

Paul et al. [8] concluded that, the reduction of $\mathrm{FeO}$ by carbon in liquid iron is controlled by mass transfer of $\mathrm{FeO}$ in the slag plus chemical reaction at gas metal interface in the case of slag containing mass contents of less than 5\% FeO. Min et al. [6] also found that the rate-determining step is the mass transfer at a low FeO contents less than $5 \mathrm{wt}$ pet. Sarma et al. [14] developed a mathematical model to calculate the flux of FeO.

$$
-J_{\text {Fer }}=J_{(O)}=\frac{m_{s} \rho}{100 M_{F e O}}\left(p c t F e O^{h}-p c t F e O^{e}\right)
$$


Where:

$\mathrm{J}$ is the reaction rate $\left(\mathrm{mol} \mathrm{cm} \mathrm{cs}^{-2}\right)$

$\mathrm{m}_{\mathrm{s}}$ is the mass transfer coefficient $\left(\mathrm{cm} \mathrm{s}^{-1}\right)$

$\mathrm{M}_{\mathrm{FeO}}$ is the molecular weight of $\mathrm{FeO}$

pct $\mathrm{FeO}^{\mathrm{b}}$ is the $\mathrm{FeO}$ content (weight percent) in the slag bulk

$p c t \mathrm{FeO}^{\circ}$ is the $\mathrm{FeO}$ content (weight percent) at the slag-gas interface

Sarma's experiments were conducted using a rotating carbon rod immersed in a slag from the system $\mathrm{CaO}-\mathrm{SiO}_{2}-\mathrm{Al}_{2} \mathrm{O}_{3}-\mathrm{FeO}$, where the content of $\mathrm{FeO}$ was less than 10 wt pct. They found that under these experimental conditions, the reaction rate increased with the content of $\mathrm{FeO}$, and also increased with the rotation speed of the carbon rod at a given $\mathrm{FeO}$ content. The measured reaction rate ranged from, $3.25^{*} 10^{-7} \mathrm{~mol} . \mathrm{cm}^{-2} . \mathrm{s}^{-1}$ at 2.1 pet FeO under static conditions to $3.6^{*} 10^{-6} \mathrm{~mol} . \mathrm{cm}^{-2} \cdot \mathrm{s}^{-1}$ at $9.5 \mathrm{pct} \mathrm{FeO}$ for a rotating rod experiment.

\subsection{Gas diffusion}

A gas halo is produced immediately after the injection of carbon. If its thickness is more than a few millimeter, it is possible that gas phase mass transfer is the rate determining step. [6] Min and Fruehan used the following equation to calculate the rate of $\mathrm{CO}_{2}$ transfer in the gas halo, [7] 


$$
\begin{aligned}
& \left(\mathrm{CO}_{2}\right)_{\mathrm{g}-\mathrm{s}} \rightarrow\left(\mathrm{CO}_{2}\right)_{\mathrm{g}-\mathrm{m}} \\
& J_{\mathrm{CO}_{2}}=\frac{m_{g}}{R T} \ln \frac{1+P_{\left(\mathrm{C}_{2}\right.}^{s}}{1+P_{C O_{2}}^{m}}
\end{aligned}
$$

where:

$\left(\mathrm{CO}_{2}\right)_{\mathrm{g}-\mathrm{s}}$ and $\left(\mathrm{CO}_{2}\right)_{\mathrm{g}-\mathrm{m}}$ are $\mathrm{CO}_{2}$ at the gas-slag and the gas-metal interfaces, respectively. $P_{\mathrm{CO}_{2}}^{m}$ and $P_{\mathrm{CO}_{2}}^{s}$, are equilibrium $\mathrm{CO}_{2}$ partial pressures of reactions (1.1) and (1.3).

$\mathrm{m}_{\mathrm{g}}$ is the gas phase mass transfer coefficient.

Reaction (1.1) and (1.3) should be in equilibrium if mass transfer of $\mathrm{CO} / \mathrm{CO}_{2}$ gas is rate determining step. The value of $\mathrm{m}_{\mathrm{g}}$ can be roughly estimated by,

$$
m_{g}=\frac{D_{\text {IIIff }}}{z}
$$

Where,

$\mathrm{z}$ is the thickness of the gas halo (millimeter)

$D_{\text {Diff }}$ is the diffusivity $\left(\mathrm{cm}^{2} / \mathrm{s}\right)$

Paramguru et al. estimated that the rate constant for gas diffusion is about $5^{*} 10^{-7}$ to $10^{-6} \mathrm{~mol} . \mathrm{cm}^{-2} \cdot \mathrm{s}^{-1}$ based on the assumption of a stagnant gas layer. [58] 


\subsection{Gas-metal and gas-carbon reaction}

$$
\begin{aligned}
& \mathrm{CO}_{2 \text { (gas) }}+\mathrm{C}=2 \mathrm{CO}_{\text {(gas) }} \\
& \mathrm{CO}+(\mathrm{FeO})=\mathrm{Fe}+\mathrm{CO}_{2}
\end{aligned}
$$

Reaction (1.3) is the gasification of carbon by reaction with reacted product $\mathrm{CO}_{2}$. In bath smelting processes, the slag char reaction can be responsible for over half the iron production. [11] [14] The other half of the iron oxides in the slag are reduced by the carbon dissolved in the metal. In oxygen steel making (OSM), a slag metal emulsion creates a large reaction area for decarburization. In the next section, both gas char and gas metal reactions are discussed as the rate determining steps.

\subsubsection{The model for gas metal reaction}

In bath smelting processes, the iron oxide dissolves into the slag, and half is reduced by carbon in iron drops.[7] [11] Sain and Belton measured the rate of the chemical reaction of $\mathrm{CO}_{2}$ with carbon dissolved in liquid iron, i.e. decarburization of liquid iron. They eliminated the effect of mass transport in the gas by using very high gas flow rates $(20-401 / \mathrm{min})$, which forces the system into a regime of interfacial reaction control. They demonstrated that the surface active element, sulfur, decreased the reaction rate greatly and concluded that the dissociation of $\mathrm{CO}_{2}$ was the rate controlling step. 
[38][39] Later Cramb and Belton measured the rate of dissociation of $\mathrm{CO}_{2}$ on liquid iron using a ${ }^{14} \mathrm{CO}_{2}$ - $\mathrm{CO}$ isotope exchange method. The rates were similar to that for decarburization confirming that the dissociation of $\mathrm{CO}_{2}$ was the rate controlling step. Mannion and Fruehan [36] confirmed Sain and Belton's findings, and also found similar effects with other surface active elements, such as, selenium, and tellurium. These workers developed a model for the calculation of gas-metal reaction rate based on the following reactions, [7]

$$
\begin{aligned}
& \mathrm{CO}+(\mathrm{FeO})=\mathrm{Fe}+\mathrm{CO}_{2} \\
& \mathrm{CO}_{2}+\underline{\mathrm{C}}=2 \mathrm{CO}
\end{aligned}
$$

For reaction (1.9), the reaction rate is calculated by,

$$
\mathrm{R}_{\mathrm{g}-\mathrm{m}}=\mathrm{k}_{\mathrm{CO}_{2}} \mathrm{~A}_{\mathrm{m}}\left(\mathrm{P}_{\mathrm{CO}_{2}}-\mathrm{P}_{\mathrm{CO}_{2}}^{c q}\right)
$$

Where:

$\mathrm{P}_{\mathrm{CO}_{2}}$ is $\mathrm{CO}_{2}$ pressure in equilibrium for reaction (1.8);

$\mathrm{P}_{\left(O_{2}\right.}^{e_{4}}$ is for reaction (1.9), which is essentially zero;

$\mathrm{k}_{\mathrm{CO}_{2}}$ is the rate constant for $\mathrm{CO}_{2}$ reaction.

The rate can be expressed in terms of pct $\mathrm{FeO}$ as

$$
\mathrm{R}_{\mathrm{g}-\mathrm{m}}=\mathrm{k}_{\mathrm{CO}_{2}} \mathrm{~A}_{\mathrm{m}} \mathrm{K}_{1} \mathrm{C}(\mathrm{pct} \mathrm{FeO})
$$


Where:

$\mathrm{K}_{1}$ is the equilibrium constant for reaction (1.8)

$\mathrm{C}$ is a constant relating the activity of $\mathrm{FeO}$ to the wt pct $\mathrm{FeO}$

$A_{m}$ is the area of the metal

Depending on the content of sulfur, Mannion and Fruehan measured the rate constant to be about $10^{-6}$ and $2.5^{*} 10^{-7}$ moles.cm ${ }^{-2} . \mathrm{s}^{-1}$ (pct FeO) $)^{-1}$ for $<0.001 \mathrm{~S}$ and 0.08 pct S, respectively. [7]

\subsubsection{The model for gas carbon reaction}

Because of the importance of the slag carbon reaction in bath smelting process, much attention has been paid to it. [6][9][13][23][40][41] In this section, the model developed by Story and Fruehan [40] is reviewed, and the work done by Warczok et al. [9] relating to the reduction of fayalite slag is discussed in detail.

\subsubsection{Story and Fruehan's model}

Story and Fruehan measured the kinetics of oxidation of carbonaceous materials by $\mathrm{CO}_{2}$ and $\mathrm{H}_{2} \mathrm{O}$, i.e. the gas carbon reaction. Their experiments were designed to ensure that the gas carbon reaction was in the limited mixed regime, where only a small volume 
of material was reacting, and external gas phase mass transfer was fast. They used equation (1.12) to calculate the reaction rate, [38]

$$
R=\frac{\left(D_{c} \rho S k\right)^{1 / 2} p^{*}}{R T}
$$

The value of the limited mixed rate constant, $k_{G C}$, may be expressed as,

$$
k_{G(C)}=\frac{\left(D_{c} \rho S k\right)^{1 / 2}}{R T}
$$

where

$D_{e}=$ effective diffusivity,

$\rho=$ density of reacting layer (carbon density),

$\mathrm{S}=$ pore surface per unit mass (specific internal surface area),

$\mathrm{p}^{\mathrm{s}}=$ pressure of the reacting gas at external surface,

$\mathrm{R}=$ gas constant,

$\mathrm{k}=$ the intrinsic rate constant expressed per unit total pore surface area.

Story et al. [13] also gave a comprehensive model to evaluate the influence of the gas-carbon reaction on the reduction rate, see Figure 1.3 and 1.4. They measured the value for $2.3 * 10^{-4}$ moles. $\mathrm{cm}^{-2} \cdot \mathrm{s}^{-1} \cdot \mathrm{atm}^{-1}$ for a commercial graphite at $1400^{\circ} \mathrm{C}, 0.5^{*} 10^{-4}$ moles. $\mathrm{cm}^{-2} \cdot \mathrm{s}^{-1} \cdot \mathrm{atm}^{-1}$ for a typical North American coke. [13] 


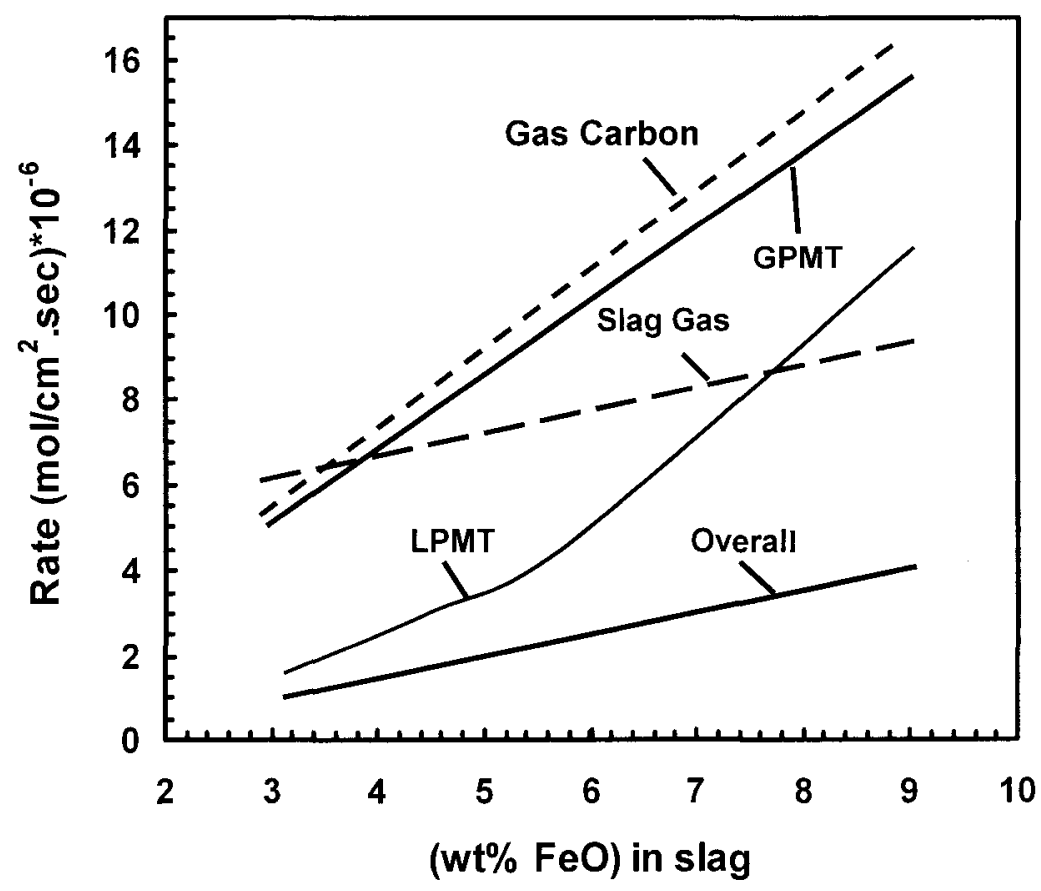

Figure (1.3): Comparison of experimental measurements with rate model predictions for stationary graphite rods. [13] 


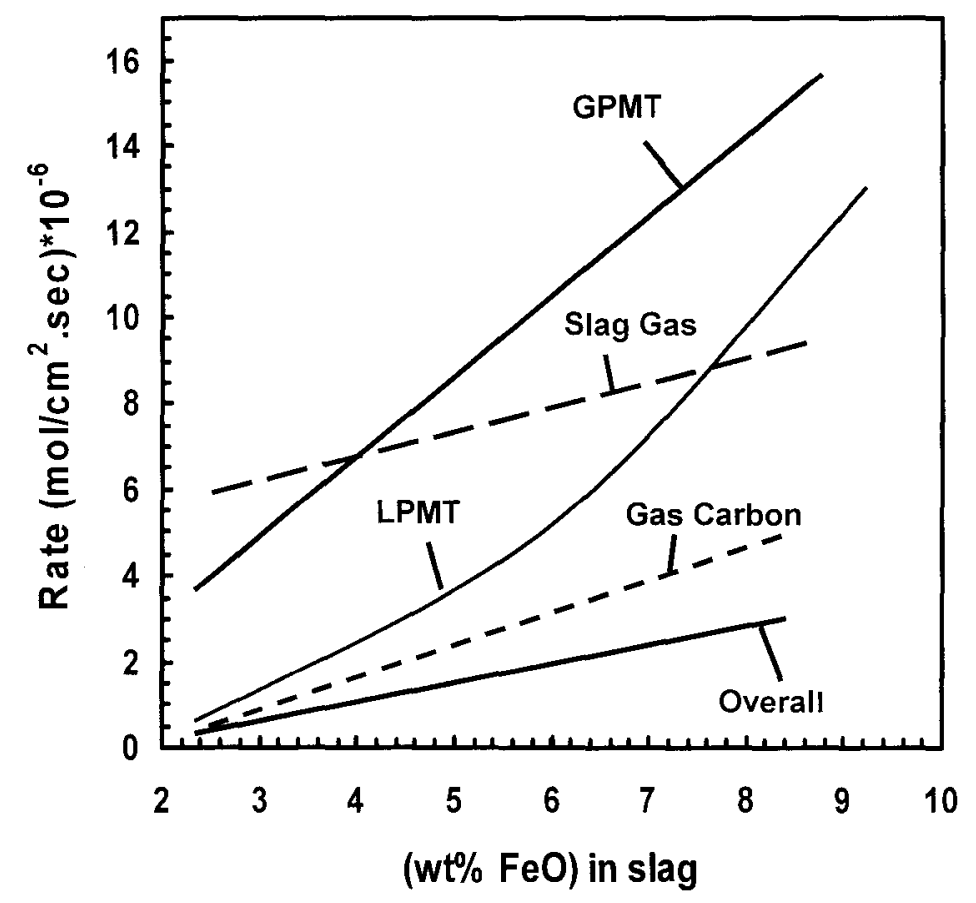

Figure (1.4): Comparison of experimental measurements with rate model predictions for stationary coke rod. [13]

According Story's model, at lower FeO content $(<10 \%)$, the slowest step is always the gas-carbon reaction when coke is used in the experiment. However, when solid graphite is used, at lower $\% \mathrm{FeO}$, the rate-determining step could be liquid phase mass transfer, at higher $\% \mathrm{FeO}$, it should be the gas-slag reaction.

\subsubsection{Warczok's work}

Warczok et al. [9] proposed that the reduction rate of fayalite slag is controlled by the Boudouard reaction. The slag composition they employed was, $52.2 \% \mathrm{Fe}, 29.7 \% \mathrm{SiO}_{2}$, 
$3.0 \% \mathrm{Fe}_{3} \mathrm{O}_{4}$, and $0.1 \% \mathrm{MgO}$. The objective of their work was to determine the reduction rate of fayalite slag and coke consumption.

\section{(1) Rate equation}

They defined the rate of slag reduction as the rate of oxygen removal, and calculated the reduction rate according to the nitrogen flowrate and $\% \mathrm{CO}$ and $\% \mathrm{CO}_{2}$ concentration using the following equation: [9]

$$
\operatorname{Rate}\left(\frac{\mathrm{molO}}{\mathrm{s} \cdot \mathrm{m}^{2}}\right)=\frac{41.3 \cdot V_{\mathrm{N}_{2}}}{A} \cdot \frac{2 \% \mathrm{CO}_{2}+\% \mathrm{CO}}{100-\% \mathrm{CO}_{2}-\% \mathrm{CO}}
$$

A is the surface area in $\mathrm{m}^{2}$,

$V_{N_{2}}$ is the nitrogen flowrate in $\mathrm{m}^{3} / \mathrm{s}$,

$\% \mathrm{CO}$ and $\% \mathrm{CO}_{2}$ are the contents in the off-gas from the reaction tube.

\section{(2) Surface area}

When studying reaction with a graphite disk, they defined the total contact area between the gases and the slag as that of slag surface. In the case of the graphite disk, the surface area is that of slag surface, in case of a graphite rod, the total contact area includes the upper slag surface plus the contact area between the graphite and the slag. These choices seem rather arbitrary. 


\begin{tabular}{|l|l|l|l|}
\hline $\begin{array}{l}\text { Reductant } \\
\text { geometry }\end{array}$ & $\begin{array}{l}\text { Graphite } \\
\text { surface }\left(\mathrm{m}^{2}\right)\end{array}$ & $\begin{array}{l}\text { Slag } \\
\text { surface }\left(\mathrm{m}^{2}\right)\end{array}$ & $\begin{array}{l}\text { Total contact } \\
\text { area }\left(\mathrm{m}^{2}\right)\end{array}$ \\
\hline Disk & $7.3^{*} 10^{-4}$ & $9.6^{*} 10^{-4}$ & $9.6^{*} 10^{-4}$ \\
\hline Rod & $4.5 * 10^{-4}$ & $9.6 * 10^{-4}$ & $14.1 * 10^{-4}$ \\
\hline
\end{tabular}

Table (1.2): Surface area. [9]

\section{(3) Experimental results}

Warczok et al. found that the off-gas $\mathrm{CO} / \mathrm{CO}_{2}$ ratio rapidly stabilized at about 4-5. For the reaction, $\mathrm{FeO}+\mathrm{CO}(\mathrm{g})=\mathrm{Fe}$ (metallic) $+\mathrm{CO}_{2}$, at $1300^{\circ} \mathrm{C}$, the equilibrium $\mathrm{CO} / \mathrm{CO}_{2}$ ratio is 5.3. The $\mathrm{CO} / \mathrm{CO}_{2}$ ratio of the gases generated was close to thermodynamic calculations. In addition, they calculated the activation energy (246 $\mathrm{kJ} / \mathrm{mol}$ ) based on the relationship between the reduction rate and temperature (see Equation (1.15)). This is in good agreement with other people's results for the Boudouard reaction. Considering all of these, they concluded that the Boudouard reaction was the rate-determining step. They also found that reduction rate increased with magnetite content (see Figure 1.5), and compared the result with that of Utigard (see Figure 1.6). Warczok et al. thought that the big difference was because the actual slag surface area might be higher than the cross sectional area of the crucible due to foaming and gas bubbles enveloping individual coke particles. It should be pointed out that if the Boudouard reaction were rate determining step, the area of enveloping slag bubbles should not be relevant. 
In their experimental results, the relationship between reduction rate and temperature is expressed by,

$$
\operatorname{Rate}\left(\frac{m o l O}{m^{2} \cdot s}\right)=5.39 \cdot 10^{6} \cdot \exp \left(\frac{29600}{T(K)}\right)
$$

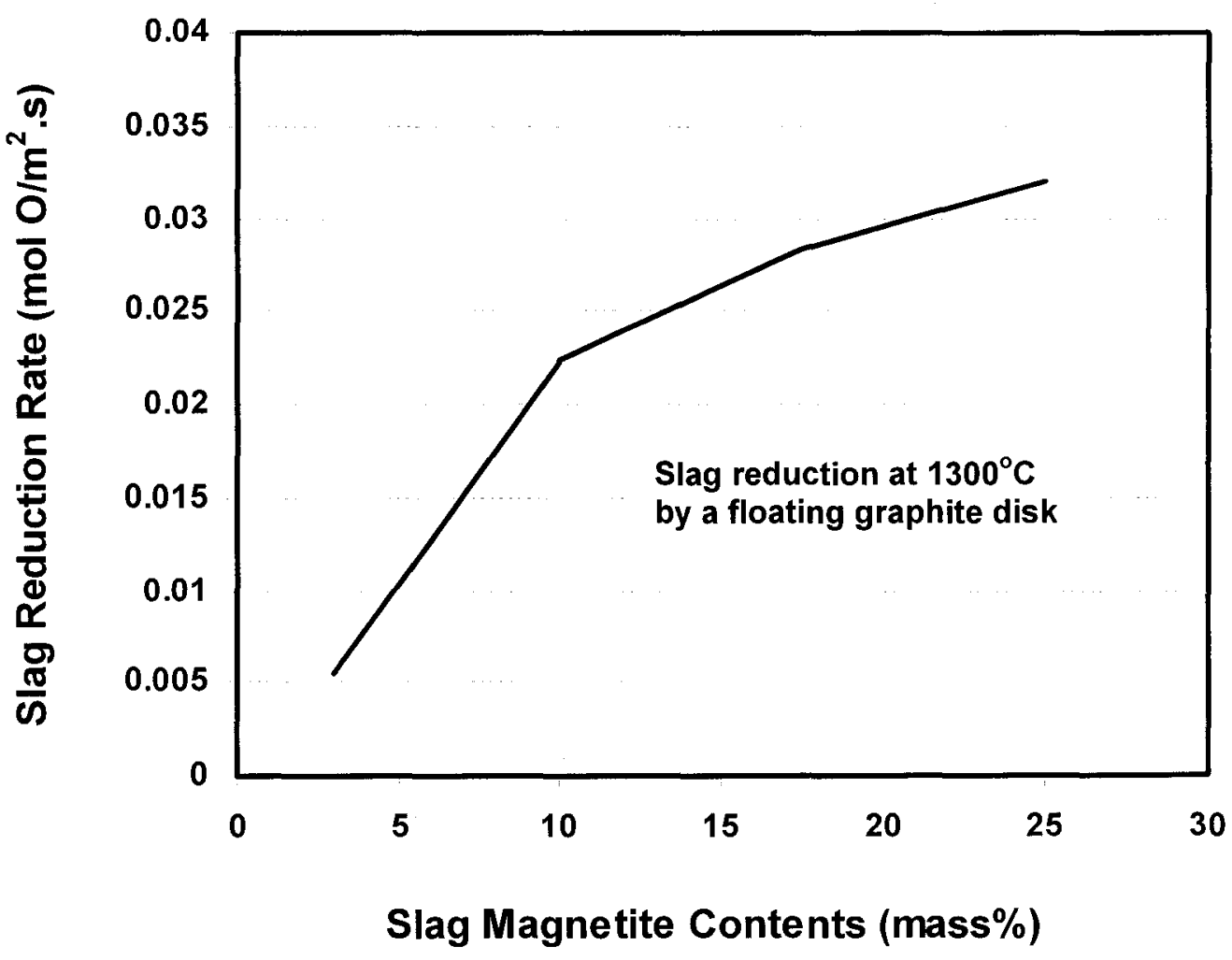

Figure (1.5): Slag reduction rate at $1300^{\circ} \mathrm{C}$ as a function of magnetite. 


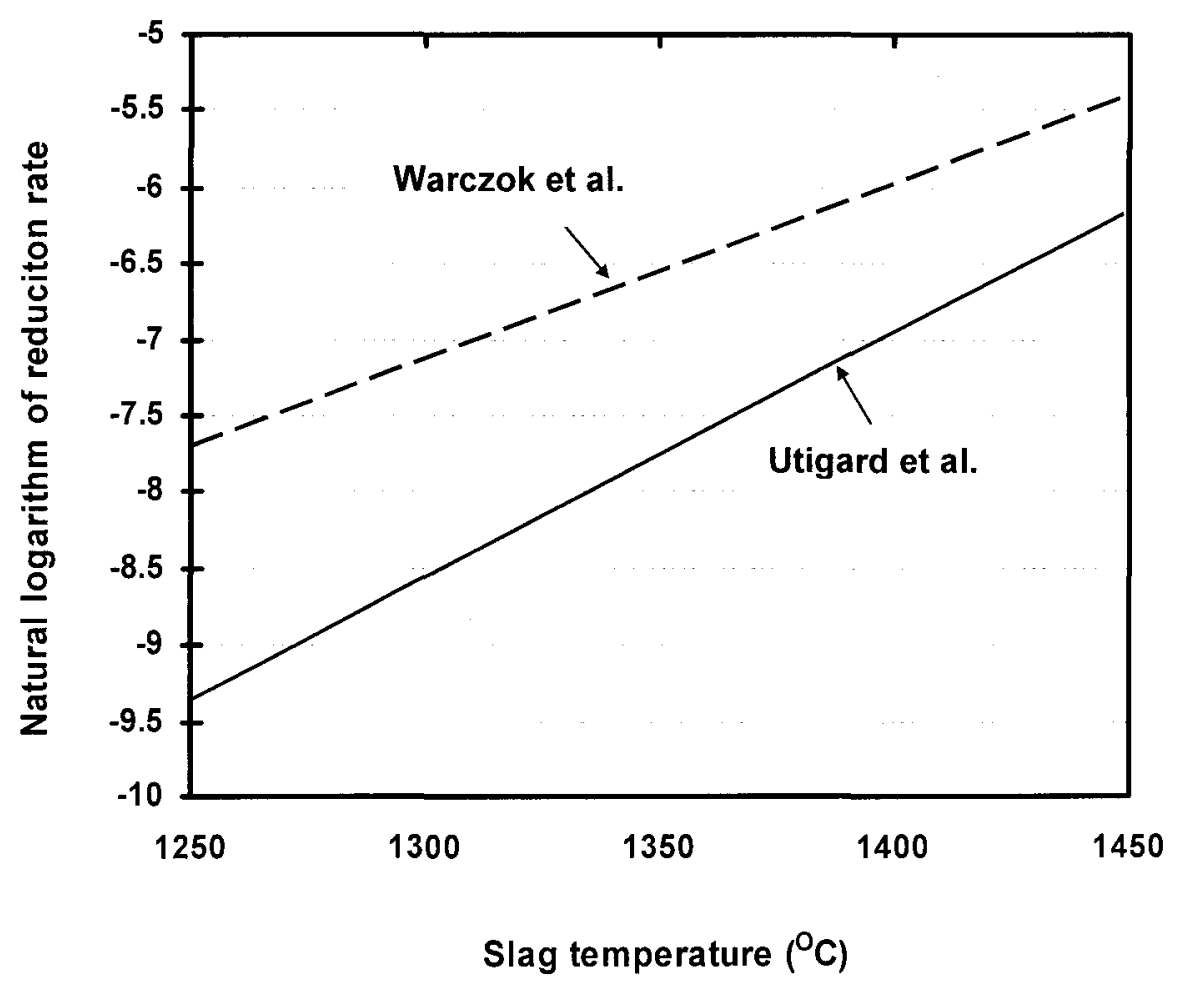

Figure (1.6): Logarithm of the rate vs inverse of absolute temperature.

The surface area is an important parameter in calculating the reaction rate. In Warczok' paper, the surface area was defined as, in case of the graphite disk, that of the slag surface, in the case of the graphite rod, the total contact area includes the upper slag surface plus the contact area between the graphite and the slag. Slag gas contact is all that 
is required for the Boudouard reaction. As discussed above the area of the carbon is the only relevant area if the Boudouard reaction controls.

\subsubsection{Summary}

In summary, good attention has been paid to gas carbon reactions with dissolved carbon or solid carbon. Sain and Belton measured the gas metal reaction rate eliminating the effect of mass transport. Story and Fruehan forced the system into the control mechanism of gas carbon reaction, and developed a comprehensive model to evaluate the effect of gas carbon on the overall reaction rate when iron oxide in the slag is less than $10 \%$. However, there are few studies on the measurement of reaction rate with fayalite type slags. 


\subsection{Models for the gas-slag reaction}

Besides the gas-carbon reaction, the other interfacial chemical reaction, the gas slag reaction also plays an important role in the reduction process of iron oxide from slags. The gas-slag reaction is a heterogeneous reaction involving liquid iron oxide containing slag and gases. Methods to measure the gas slag reaction rate are: thermogravimetric technique; isotope exchange method; and measurement of evolved gas compositions. Belton and his associates [15]-[19] have done a lot of work on gas slag reaction kinetics using the isotope exchange method. This work mostly employed radioactive carbon, ${ }^{14} \mathrm{C}$. In this section, their work is reviewed, and the effects of different oxides on the rate constant are discussed. The thermo-gravimetric technique recently used by Y. Li et al. is also introduced, and compared with the work of Belton.

\subsubsection{Isotope exchange method}

In 1964, Grabke used isotope exchange methods to measure the oxygen transfer rate on the surface of iron. [27] This is the first use of this method for the study of high temperature metallurgical reactions. And later, in the 1970s, Belton and his associates measured the $\mathrm{CO}_{2}$ dissociation rate on liquid slags using the same method. The method has the advantage that it eliminates the effect of mass transfer in the condensed phase, and by choosing an appropriate flow rate, eliminates control by mass transport in the gas 
phase. Therefore data can be obtained in a regime where only the interfacial reaction can control. In addition, all measurements are conducted at chemical equilibrium, thus eliminating any driving force effect.

When ${ }^{14} \mathrm{CO}_{2}$ enriched gas is introduced into a mixture of $\mathrm{CO}$ and $\mathrm{CO}_{2}$, the following reaction happens,

$$
{ }^{14} \mathrm{CO}_{2}(\mathrm{~g})+{ }^{12} \mathrm{CO}(\mathrm{g})={ }^{14} \mathrm{CO}(\mathrm{g})+{ }^{12} \mathrm{CO}_{2}(\mathrm{~g})
$$

The reaction (1.16) could be considered to proceed by two steps;

$$
{ }^{14} \mathrm{CO}_{2}(\mathrm{~g})={ }^{14} \mathrm{CO}(\mathrm{g})+\mathrm{O}(\mathrm{ad})
$$

and,

$$
\mathrm{O}(\mathrm{ad})+{ }^{12} \mathrm{CO}(\mathrm{g})={ }^{12} \mathrm{CO}_{2}(\mathrm{~g})
$$

Reaction (1.17) can be further broken down to the elementary steps:

$$
\begin{aligned}
& \mathrm{CO}_{2}(\mathrm{~g})=\mathrm{CO}_{2}(\mathrm{ad}) \\
& \mathrm{CO}_{2}(\mathrm{ad})=\mathrm{CO}(\mathrm{ad})+\mathrm{O}(\mathrm{ad}) \\
& \mathrm{CO}(\mathrm{ad})=\mathrm{CO}(\mathrm{g})
\end{aligned}
$$


The ${ }^{14} \mathrm{CO}_{2}$ content of total $\mathrm{CO}_{2}$ is very low, therefore, the back reaction may be negligible. Therefore, the measurement of reaction (1.17) makes it possible to know the rate constant of untagged reaction (1.22),

$$
\mathrm{CO}_{2}(\mathrm{~g})=\mathrm{CO}(\mathrm{g})+\mathrm{O}(\mathrm{ad})
$$

Considering the natural abundance $P_{{ }^{+}(C)}=0$ in gas mixtures at initial conditions (T=0), the rate constant can be determined by,

$$
k_{f}=\frac{\dot{V}}{A R T} \frac{1}{1+B} \ln \frac{1}{1-p_{1 t_{c o}} /\left(p_{1_{c o}}\right)_{e q}}
$$

where: $\dot{V}$ is the volume flow rate of the gas mixture; $p_{{ }^{{ }^{4}}(C)}$ is the partial pressures after reaction; $\left(p_{{ }^{+}+(O)}\right)_{c q}$ is the partial pressure of tagged ${ }^{14} \mathrm{CO}_{2}$ if complete isotope equilibrium were to be achieved; $\mathrm{B}$ refers to $p_{\left(C_{2}\right.} / p_{(\mathrm{C})} ; \mathrm{R}$ is the gas constant; $\mathrm{A}$ is the surface area.

Using the above equation (1.19), Sasaki et al. [17] measured the rate constant of iron oxides, at $\mathrm{T}=1500^{\circ} \mathrm{C}, k_{a}^{0}$ is $1.7^{*} 10^{-5} \mathrm{~mol} \cdot \mathrm{cm}^{-2} \cdot \mathrm{s}^{-1} \cdot \mathrm{atm}^{-1}$. See Figure 1.7 for the comparison between his work and Li by thermo-gravimetric technique. The rate constant obtained by Sasaki et al. is lower than that obtained from the conventional method by a factor of 2. The reason could not be explained by these workers. It is possible that the 
flowrate used in Sasaki's experiment was too low, $200-390 \mathrm{ml} / \mathrm{min}$ for this slag system and that there was some element of mass transport control. However, it should be noted that the dependency on $\mathrm{CO}_{2} / \mathrm{CO}$ is almost identical for each set of workers.

Figure 1.8 is the comparison of rate constants for liquid iron oxide containing slags after adding $\mathrm{CaO}$ or $\mathrm{SiO}_{2}$. [16] Sasaki et al. measured the rates of $\mathrm{CO}_{2}$ dissociation on liquid iron oxides and $\mathrm{CaO}$-saturated calcium ferrites, and found that the rate constant in $\mathrm{CaO}$ saturated liquid calcium ferrites is higher by a factor of 5 than in liquid iron oxide. Rahaiby et al. [18] studied the interfacial rate of reaction of $\mathrm{CO}_{2}$ with liquid iron silicates, and silica-saturated manganese silicates. They found that the rate constant decreased with the addition of $\mathrm{SiO}_{2}$.

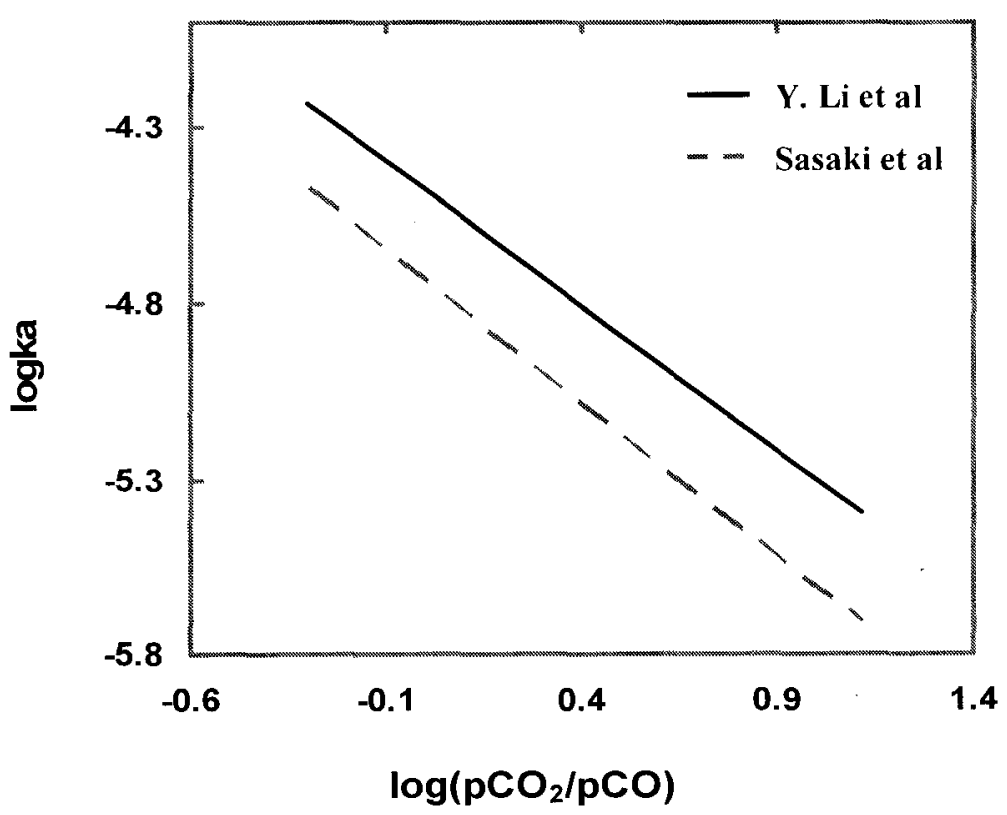

Figure (1.7): The relationship between rate constant and oxygen potentials. 


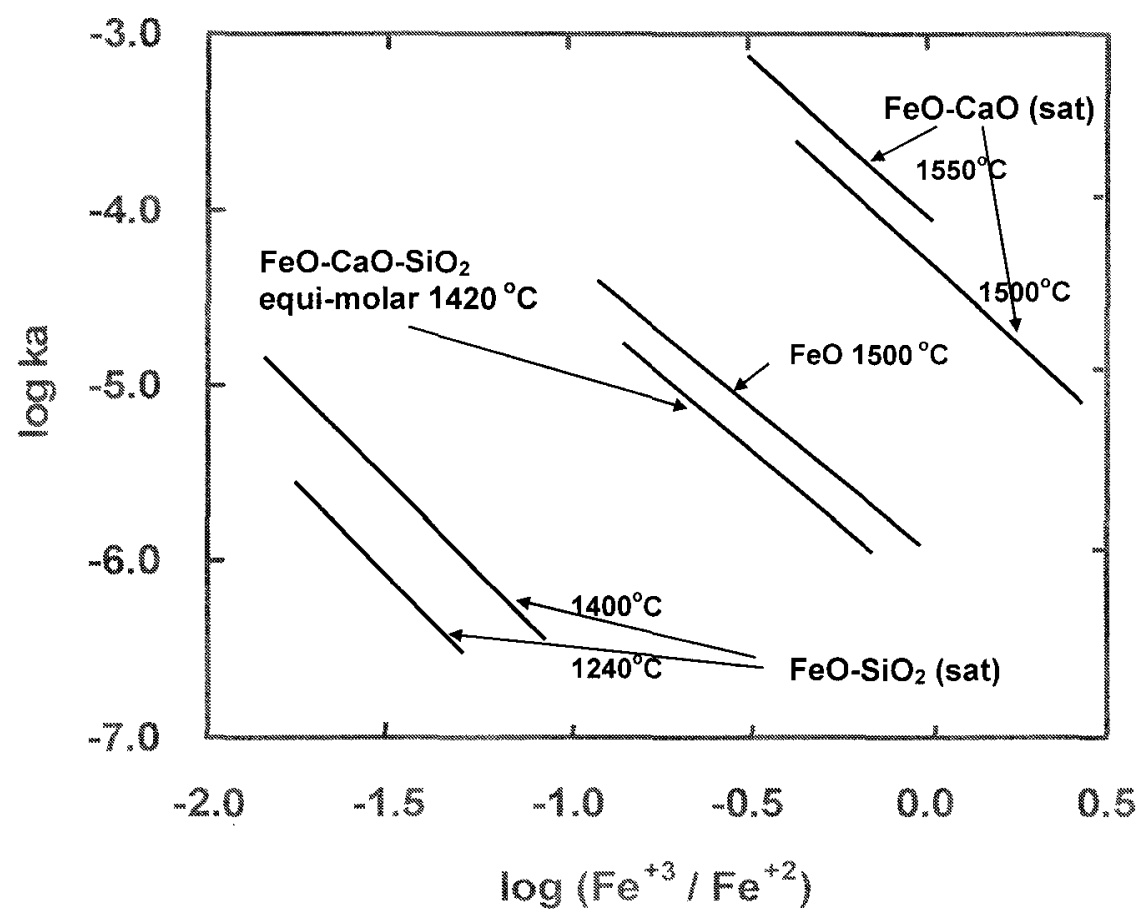

Figure (1.8): Comparison of the apparent forward rate constants between liquid $\mathrm{CaO}$-saturated calcium ferrites and liquid iron oxide at $1500^{\circ} \mathrm{C}$. [17]

Sasaki tried to explain why the addition of $\mathrm{CaO}$ to liquid iron oxide increases the rate constant (in terms of surface tension). However, it has not been possible to confirm this. The effects of the addition of different oxides on the rate constants have been studied by Li et al., see Table 1.4. [12]

In summary, strong basic oxides increase the reaction rate, acidic oxides decrease it. 


\begin{tabular}{|c|c|c|}
\hline slag system & $\begin{array}{l}\text { FeO content } \\
\text { (wt pct) }\end{array}$ & $\begin{array}{l}\text { rate constant } \\
\left(\mathrm{mol} \mathrm{O} \mathrm{cm}^{-2} \mathrm{~s}^{-1} \mathrm{~atm}^{-1}\right)\end{array}$ \\
\hline $\mathrm{BaO}-\mathrm{Fe}_{\mathrm{x}} \mathrm{O}$ & 52.4 & 22 \\
\hline $\mathrm{CaO}-\mathrm{Fe}_{\mathrm{x}} \mathrm{O}$ & 70 & 9.8 \\
\hline $\mathrm{Fe}_{\mathrm{x}} \mathrm{O}$ & 100 & 4.1 \\
\hline $\mathrm{Al}_{2} \mathrm{O}_{3}-\mathrm{Fe}_{\mathrm{x}} \mathrm{O}$ & 85 & 3.3 \\
\hline \multirow[t]{2}{*}{$\mathrm{TiO}_{2}-\mathrm{Fe}_{\mathrm{x}} \mathrm{O}$} & 70 & 1.7 \\
\hline & 47.37 & 1.1 \\
\hline $\mathrm{SiO}_{2}-\mathrm{Fe}_{\mathrm{x}} \mathrm{O}$ & 70 & 1 \\
\hline
\end{tabular}

Table (1.3): The rate constants for different binary systems at $T=1773 \mathrm{~K}$. [12]

\subsubsection{Thermo - gravimetric technique}

Li et al. [11][12] have studied the rate of interfacial reaction between liquid iron oxide and gas mixture of $\mathrm{CO}-\mathrm{CO}_{2}$ using a conventional thermo-gravimetric method, and eliminated the effect of mass transfer in gas and liquid phases. Their experiment was conducted under a gas flowrate high enough to minimize the effect of mass transfer in the gas phase, but not too high to cause significant change in the interfacial area. They measured the reaction rate using the following equation,

$$
v=\frac{1}{16 A} \frac{d w}{d t}
$$


Where: $\mathrm{v}$ is the reaction rate (mol- $\left.\mathrm{C} \mathrm{cm}^{-2} \mathrm{~s}^{-1}\right), \mathrm{A}$ is the surface area $\left(\mathrm{cm}^{2}\right)$ of the metal, $\mathrm{dw} / \mathrm{dt}$ is the weight loss/gain rate $(\mathrm{g} / \mathrm{s})$. The apparent first order rate constant, $\mathrm{k}_{\text {red }}$ or $\mathrm{k}_{\mathrm{oxi}}$. is calculated using equations (1.21) and (1.22).

$$
\begin{aligned}
& v=k_{r e d}\left[P c o-P c O_{2}\left(\frac{P c o_{2}}{P c o}\right)_{e q I}^{-1}\right] \\
& v=k_{o x i}\left[P c o_{2}-P \operatorname{co}\left(\frac{P c O_{2}}{P c o}\right)_{e q}\right]
\end{aligned}
$$

where: $\mathrm{PcO}_{2}$ and $P c o$ are the partial pressures of $\mathrm{CO}_{2}$ and $\mathrm{CO}$, respectively. $\left(\frac{P \mathrm{PO}_{2}}{P c o}\right)_{e q}$ is $\mathrm{CO}_{2} / \mathrm{CO}$ ratio at chemical reaction equilibrium.

They found that the rate constant increases with the increase of $\mathrm{FeO}$ content at a fixed ratio of $42.5 \mathrm{CaO}-42.5 \mathrm{SiO}_{2}-15 \mathrm{Al}_{2} \mathrm{O}_{3}$ slag system, see Figure 1.9. Barati et al. further confirmed these results using the isotope exchange method. [1]

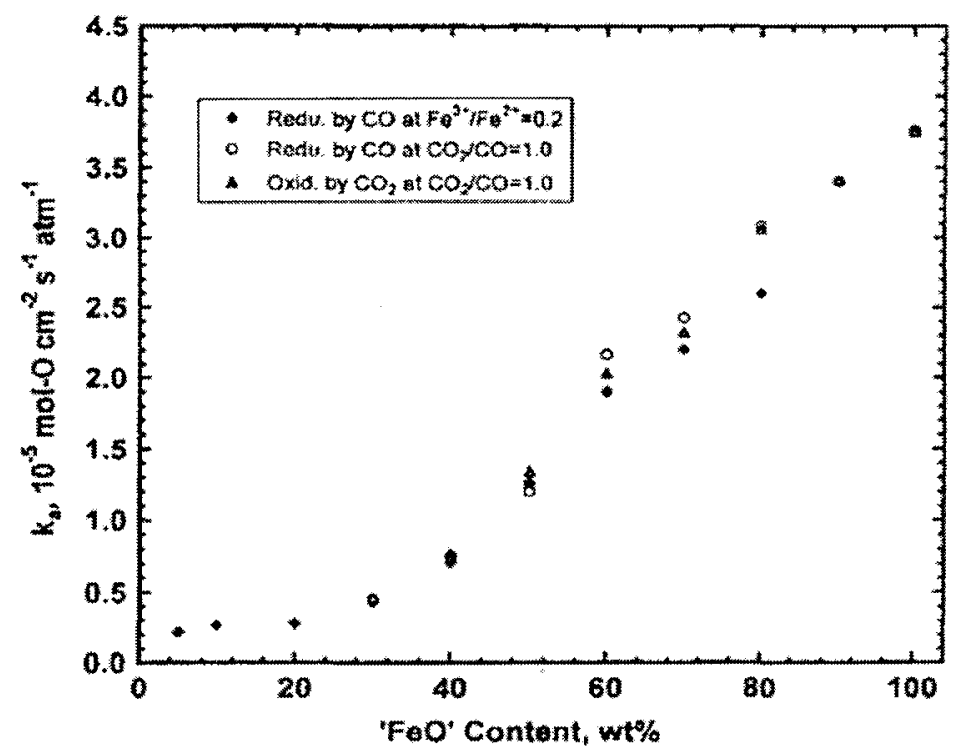

Figure (1.9): The dependence of the apparent rate constant on iron oxide content at 1773K. [11] 


\subsubsection{The work done by Utigard et al.}

Utigard et al. studied the reduction kinetics of liquid iron oxide-containing slags by $\mathrm{CO}$. The objective of their work was to measure the rate of gaseous $\mathrm{CO}$ reduction of fayalite-type slags at temperatures between $1150{ }^{\circ} \mathrm{C}$ and $1350{ }^{\circ} \mathrm{C}$. The compositions of the slag used in his work are: $5.6 \% \mathrm{Cu}, 41.8 \% \mathrm{Fe}, 29.8 \% \mathrm{Fe}_{3} \mathrm{O}_{4}, 0.5 \% \mathrm{~S}, 27.9 \% \mathrm{SiO}_{2}$, $5.4 \% \mathrm{Al}_{2} \mathrm{O}_{3}, 0.6 \% \mathrm{CaO}, 0.9 \% \mathrm{MgO}$, and $0.088 \% \mathrm{Cr}_{2} \mathrm{O}_{3}$. The following equation was used to calculate the rate of reduction.

$$
\operatorname{Rate}\left(\frac{\mathrm{molO} O}{s \cdot m^{2}}\right)=\frac{V \cdot\left(p_{c o, i n}-p_{c(0, o u t}\right)}{A \cdot R \cdot T}
$$

According to a measured activation energy of $360 \mathrm{~kJ} / \mathrm{mole}$, they concluded that the rate-limiting step is either the adsorption of $\mathrm{CO}$ at the gas/slag interface or the chemical reaction between the adsorbed $\mathrm{CO}$ and oxygen ions in the slag, because such a high activation energy is inconsistent with mass transfer as the rate limiting step. From the conclusions, it can be seen that the rate determining step is ill-defined.

Grabke studied the kinetics of oxygen transfer from carbon dioxide on the surface of iron, and concluded that the rupture of one the $\mathrm{C}-\mathrm{O}$ bonds of an adsorbed $\mathrm{CO}_{2}$ molecule is most likely to be the rate determining step rather than physical adsorption of 
$\mathrm{CO}_{2}$ or desorption of $\mathrm{CO}$. Employing the same logic, for Utigard's experiment, the adsorption of $\mathrm{CO}$ could not be the rate determining step.

When studying the reduction kinetics using gases, three possible rate-determining steps could be involved, namely, mass transfer in the gas phase, interfacial chemical reaction, and liquid phase mass transfer.

Below is the comparison between Utigard's experimental setup and other researchers.

\begin{tabular}{|c|c|c|c|c|c|}
\hline & $\begin{array}{l}\text { Temperature } \\
(\mathrm{K})\end{array}$ & $\begin{array}{l}\text { Slag } \\
\text { composition }\end{array}$ & $\begin{array}{l}\text { Slag } \\
\text { weight } \\
\text { (g) }\end{array}$ & $\begin{array}{l}\text { Diameter of } \\
\text { crucibles } \\
(\mathrm{mm})\end{array}$ & $\begin{array}{l}\text { Flowrate } \\
(\mathrm{ml} / \mathrm{min})\end{array}$ \\
\hline Utigard et al. & 1623 & $\begin{array}{l}5.6 \% \mathrm{Cu} \\
41.8 \% \mathrm{TFe} \\
29.8 \% \mathrm{Fe}_{3} \mathrm{O}_{4} \\
27.9 \% \mathrm{SiO}_{2} \\
0.5 \% \mathrm{~S} \\
\end{array}$ & $150-270$ & 36 & 150 \\
\hline Li et al. & 1773 & $\begin{array}{l}\mathrm{FeO} 70 \% \\
\mathrm{SiO} 230 \%\end{array}$ & 10 & 25 & 2000 \\
\hline EL-Rahaiby et al. & 1673 & $\begin{array}{l}\mathrm{FeO} 70 \% \\
\mathrm{SiO} 230 \%\end{array}$ & 0.5 & 13 & $200-300$ \\
\hline
\end{tabular}

Table (1.4): The comparisons of gas flowrate used in different experiments. 
According to the above table, the flowrate used in Utigard's experiment should be much too low compared with other people's. Results presented later will show that at least $400 \mathrm{ml} / \mathrm{min}$ is required.

\subsection{Critical Assessment of the Literature}

As for the four possible rate-determining steps during slag reduction, good attention has been paid in the iron and steel-making industry and individual kinetic models have been developed. However, for copper-making, few kinetic data are available for the reduction of fayalite slags, and the published work has some limits which are summarized as follows.

\section{a. Warczok's work}

In their work, the surface area is ill-defined. They treated the total gas slag contact area as constant. If the rate is controlled by the Boudouard reaction as they suggested, only the carbon surface area is relevant.

\section{b. Utigard's work}


When measuring slag reduction rate using gases instead of carbon or graphite, three possible rate-determining steps could be involved, namely, mass transfer in the gas phase, interfacial chemical reaction, and liquid phase mass transfer. Consideration should be given in their experiment to eliminate the effect of gas mass transfer comparing with other researcher's work. 


\section{Chapter 2:}

\section{${ }^{13}$ C Isotope Exchange Method}

To measure the reaction rate, there are some methods applicable, such as the thermo-gravimetric technique, and the isotope exchange method. The Isotope exchange method is used in this study because it measures reaction rate under control by the gas slag reaction, and eliminates the effect of mass transfer. In addition, the chemical condition of the system is constant throughout the experiment, and is known precisely.

Grabke was the first person to use the isotope exchange method to study high temperature metallurgical reactions, the oxygen transfer rate on the surface of iron. [27] Later, Belton and his associates measured the dissociation rate of $\mathrm{CO}_{2}$ on slags using the same method. However, due to the radioactive nature of ${ }^{14} \mathrm{C}$ and the length of time required for these experiments, a method using ${ }^{13} \mathrm{C}$ has been adopted for this study.

The purpose of this chapter is to derive an equation for the determination of the rate constant using ${ }^{13} \mathrm{C}$. Section (2.2) gives the detailed derivation of the equation, section (2.3) describes the calculation of the parameters used in the equation. In addition, a non- 
standard method is also developed in the study. This method measures the increase of ${ }^{13} \mathrm{C}$ in outgoing $\mathrm{CO}$, because the very low reaction rate makes it impossible to measure the decrease of ${ }^{13} \mathrm{C}$ in $\mathrm{CO}_{2}$. Section (2.4) explains the recalculation of the parameters if using the non-standard method.

\subsection{The rate-limiting step for isotope exchange reaction}

${ }^{13} \mathrm{CO}_{2}$ is introduced into a gas mixture of $\mathrm{CO}$ and $\mathrm{CO}_{2}$, the following isotope exchange reaction proceeds,

$$
{ }^{13} \mathrm{CO}_{2}(\mathrm{~g})+{ }^{12} \mathrm{CO}(\mathrm{g})={ }^{13} \mathrm{CO}(\mathrm{g})+{ }^{12} \mathrm{CO}_{2}(\mathrm{~g})
$$

It can be reasonably supposed that the reaction (2.1) occurs by the two partial reactions (2.2) and (2.3),

$$
\begin{aligned}
& { }^{13} \mathrm{CO}_{2}(\mathrm{~g})={ }^{13} \mathrm{CO}(\mathrm{g})+\mathrm{O}(\mathrm{ad}) \\
& \mathrm{O}(\mathrm{ad})+{ }^{12} \mathrm{CO}(\mathrm{g})={ }^{12} \mathrm{CO}_{2}(\mathrm{~g})
\end{aligned}
$$


By the same logic as ${ }^{14} \mathrm{C}$ method, reaction (2.2) is the rate determining step for the isotope exchange reaction. Therefore, the measurement of reaction (2.2) makes it possible to know the rate constant of untagged reaction (1.22),

$$
\mathrm{CO}_{2}(\mathrm{~g})=\mathrm{CO}(\mathrm{g})+\mathrm{O}(\mathrm{ad})
$$

\subsection{The equation of ${ }^{13} \mathrm{C}$ method}

Grabke and Belton measured the $\mathrm{CO}_{2}$ dissociation rate by radioactive carbon. ${ }^{14} \mathrm{CO}_{2}$ was introduced after the specimen had been held under a desired $\mathrm{CO}_{2} / \mathrm{CO}$ for several hours. Samples for counting were taken from the ingoing gas after a few minutes and from the exit gas after about 30 minutes.

They used the following rate equation to calculate the rate constant, [15]-[19][27]

$$
k_{f}=\frac{\dot{V}}{A R T} \frac{1}{1+B} \ln \frac{1}{1-p_{1+c o} /\left(p_{1+c o}\right)_{c q}}
$$

The term $p_{{ }^{1+}(O)} /\left(p_{\left.{ }^{+C_{C} O}\right)}\right)_{e q}$ in equation (1.19) is related to the radioactive count rate of the ingoing $\mathrm{CO}_{2}, N^{\prime}$, and that of $\mathrm{CO}_{2}$ which results from conversion of outgoing $\mathrm{CO}, \mathrm{N}$, by the expression,

$$
p_{{ }^{1+}(C)} /\left(p_{{ }^{1+}(O)}\right)_{e q}=N(1+B) / N^{\prime} B
$$

Then the equation (1.19) becomes, 


$$
k_{f}=\frac{\dot{V}}{A R T} \frac{1}{1+B} \ln \frac{1}{1-N(1+B) / N^{\prime} B}
$$

$\mathrm{N}$ and $N^{\prime}$ are counting by Geiger Muller tube using the methods of Brown and Miller. [26]

The initial condition for Equation (1.19) is that the natural abundance of radiocarbon ${ }^{14} \mathrm{C}$ in gas mixture is zero. For natural abundance of $1.11 \%$ of ${ }^{13} \mathrm{C}$, the equation is significantly different.

The dissociation rate of $\mathrm{CO}_{2}$ (reaction 2.2) on slag surface can be calculated by,

$$
\frac{d n_{{ }^{13}} \mathrm{CO}}{d t}=k^{\prime}\left(1-\sum_{i} \theta_{i}\right) p_{{ }^{13} \mathrm{CO}_{2}}-k^{\prime \prime} p_{{ }^{13} \mathrm{co}} \theta_{0}
$$

Where:

$\mathrm{k}^{\prime \prime}:$ is defined as the forward rate constant of reaction $(2.2)$;

$\theta_{\mathrm{i}}:$ represents the fractional coverage of adsorbed species, $\mathrm{i}$ which can prevent dissociation of $\mathrm{CO}_{2}$ by adsorption on reaction sites;

$\theta_{0}:$ is the fractional coverage by oxygen;

$\mathrm{k}^{\prime \prime}$ : is the reverse rate constant;

$\mathrm{n}$ and $\mathrm{p}$ represent number of moles and partial pressure, respectively. 
For reaction (2.1), at isotope exchange equilibrium,

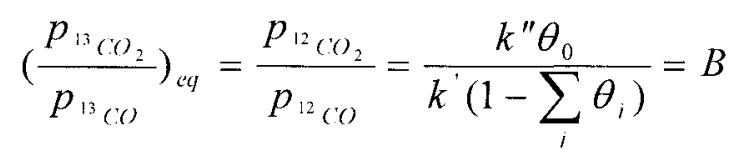

then,

$$
k^{\prime \prime} \theta_{0}=B k^{\prime}\left(1-\sum_{i} \theta_{i}\right)
$$

Noting at any time, $p_{{ }^{13} \mathrm{CO}_{2}}+p_{{ }^{13} \mathrm{CO}}=p^{0}{ }^{13} \mathrm{CO}_{2}+p^{0}{ }^{13} \mathrm{CO}$

Substitute (2.6) and (2.7) into (2.4),

$$
\frac{d n_{13} \mathrm{CO}}{d t}=k^{\prime}\left(1-\sum_{i} \theta_{i}\right)\left[p^{0}{ }^{13} \mathrm{CO}_{2}+p^{0}{ }^{13} \mathrm{CO}-(1+B) p_{{ }^{13} \mathrm{CO}}\right]
$$

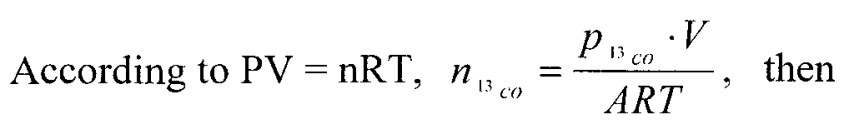

$$
\frac{d n_{13(0)}}{d t}=\frac{V}{A R T} \cdot \frac{d p_{13}(t)}{d t}
$$

Combined equation (2.8) and (2.9), 


$$
\begin{aligned}
& \frac{d p_{1^{3} C O}}{d t}=\frac{A R T}{V} \cdot k^{\prime}\left(1-\sum \theta_{i}\right)\left[p_{{ }^{13} C^{C} O_{2}}^{0}+p_{{ }^{13} C O}^{0}-(1+B) p_{{ }^{13} C O}\right] \\
& -\frac{1}{1+B} d \ln \left[p_{{ }^{13} C_{2}}^{0}+p_{{ }^{13} C O}^{0}-(1+B) p_{{ }^{13} C O}\right]=\frac{A R T \cdot k^{\prime}\left(1-\sum \theta_{i}\right)}{V} d t
\end{aligned}
$$

Integrating the above equation (2.11) from $t=0$ to $t$ with the initial conditions that

$$
\begin{aligned}
& p_{{ }^{13} \mathrm{CO}}=p_{13}^{0} \mathrm{CO},
\end{aligned}
$$

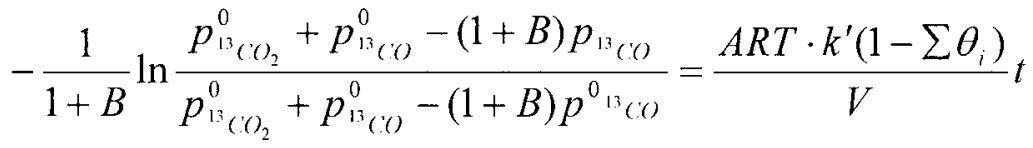

$$
\begin{aligned}
& p^{{ }^{{ }_{13}} \mathrm{CO}_{2}}+p^{0_{13} \mathrm{CO}}=\left(p_{{ }^{13} \mathrm{CO}_{2}}\right)_{e q}+\left(p_{{ }^{13} \mathrm{CO}}\right)_{e q}=(1+B)\left(p_{{ }^{13} \mathrm{CO}}\right)_{e q}
\end{aligned}
$$

Substitute (2.13) into (2.12), and noting that $\quad \dot{V}=\frac{V}{t}$

$$
\begin{aligned}
& \frac{\dot{V}}{A R T} \frac{1}{1+B} \ln \frac{(1+B)\left(p_{{ }^{3} C O}\right)_{c q}-(1+B) p^{0}{ }^{{ }^{3} C O}}{(1+B)\left(p_{{ }^{13} C O}\right)_{c q}-(1+B) p^{{ }^{13}(O)}}=k^{\prime}\left(1-\sum \theta_{i}\right) \\
& \because k_{a}=k^{\prime}\left(1-\Sigma_{i} \theta_{i}\right)
\end{aligned}
$$




$$
\therefore k_{a}=\frac{\dot{V}}{A R T} \frac{1}{1+B} \ln \frac{1-\frac{p_{13}^{o}}{\left(p_{13}\right)_{c q}}}{1-\frac{\left.p_{13}\right)_{c o}}{\left(p_{13}\right)_{c q}}}
$$

If equation (2.15) is expressed by $p_{\mathrm{CO}_{2}}$, the same deduction can be done.

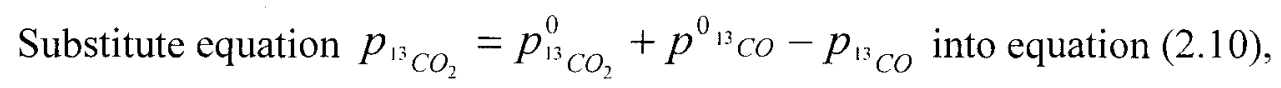

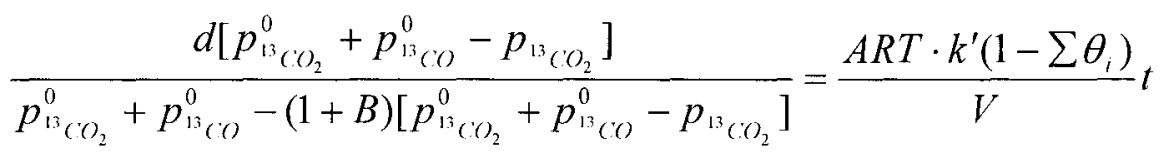

$$
\begin{aligned}
& -\frac{d p_{{ }^{13} C_{2}}}{(1+B) p_{{ }^{3} C_{2}}-B\left(p_{{ }^{13} \mathrm{CO}_{2}}^{0}+p_{\left.{ }^{13} \mathrm{CO}\right)}^{0}\right)}=\frac{A R T \cdot k^{\prime}\left(1-\sum \theta_{i}\right)}{V} t \\
& -\frac{1}{1+B} d \ln \left[(1+B) p_{{ }^{13}{ } \mathrm{CO}_{2}}-B\left(p_{{ }^{3}{ }^{\circ} \mathrm{CO}_{2}}^{0}+p_{\left.{ }^{13} \mathrm{C} \mathrm{C}\right)}^{0}\right)\right]=\frac{A R T \cdot k^{\prime}\left(1-\sum \theta_{i}\right)}{V} d t
\end{aligned}
$$

Integrating the above equation from $\mathrm{t}=0$ to $\mathrm{t}$ with the initial conditions that $p_{{ }^{13} \mathrm{C} \mathrm{CO}_{2}}=p_{{ }^{13} \mathrm{CO}_{2}}^{0}$,

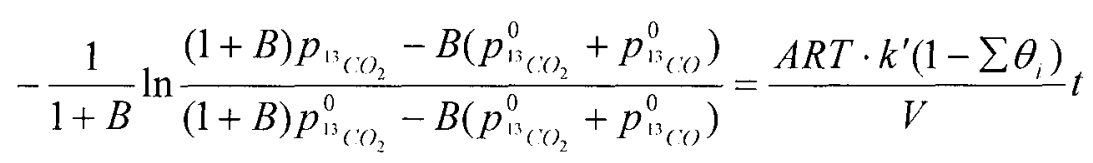




$$
\begin{aligned}
& p^{{ }^{13} \mathrm{CO}_{2}}+p^{0}{ }^{13} \mathrm{CO}=\left(p_{{ }^{13} \mathrm{CO}_{2}}\right)_{e q}+\left(p_{{ }^{13} \mathrm{CO}}\right)_{e q}=\frac{1+B}{B}\left(p_{{ }^{13} \mathrm{CO}_{2}}\right)_{e q} \\
& -\frac{1}{1+B} \ln \frac{p_{{ }^{13} \mathrm{CO}_{2}}-\left(p^{13} \mathrm{CO}_{2}\right)_{e q}}{p_{{ }^{13} \mathrm{CO}_{2}}^{0}-\left(p_{{ }^{13} \mathrm{CO}_{2}}\right)_{e q}}=\frac{A R T \cdot k^{\prime}\left(1-\sum \theta_{i}\right)}{V} t
\end{aligned}
$$

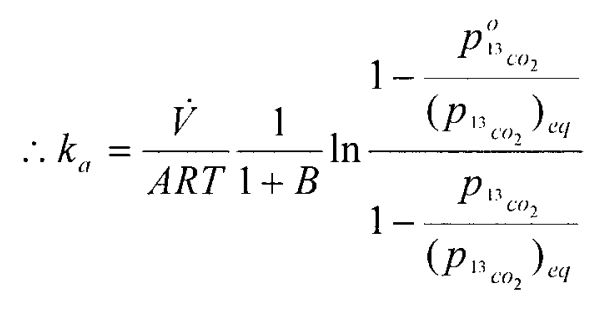

Equation (2.16) is the same as that obtained by Hiroyuki Matsuura et al. [28]

\subsection{The calculation of parameters in the equation $\left(\mathrm{CO}_{2}\right.$ method)}

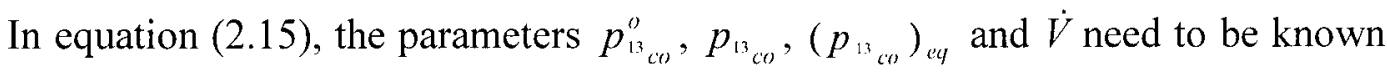
in order to calculate the rate constants. In the ${ }^{14} \mathrm{C}$ method, the partial pressures are determined by measuring the radioactive carbon count rate of the ingoing $\mathrm{CO}_{2}, N^{\prime}$, and that of $\mathrm{CO}_{2}$ which results from conversion of outgoing $\mathrm{CO}, \mathrm{N}$. In the ${ }^{13} \mathrm{C}$ method, we use a combination of Gas chromatography (Auto-system XL GC) and mass spectrometry (Isoprime isotope ratio mass spectrometry, MS). The GC is used to separate $\mathrm{CO}$ and $\mathrm{CO}_{2}$, 
a sample size of a few micromoles of a pure compound is usually sufficient. [22] IRMS is used to measure the enrichment, $\delta$, which is the excess of any particular isotope species in the sample compared to the same isotopic species in the reference, and it is usually expressed in parts per thousand and written as $\%_{0}$ or per mil.

$$
R_{\text {sam }}=R_{r e f}(1+\delta / 1000)
$$

where, $\quad R_{\text {sam }}=\frac{C O_{2}^{13}}{\mathrm{CO}_{2}^{12}}($ sample $) \quad R_{\text {ref }}=\frac{\mathrm{CO}_{2}^{13}}{\mathrm{CO}_{2}^{12}}($ reference $)$

$R_{\text {sam }}, R_{r e f}$ are the sample and reference ratios of minor to major beam as measured on the isotope ratio instrument.

\subsection{1 $p_{{ }^{\prime} c o}^{o}:{ }^{13} \mathrm{CO}$ partial pressure in ingoing gas}

The isotope exchange proceeds at chemical equilibrium, the total pressure is $1 \mathrm{~atm}$, the partial pressure of $\mathrm{CO}$ should be,

$$
p_{C O}=\frac{1}{1+B}
$$


If the natural fraction of ${ }^{13} \mathrm{CO}$ in the ingoing gases is represented as $\left(\frac{2}{1}\right)_{i n}^{(i)}$, (note ${ }^{13} \mathrm{CO}$ is detected by detector number 2 and ${ }^{12} \mathrm{CO}$ by detector number 1$)$,

$$
\frac{p_{1^{3}(O)}^{o}}{p_{1^{2}(O)}^{o}}=\left(\frac{2}{1}\right)_{i n}^{c o},
$$

and

$$
p_{{ }^{13}(O)}^{o}+p_{{ }^{2} C_{C O}}^{o}=p_{C O}=\frac{1}{1+B}
$$

Combine (2.18) and (2.19),

$$
p_{1_{c o}}^{o}=\frac{1}{1+B} \frac{\left(\frac{2}{1}\right)_{i n}^{c o}}{1+\left(\frac{2}{1}\right)_{i n}^{c o}}
$$

where, $\left(\frac{2}{1}\right)_{m}^{c o}=\left(1+\delta_{i}^{c o} / 1000\right)\left(\frac{2}{1}\right)_{r e f}$.

\subsection{2 $p_{{ }^{3} c o}$ : the partial pressure of ${ }^{13} \mathrm{CO}$ after the isotope exchange}

From equation (2.6), the partial pressure of $\mathrm{CO}$ after isotope exchange is,

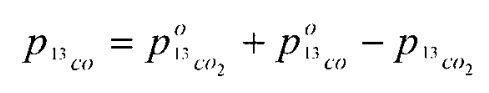

$P_{1^{3} \mathrm{CO}_{2}}^{\mathrm{O}}$ and $P_{\mathrm{13}^{3} \mathrm{CO}_{2}}$ can be calculated by, 


$$
\left(p_{\mathrm{CO}_{2}}\right)_{t \text { total }}=p_{{ }^{12} \mathrm{CO}_{2}}^{o}+p_{{ }^{13} \mathrm{CO}_{2}}^{o}=\frac{B}{1+B}
$$

and

$$
\frac{p_{13}^{O} \mathrm{CO}_{2}}{p_{{ }^{2} \mathrm{CO}_{2}}^{O}}=\left(\frac{2}{1}\right)_{\mathrm{in}}^{\mathrm{CO}_{2}}
$$

$\left(\frac{2}{1}\right)_{\text {in }}^{c_{2}}$ is the abundance of ${ }^{13} \mathrm{CO}_{2}$ in the ingoing gases.

Combining equation (2.22) and (2.23),

$$
p_{\left(C_{2}\right)_{2}}^{o}=\frac{B}{1+B} \frac{\left(\frac{2}{1}\right)_{i n}^{\mathrm{CO}_{2}}}{1+\left(\frac{2}{1}\right)_{i n}^{\mathrm{CO}_{2}}}
$$

The same calculation for $p_{13} \mathrm{CO}_{2}$,

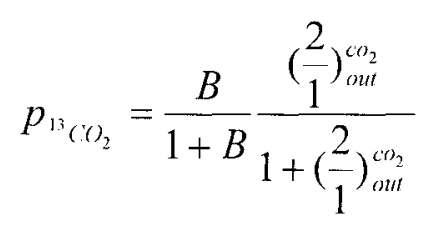

$\left(\frac{2}{1}\right)_{o u i}^{c_{2}}$ is the abundance of ${ }^{13} \mathrm{CO}_{2}$ in the outgoing gases.

Combine (2.14), (2.18) and (2.19),

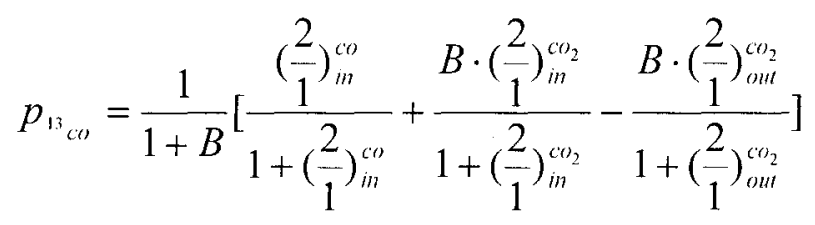

where, $\left(\frac{2}{1}\right)_{i n}^{c o_{2}}=\left(1+\delta_{i}^{c o_{2}} / 1000\right)\left(\frac{2}{1}\right)_{r e f} \quad\left(\frac{2}{1}\right)_{o u t}^{c o_{2}}=\left(1+\delta_{o u t}^{c o_{2}} / 1000\right)\left(\frac{2}{1}\right)_{r e f}$ 


\subsubsection{The calculation of $\left(p_{{ }^{13} c o}\right)_{e q}$ partial pressure of ${ }^{13} \mathrm{CO}$ at equilibrium}

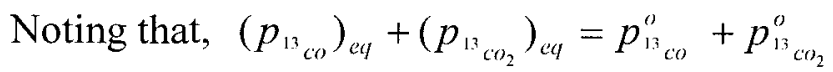

Considering $\frac{\left(p_{\mathrm{li} \mathrm{OO}}\right)_{c q}}{\left(p_{1 \mathrm{~s}(\mathrm{O})}\right)_{c q}}=B$

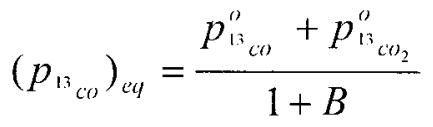

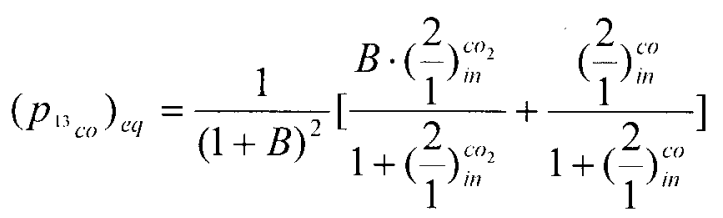

\subsection{The recalculation of parameters in the equation (CO method)}

The above calculation of the parameters in equation (2.8) is based on the measurement of ${ }^{13} \mathrm{C}$ change in the ingoing and outgoing $\mathrm{CO}_{2}$. However, if the rate of exchange is too low to measure this, another method which measures the increase of ${ }^{13} \mathrm{C}$ in outgoing gas $\mathrm{CO}$ can be used. Normally, this method is used when $p_{\mathrm{CO}}<<p_{\mathrm{CO}_{2}}$, therefore the same exchange gives a much larger percentage change in $\mathrm{CO}$. Then, the parameters $p_{1_{c o}}^{o}, p_{1_{c o}},\left(p_{b_{c o}}\right)_{c q}$ in the formulae (2.8) have to be recalculated. At this time, we measure the enrichment of ${ }^{13} \mathrm{CO}$ in ingoing and outgoing gases. 
2.4.1 $p_{{ }^{\circ}(o)}^{\circ}:{ }^{13} \mathrm{CO}$ partial pressure in ingoing gas

$$
p_{13_{c o}}^{o}=\frac{1}{1+B} \frac{\left(\frac{2}{1}\right)_{i n}^{c o}}{1+\left(\frac{2}{1}\right)_{i n}^{c i n}}
$$

where, $\left(\frac{2}{1}\right)_{i n}^{c o}=\left(1+\delta_{i}^{c o} / 1000\right)\left(\frac{2}{1}\right)_{r e f}$.

\subsection{2 $p_{l^{30}}:{ }^{13} \mathrm{CO}$ partial pressure after isotope exchange}

$$
\begin{aligned}
& p_{{ }^{13}(O)}+p_{{ }^{12} C_{C O}}=p_{C O}=\frac{1}{1+B} \\
& \frac{p_{{ }^{13} C O}}{p_{{ }^{2} C O}}=\left(\frac{2}{1}\right)^{C O U}
\end{aligned}
$$

$\left(\frac{2}{1}\right)_{o I I}^{C O}$ is the abundance of ${ }^{13} \mathrm{CO}$ in the outgoing gases

Solving equation (2.17) and (2.32),

$$
p_{1 s^{\prime \prime l ~}}=\frac{1}{1+B} \frac{\left(\frac{2}{1}\right)_{o u t}^{c o}}{1+\left(\frac{2}{1}\right)_{m u t}^{c o t}}
$$


where, $\left(\frac{2}{1}\right)_{o u t}^{c o}=\left(1+\delta_{o u t}^{c o} / 1000\right)\left(\frac{2}{1}\right)_{r e f}$

\subsection{3 $\left(p_{{ }^{13} c o}\right)_{e q}$ : the partial pressure of ${ }^{13} \mathrm{CO}$ at equilibrium}

According to equation (2.24),

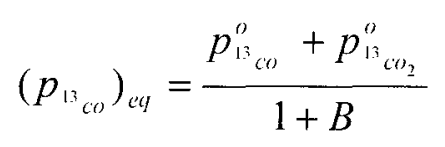

$p_{\mathrm{B}_{\mathrm{CO}}}^{o}, p_{{ }^{13} \mathrm{CO}_{2}}^{o}$ are known from (2.23) and (2.17)

$$
\left(p_{13_{c o}}\right)_{c q}=\frac{1}{(1+B)^{2}}\left[\frac{B \cdot\left(\frac{2}{1}\right)_{i n}^{c o_{2}}}{1+\left(\frac{2}{1}\right)_{i n}^{c o_{2}}}+\frac{\left(\frac{2}{1}\right)_{t n}^{c o}}{1+\left(\frac{2}{1}\right)_{i n}^{c o}}\right]
$$

Once the equation and the parameters in the equation are decided, the experiments can be carried out to measure the dissociation rate of $\mathrm{CO}_{2}$ on the surface of liquid slags. In chapter 3 , the detailed experimental arrangement and materials are introduced. 


\section{Chapter 3:}

\section{Experimental setup}

In chapter Two, equations have been developed for calculating the rate constants from new experimental data, and the parameters used in the equation have been explained in detail. In this chapter, the experimental setup and the materials used are introduced.

\subsection{The furnace}

The high temperature experiments were carried out in a furnace with molybdenum disilicide elements. Figure 3.1 gives the detailed arrangement inside the furnace. It mainly consists of an alumina working tube with $\mathrm{ID}=70 \mathrm{~mm}, \mathrm{OD}=80 \mathrm{~mm}$. Both the top and bottom of the working tube are sealed with an O-ring and stainless steel end caps, which are water-cooled throughout the experiment. A crucible containing the slags and the reaction tube are placed inside the work tube. The reaction tube attached to the crucible was inserted into the working tube from the top. A thermocouple (type B: Pt-6 pct Rh/Pt-30 pct Rh) inserted from the bottom was located close to the sample. The top of the reaction tube is also sealed with an O-ring and end cap, and the outgoing gas samples 


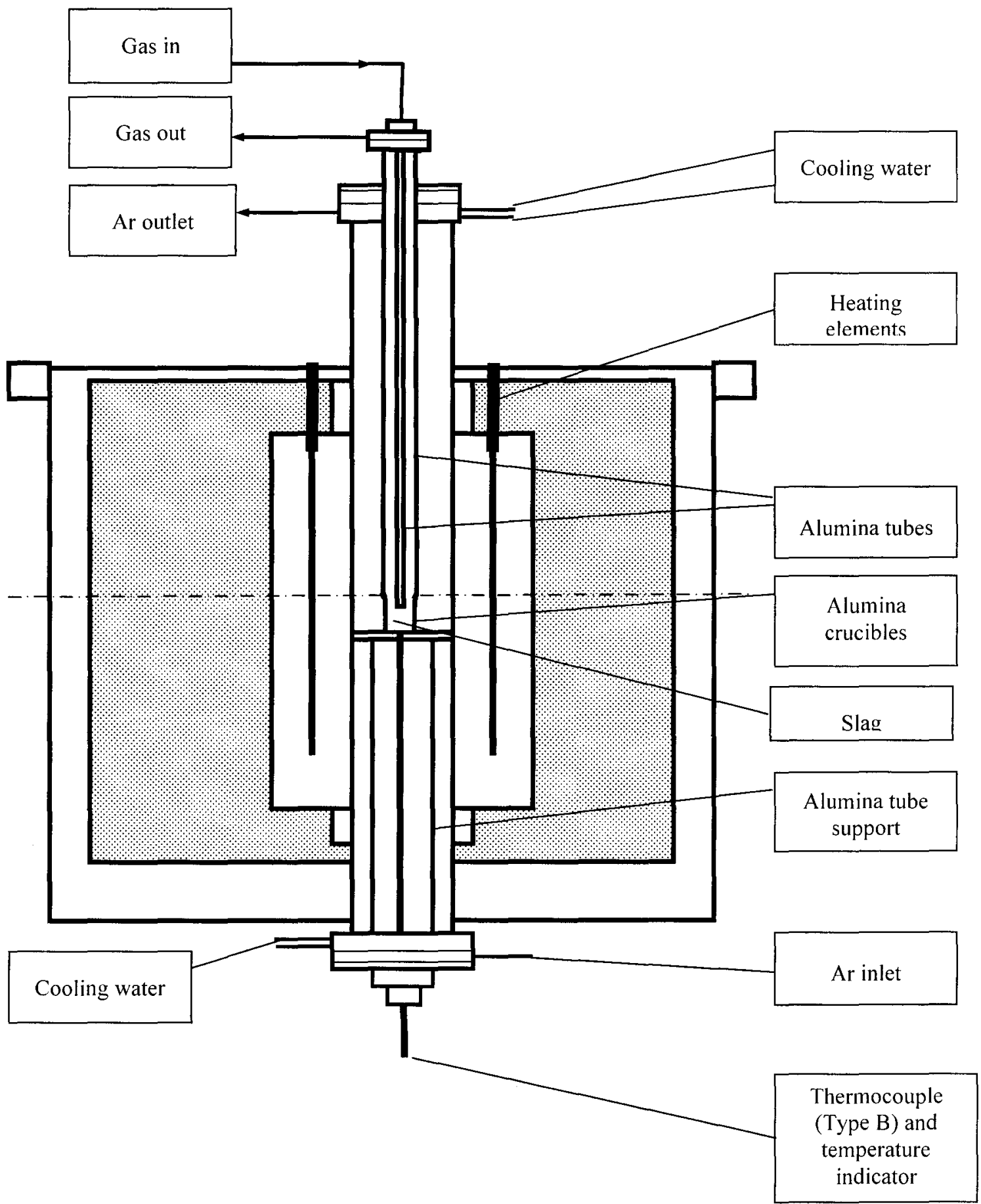

Figure (3.1): Schematic diagram of the experimental setup. 
were taken from the outlet gas line. The whole system was sealed and the work tube flushed with argon in order to prevent the air from penetrating into the reaction area. The argon was purified before entering the furnace by passing through a bed of copper turnings at $600^{\circ} \mathrm{C}$. Temperature control was achieved using a EUROTHERM controller. The temperature profiles in the working tube were carefully measured, a hot zone of 40 $\mathrm{mm}$ long was identified in which the temperature varied within $\pm 1^{\circ} \mathrm{C}$ as shown in figure

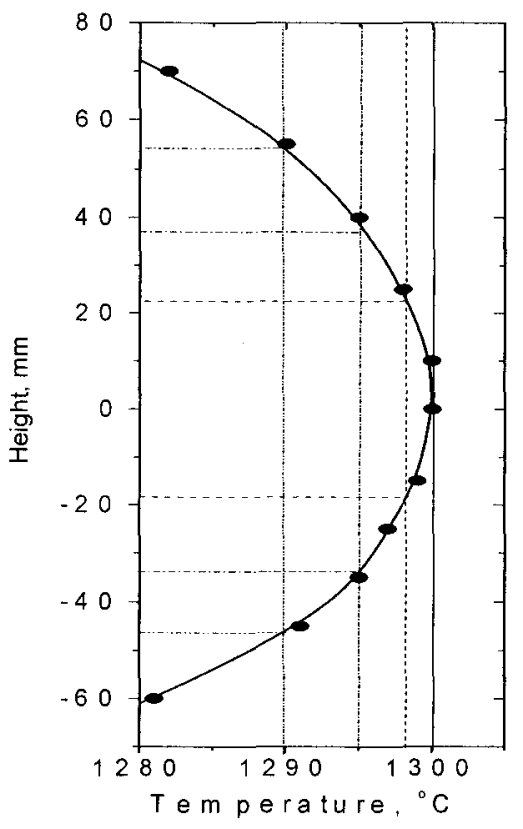

Vertical temperature distribution of the 1730 VY Rapid Temp Furnace at $1300^{\circ} \mathrm{C}$.

For temperature $\pm 5^{\circ} \mathrm{C}$, the uniform temperature zone is about $100 \mathrm{~mm}$ in height.

For temperature $\pm 2.5^{\circ} \mathrm{C}$, the uniform temperature zone is about $75 \mathrm{~mm}$ in height.

For temperature $\pm 1^{\circ} \mathrm{C}$, the uniform temperature zone is about $40 \mathrm{~mm}$ in height.

Figure (3.2): The temperature profile of the furnace 


\subsection{GC and MS}

Figure 3.3 gives the overall view of the arrangement of the equipment, including the gas system, the furnace and their connection. The gases used in this experiment include $\mathrm{CO}, \mathrm{CO}_{2}$, gas mixture of $1 \% \mathrm{CO}$ balanced with $\mathrm{CO}_{2}$ (Air Liquide), and labeled gas containing $\mathrm{CO}_{2} 10 \%{ }^{13} \mathrm{CO}_{2}$ by volume (Icon Isotopes). All of the gases were purified by passing through columns of "Drierite", and $\mathrm{CO}$ was further purified by passing through an Ascarite column (granulated sodium hydroxide on support) in order to remove $\mathrm{CO}_{2}$. Before entering the furnace, the gases were mixed by passing through a mixing column. The flowrate of the gases was controlled by computer controlled mass flow controllers. The controllers were calibrated by means of soap-film burettes. The reacted $\mathrm{CO}$ was burned in a natural gas burner after taking samples.

Figure 3.5 shows a picture of the gas chromatograph (Auto-system XL GC) and mass spectrometer (Isoprime isotope ratio mass spectrometer, IRMS). The GC is used to prepare a pure sample for the MS. It also gives the chemical composition of the gas sample (i.e. percentages of $\mathrm{CO}$ and $\mathrm{CO}_{2}$ ). $\mathrm{MS}$ is used to measure the enrichment of the sample gas. Attention should be paid to the amount of sample so that the GC supplies sufficient sample for analysis in the MS. Usually, the following equation is used for the calculation of the amount of sample,

$$
\text { Sample volume }=\frac{0.08}{\mathrm{CO}_{2} \text { Concentration in Sample, } \%} \times 100 \mathrm{ml}
$$




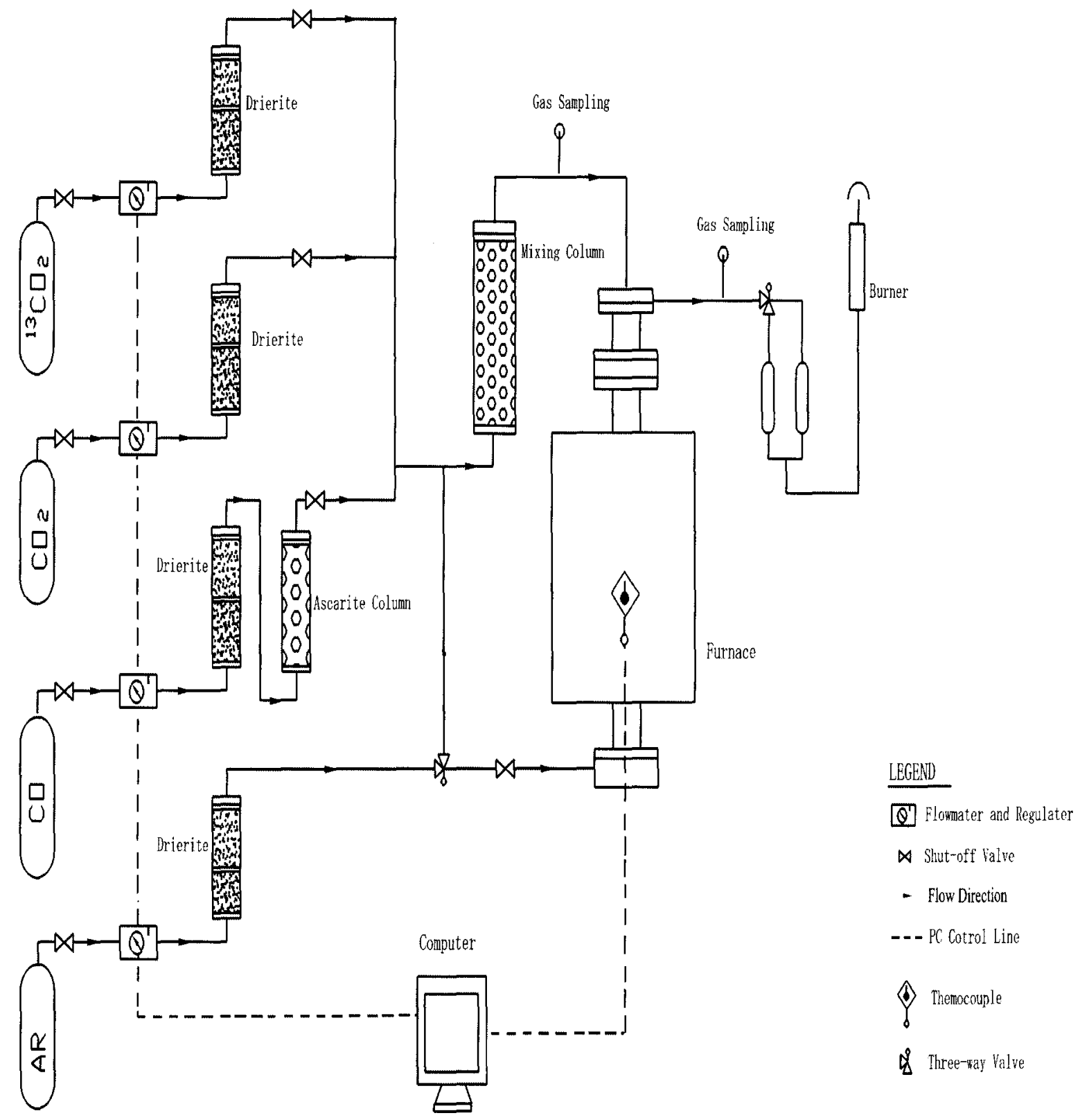

Figure (3.3): The overall view of experimental arrangement. 


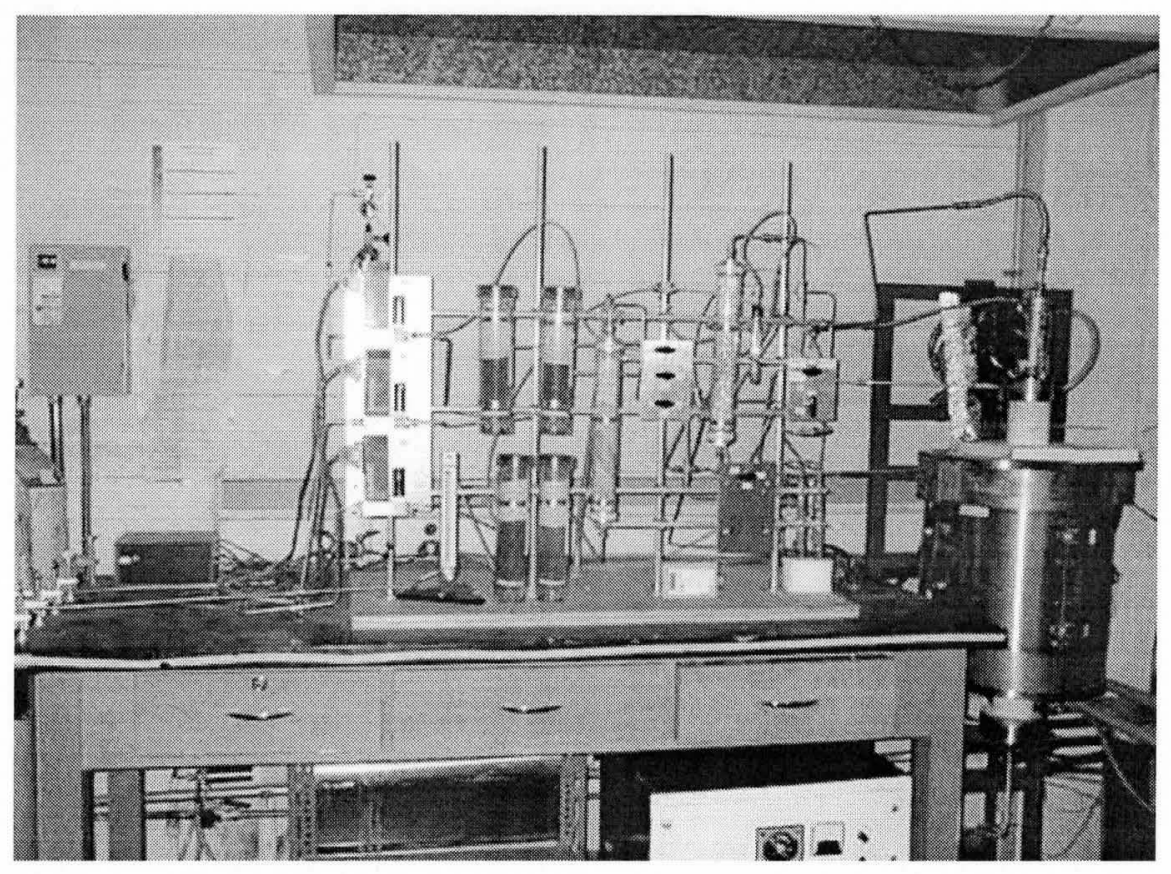

Figure (3.4): The furnace and gas train.

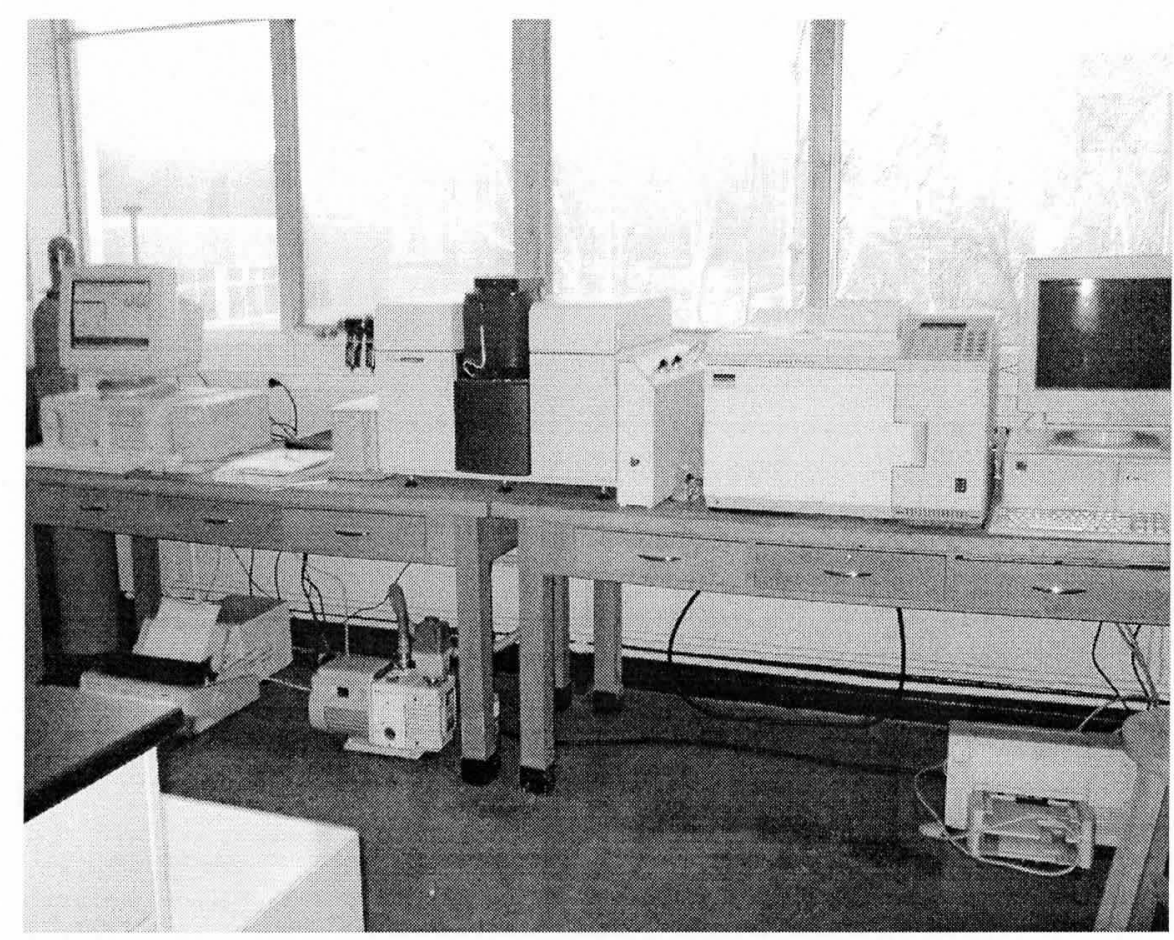

Figure (3.5): The GC and MS. 


\subsection{The experimental materials}

Figure 3.6 shows the detailed arrangement inside the working tube. An inner diameter $11.11 \mathrm{~mm}$ of alumina reaction tube (Vesuvius McDanel, USA) with flat base was attached using alumina cement to a crucible containing slag. The outside diameter of the reaction tube was $17.46 \mathrm{~mm}$. Two kinds of crucibles were used in this study, one was alumina (Vesuvius McDanel, USA), which was used when the slag was saturated with $\mathrm{Al}_{2} \mathrm{O}_{3}$. Another was zirconia (Almath Crucibles Ltd., UK), which was used when the slag did not contain $\mathrm{Al}_{2} \mathrm{O}_{3}$. The crucible size was the same in each case, inner diameter was $11 \mathrm{~mm}$, outside diameter was $13 \mathrm{~mm}$, height was $20 \mathrm{~mm}$. The alumina blowing tube (Vesuvius McDanel, USA) had an inner diameter $4.75 \mathrm{~mm}$ and an outside diameter of $6.35 \mathrm{~mm}$. It was held coaxially within the reaction tube to deliver the reaction gases to the surface of the slag, its end was positioned $5 \mathrm{~mm}$ above liquid slag surface.

\subsection{The Procedure}

$0.5 \mathrm{~g}$ of slag sample was loaded into the crucible and attached to the reaction tube using alumina cement. Crucible and tube were left in air for half an hour, and then placed in the furnace. The furnace temperature was set to $120^{\circ} \mathrm{C}$, and held for a few hours to dry the cement. The entire assembly was then heated to the desired temperature under argon flowing from the bottom of the furnace. Once the desired temperature was achieved, a $\mathrm{CO}$ and $\mathrm{CO}_{2}$ gas mixture was introduced via the blowing tube. After about one hour, the 
slag and gas achieved chemical equilibrium, and labeled ${ }^{13} \mathrm{CO}_{2}$ was introduced. Samples for analysis were taken after a period of about $15 \mathrm{~min}$ when the isotope exchange reaction reached steady state. Usually, a second sample was taken after a further 10 to $15 \mathrm{~min}$ to confirm that steady state had been achieved.

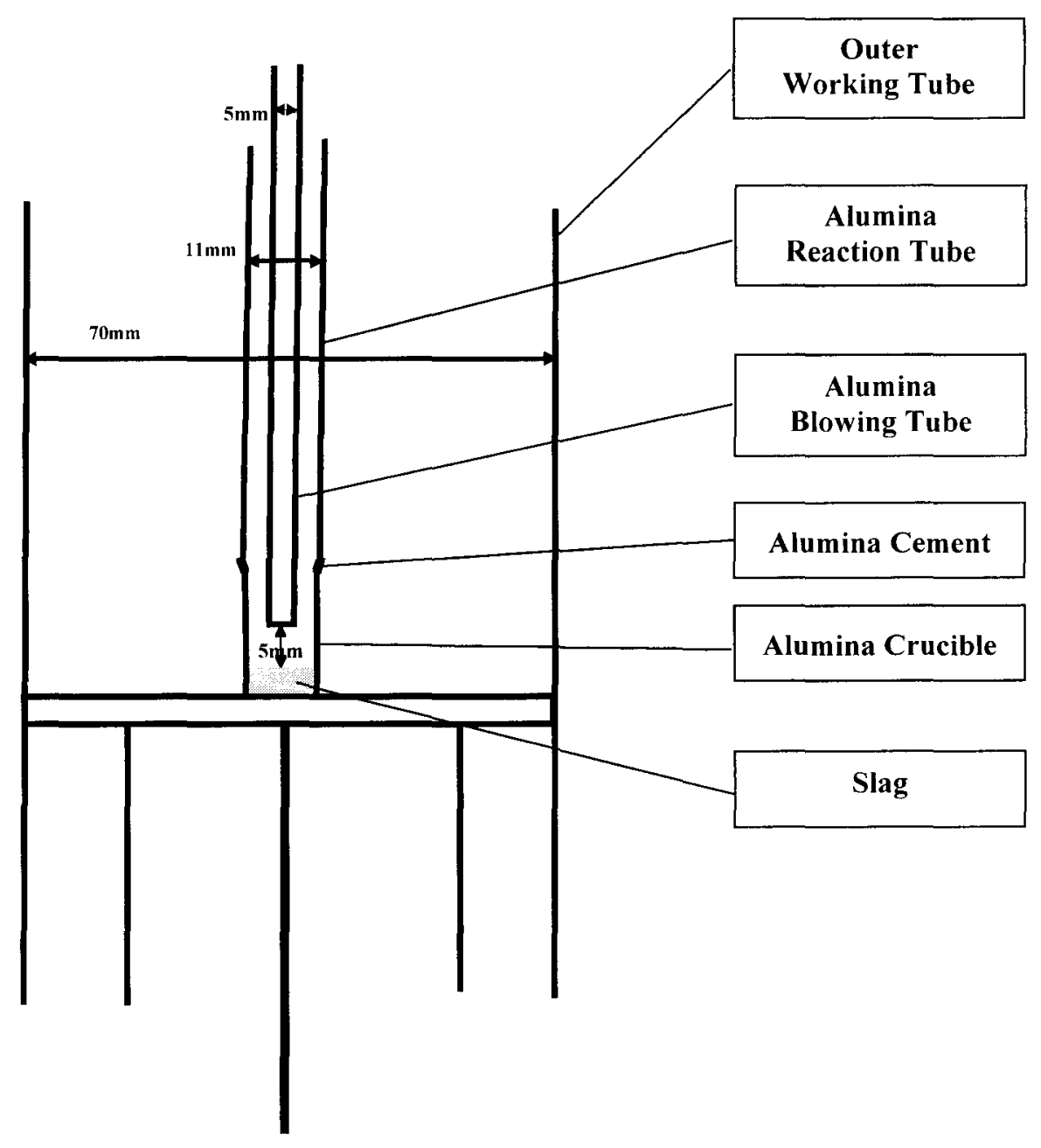

Figure (3.6): The detail arrangement of crucible and blowing tube. 


\subsection{Experimental errors}

No physical quantity can be measured with perfect certainty; there are always errors in any measurement. There is no exemption for this study. The following gives the analysis of experimental errors.

The systematic errors exist in the study due to the calibration of the gas flowrate by means of soap-film burettes. For MS, leaking of atmospheric gases into the vacuum enclosure causes contamination, the cleanliness of the vacuum enclosure can be visualized by performing background scans. In addition, the stability of the MS has to be checked every time before sample analysis. A system is declared stable if the standard deviation of the fit is less than $1 \mathrm{E}-6$.

According to the equation (2.15), the uncertainty in the measurement of rate constant can be expressed by,

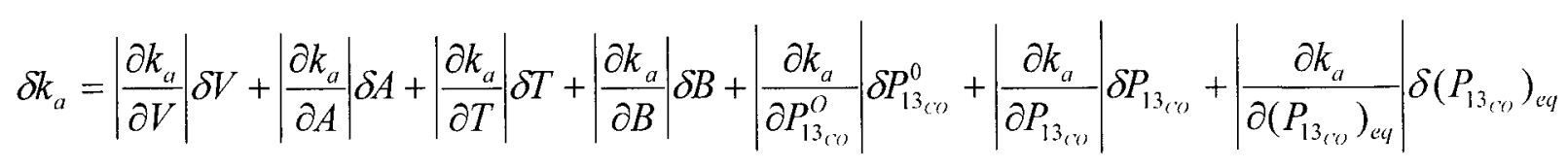

The calculated uncertainty is calculated to be about $5 \%$ in this study. Observed scatter in the measured values is consistent with the foregoing calculation. 


\section{Chapter 4:}

\section{Experimental Results}

The experiments were carried out by jetting gas onto the surface of a series of different slags in order to understand the effects of oxygen potential, temperature, cuprous oxide and metallic copper on the dissociation rate of $\mathrm{CO}_{2}$ on the surface of liquid copper slags. All of the experimental results are given in this chapter. Further comparisons between these results and others are given in Chapter 5. Through the discussion, further insight into these effects will be obtained.

When measuring the slag reduction rate, if gas mixtures are used instead of carbon or graphite, three possible rate-determining steps could be involved, mass transfer in the gas phase, gas slag chemical reaction, and mass transfer in liquid phase. Because the measurement is done at chemical reaction equilibrium, the effect of liquid mass transfer in melts can be eliminated. However, experiments have to be carried out to decide the gas flowrate so that the effect of mass transfer in the gas is minimized. The 
experiments require gas flow rate high enough to minimize the effect of mass transfer in gas phase, but not too high to cause a significant change in the interfacial surface area, or to decrease the concentration change measured in the outgoing gas.

\subsection{Liquid aluminum iron silicates}

To find the optimum flowrate, experiments were carried out with total gas flowrate varying from 150 to $600 \mathrm{ml} / \mathrm{min}$, see Figure 4.1, the relationship between rate constants and gas flowrate. The rate constant should not change with flow rate, when under chemical reaction control.

The rate constant was determined from measured enrichment data using the equation developed in Chapter 2. The measured rate constant became independent of flowrate when it was above $450 \mathrm{ml} / \mathrm{min}$. So, the flowrate of $450 \mathrm{ml} / \mathrm{min}$ was used for all subsequent experiments.

$$
k_{a}=\frac{\dot{V}}{A R T} \frac{1}{1+B} \ln \frac{1-\frac{p_{1_{c o}}^{o}}{\left(p_{1_{c o}}\right)_{e q}}}{1-\frac{p_{1_{c o}}}{\left(p_{1_{c o}}\right)_{e q}}}
$$

Because the isotope exchange method is conducted at gas/slag chemical equilibrium, experiments were also carried out in order to find the time required to 
achieve equilibrium. The equilibrium time was decided by taking a reacted gas sample every 15 minutes and analyzing the percentage of $\mathrm{CO}$ and $\mathrm{CO}_{2}$ by gas chromatography. It was found that the gas compositions did not change with time after 30 minutes. So, labeled gases were introduced after an hour in all of the subsequent experiments.

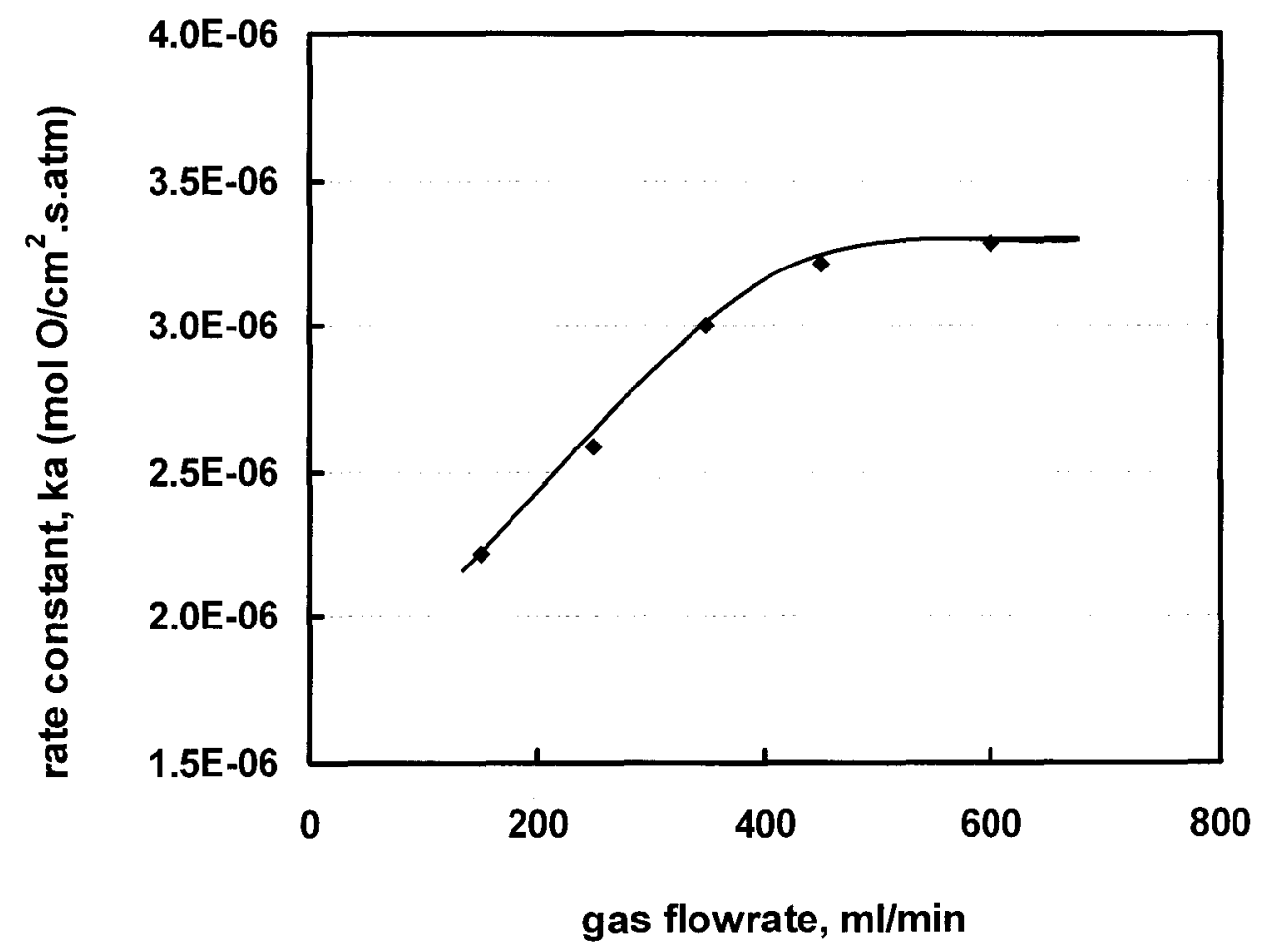

Figure (4.1): The effect of gas flowrate on the apparent rate constant for slag $60 \mathrm{Fe}_{\mathrm{x}} \mathrm{O}-30 \mathrm{SiO}_{2}-10 \mathrm{Al}_{2} \mathrm{O}_{3}$ at $\mathrm{T}=1585 \mathrm{~K}$ and $\mathrm{pCO}_{2} / \mathrm{pCO}=1$. 


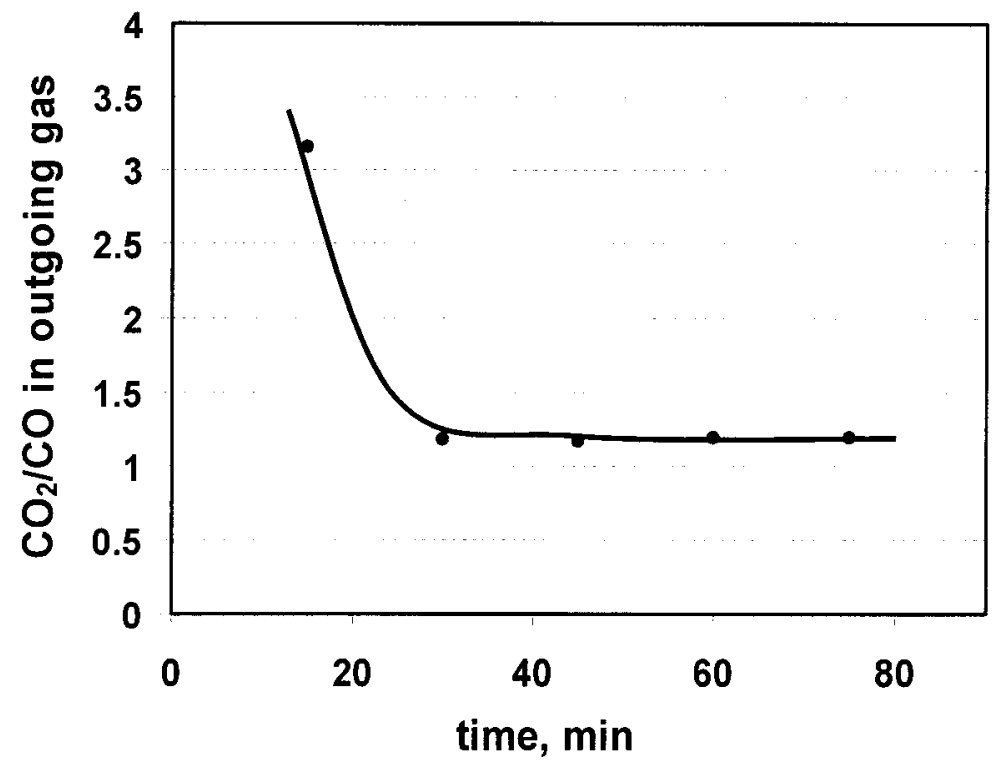

Figure (4.2): The time for achieving equilibrium for slag $60 \mathrm{Fe}_{x} \mathrm{O}-30 \mathrm{SiO}_{2}-10 \mathrm{Al}_{2} \mathrm{O}_{3}$ at $\mathrm{T}=1585 \mathrm{~K}$ and $\mathrm{pCO}_{2} / \mathrm{pCO}=1$.

The dependence of the apparent rate constant on the $\mathrm{CO}_{2} / \mathrm{CO}$ ratio was examined at $1585 \mathrm{~K}$ for liquid aluminum iron silicates, the slag compositions were: $\mathrm{Fe}_{2} \mathrm{O}_{3}-60 \%$, $\mathrm{SiO}_{2}-30 \%$ and $\mathrm{Al}_{2} \mathrm{O}_{3}-10 \%$. Flowrate was kept $450 \mathrm{ml} / \mathrm{min}$. Apparent rate constants, in units of mol cm $\mathrm{cm}^{-2} \mathrm{~atm}^{-1}$, are presented as a function of the $\mathrm{CO}_{2} / \mathrm{CO}$ ratio in logarithmic form in Figure 4.3. 


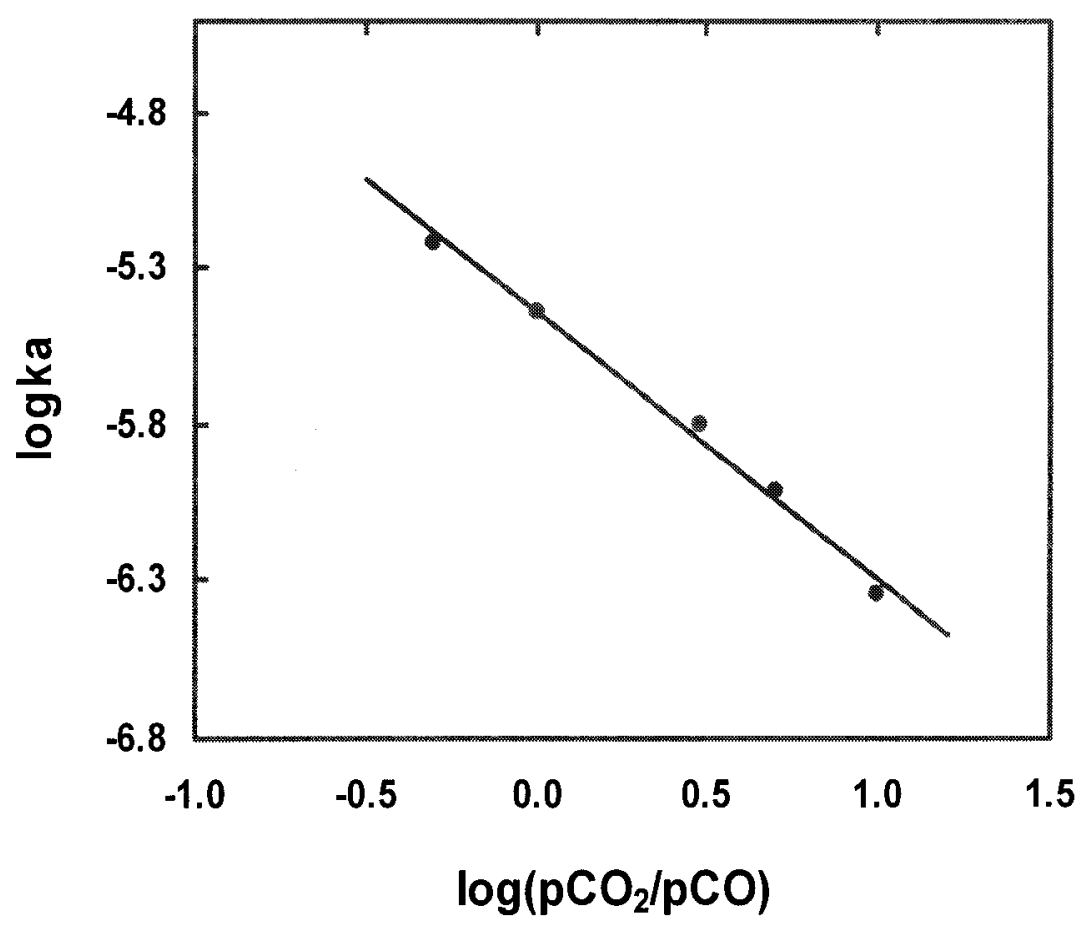

Figure (4.3): Apparent rate constants $\left(\mathrm{mol} \mathrm{cm} \mathrm{s}^{-2} \mathrm{~s}^{-1} \mathrm{~atm}^{-1}\right)$ for the dissociation of $\mathrm{CO}_{2}$ on liquid aluminum iron silicates at $1585 \mathrm{~K}$ as a function of the equilibrium $\mathrm{CO}_{2} / \mathrm{CO}$ ratio.

The apparent rate constant was expressed by in Figure 4.3,

$$
k_{a}=k_{a}^{0}\left(p c o_{2} / p c o\right)^{-0.85}
$$

Where $\mathrm{k}_{\mathrm{a}}^{0}$ is a temperature dependent constant at $\mathrm{pCO}_{2} / \mathrm{pCO}=1, \mathrm{k}_{\mathrm{a}}^{0}=3.6^{*} 10^{-6}$ in this experiment, so, expression (4.1) became,

$$
k_{a}=3.6^{*} 10^{-6}\left(\mathrm{pco}_{2} / \mathrm{pco}\right)^{-0.85}
$$


The rate constants at $\mathrm{T}=1723 \mathrm{~K}$ were also measured, see figure 4.4. It can be seen that the rate constants are 3 times higher at $T=1723 \mathrm{~K}$ than those at $\mathrm{T}=1585 \mathrm{~K}$, and was expressed by the following equation,

$$
k_{a}=10^{-5}\left(\mathrm{pco}_{2} / \mathrm{pco}\right)^{-0.82}
$$

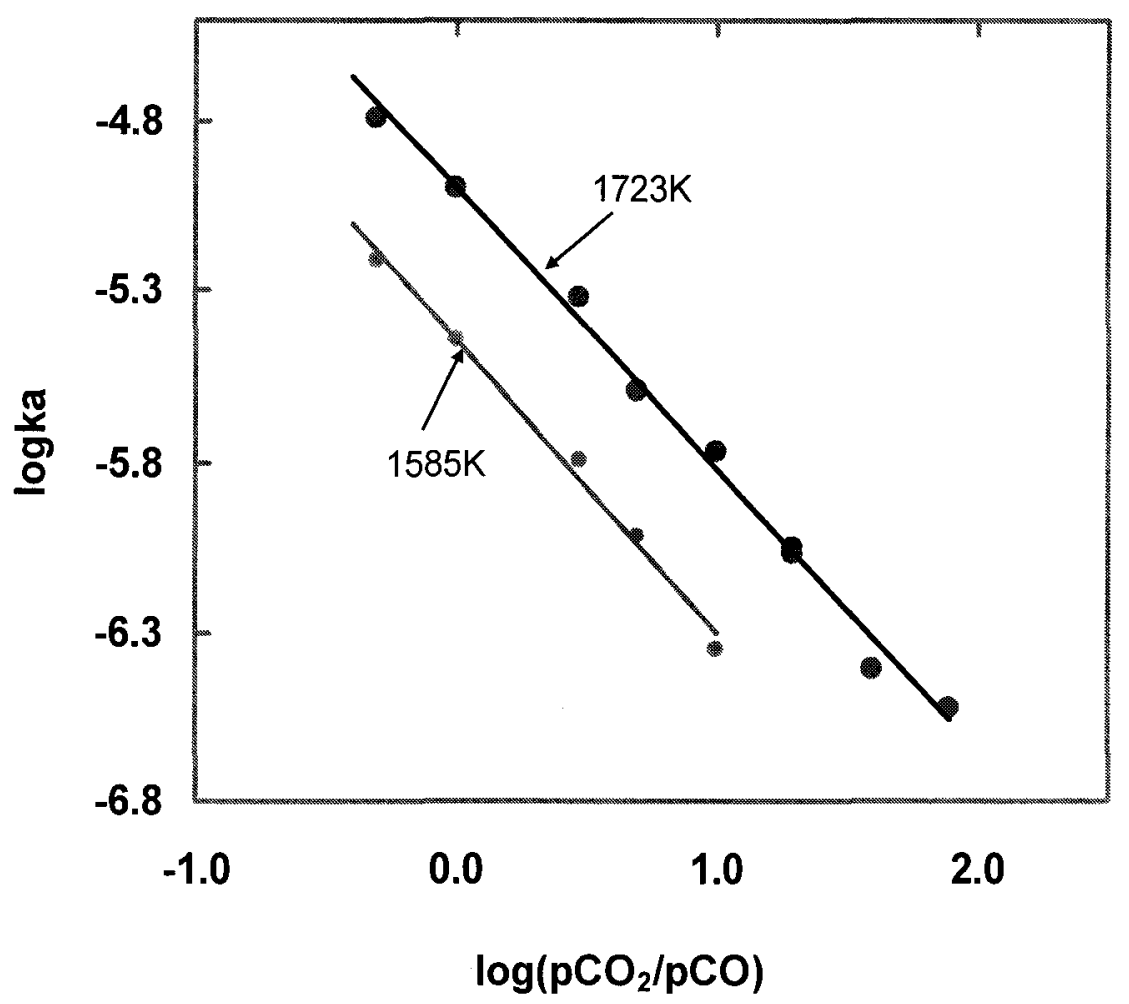

Figure (4.4): Apparent rate constants $\left(\mathrm{mol} \mathrm{cm}^{-2} \mathrm{~s}^{-1} \mathrm{~atm}^{-1}\right)$ for the dissociation of $\mathrm{CO}_{2}$ on liquid aluminum iron silicates at $1585 \mathrm{~K}$ and $1723 \mathrm{~K}$ as a function of the equilibrium $\mathrm{CO}_{2} / \mathrm{CO}$ ratio.

Results obtained as a function of temperature for a fixed $\mathrm{CO}_{2} / \mathrm{CO}$ ratio of 1 are presented in Figure 4.5. 


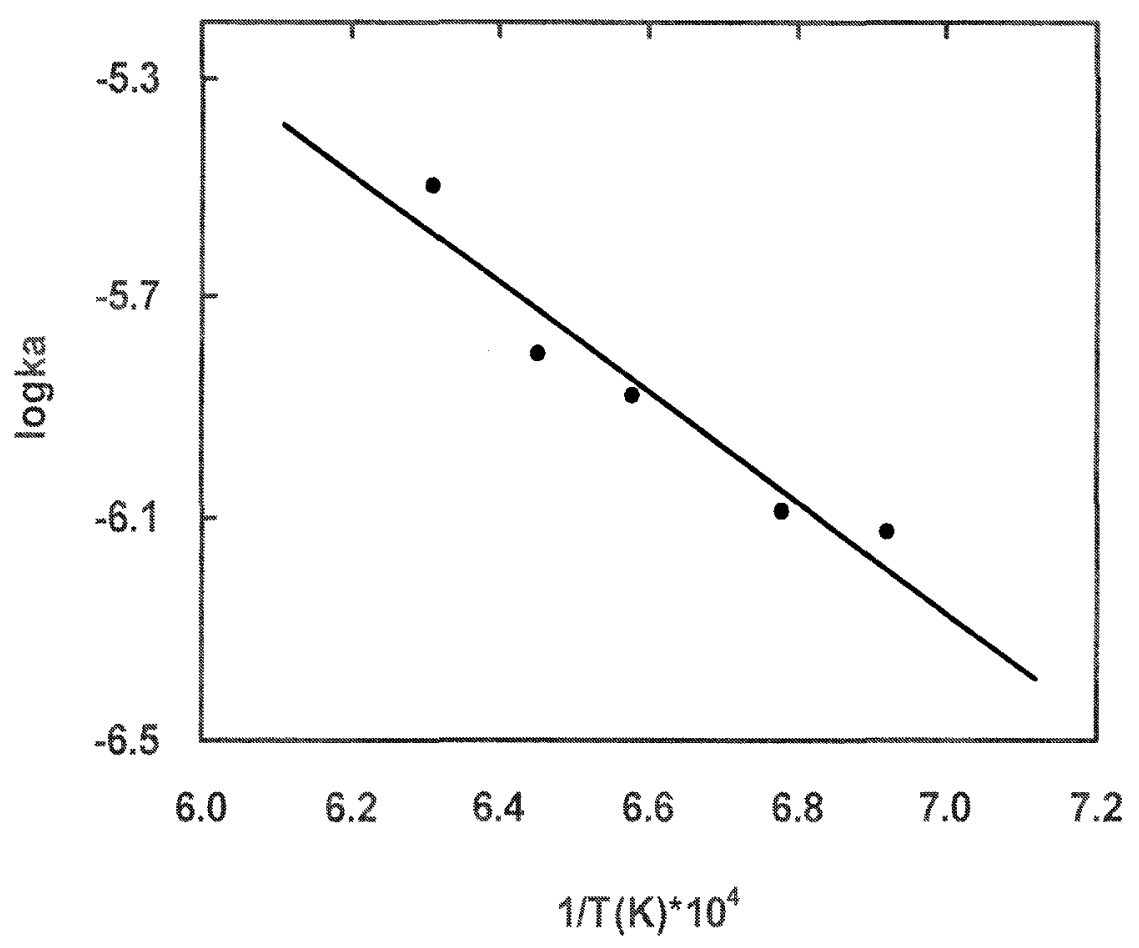

Figure (4.5): Arrhenius plot of the apparent rate constants for liquid aluminum iron silicates at an equilibrium $\mathrm{CO}_{2} / \mathrm{CO}$ ratio of 1 .

The equation for the straight line is given in equation (4.4), the calculated activation energy is $190 \mathrm{~kJ} / \mathrm{mole}$.

$$
\log k_{a}^{0}=-9926 / \mathrm{T}+0.6814
$$

\subsection{Liquid copper-making slag}


For liquid iron oxide containing slag, the oxygen potential was controlled within the range in which no metallic iron was reduced. However, with cuprous oxide being added to the slag, metallic copper was produced even if the oxygen potential was controlled in that range. In order to see both of the effects of copper oxide and metallic copper on the rate constant, the oxygen potential was calculated for different percentages of cuprous oxide containing slag to determine if metallic copper is present in the slag.

The oxidation reaction of copper: [32] [43]

$$
\begin{gathered}
\mathrm{Cu}(\mathrm{l})+1 / 2 \mathrm{CO}_{2}(\mathrm{~g})=\mathrm{CuO}_{0.5}(\mathrm{l})+1 / 2 \mathrm{CO}(\mathrm{g}) \\
\Delta \mathrm{G}^{0}=16,260-3.16 \mathrm{~T} \text { (cal/mole) }
\end{gathered}
$$

and the equation of the activity of cuprous oxide, [33] [34]

$$
\% \mathrm{Cu} \text { in slag }=29.73\left(\mathrm{a}_{\mathrm{Cu} 2 \mathrm{O}}\right)^{1 / 2}=29.73\left(\mathrm{a}_{\mathrm{CuO} 0.5}\right)
$$

For different percentages of $\mathrm{Cu}_{2} \mathrm{O}$, critical oxygen potentials can be calculated, for example, at $\mathrm{T}=1723 \mathrm{~K}$,

$$
\begin{array}{ll}
1 \% \mathrm{Cu} \text { in slag }=1 \%, & P_{\mathrm{CO}_{2}} / P_{C O}=0.63 \\
3 \% \mathrm{Cu} \text { in slag }=3 \%, & P_{\mathrm{CO}_{2}} / P_{C O}=5.67
\end{array}
$$




$$
\begin{array}{ll}
6 \% \mathrm{Cu} \text { in slag }=7 \%, & P_{\mathrm{CO}_{2}} / P_{C O}=22.67 \\
8 \% \mathrm{Cu} \text { in slag }=10 \%, & P_{\mathrm{CO}_{2}} / P_{C O}=40
\end{array}
$$

\subsubsection{The effect of metallic copper on the dissociation of $\mathrm{CO}_{2}$}

According to the above thermodynamic calculation, it can be known that metallic copper will be reduced from the slag within all of the experimental oxygen potentials at $\mathrm{T}=1585 \mathrm{~K}$ and $1723 \mathrm{~K}$.

At $\mathrm{T}=1585 \mathrm{~K}$, the rate constant increased by a factor of 1.65 after adding $10 \%$ $\mathrm{Cu}_{2} \mathrm{O}$ into the slag, and the equation for the straight line is expressed by,

$$
k_{a}=5.6 * 10^{-6}\left(\mathrm{Pco}_{2} / \mathrm{Pco}\right)^{-0.79}
$$




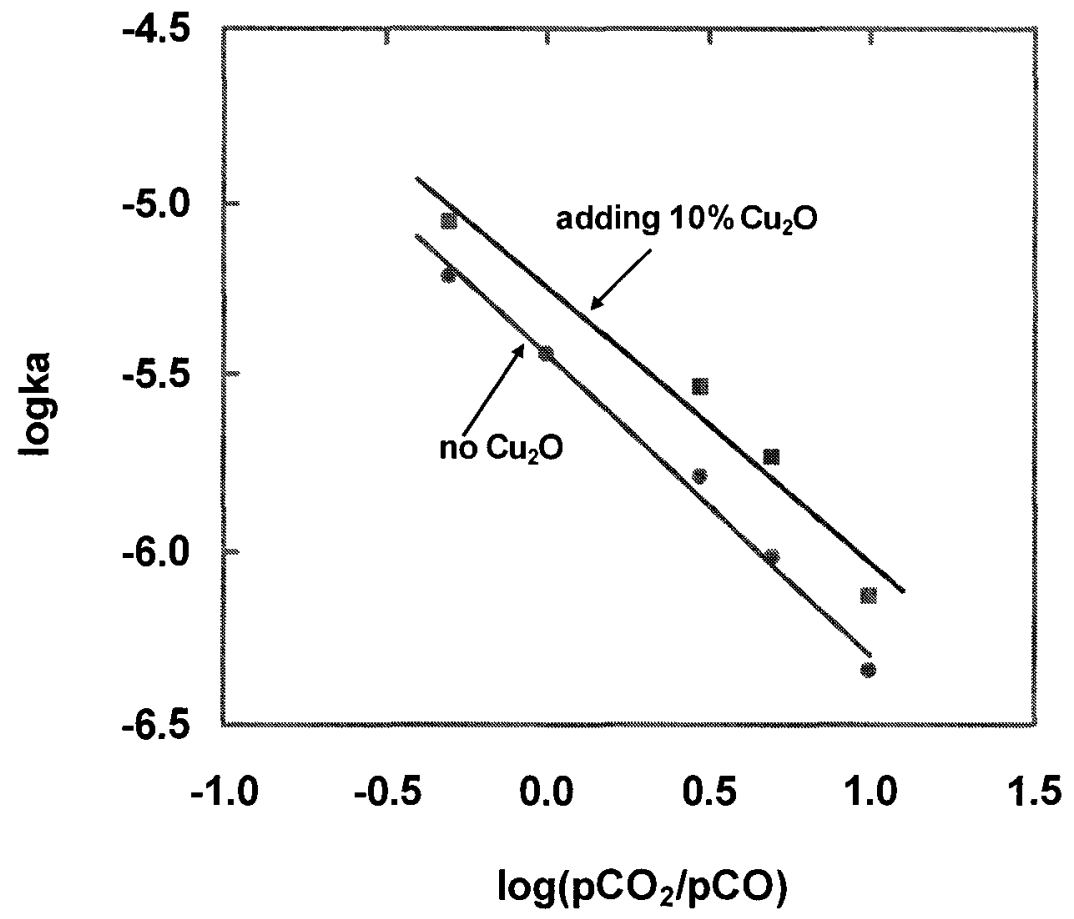

Figure (4.6): Apparent rate constants $\left(\mathrm{mol} \mathrm{cm}^{-2} \mathrm{~s}^{-1} \mathrm{~atm}^{-1}\right)$ for the dissociation of $\mathrm{CO}_{2}$ on slag of $60 \mathrm{Fe}_{\mathrm{x}} \mathrm{O}-30 \mathrm{SiO}_{2}-10 \mathrm{Al}_{2} \mathrm{O}_{3}$ and $60 \mathrm{Fe}_{\mathrm{x}} \mathrm{O}-30 \mathrm{SiO}_{2}-10 \mathrm{Al}_{2} \mathrm{O}_{3}$ $10 \mathrm{Cu}_{2} \mathrm{O}$ at $1585 \mathrm{~K}$ as a function of the equilibrium $\mathrm{CO}_{2} / \mathrm{CO}$ ratio.

At $\mathrm{T}=1723 \mathrm{~K}$, the rate constant increased by a factor of 2.3 after also adding $10 \%$ $\mathrm{Cu}_{2} \mathrm{O}$, see Figure (3.12). The rate constant was expressed by,

$$
k_{a}=2.1 * 10^{-5}\left(p_{C O_{2}} / p_{C O}\right)^{-0.73}
$$




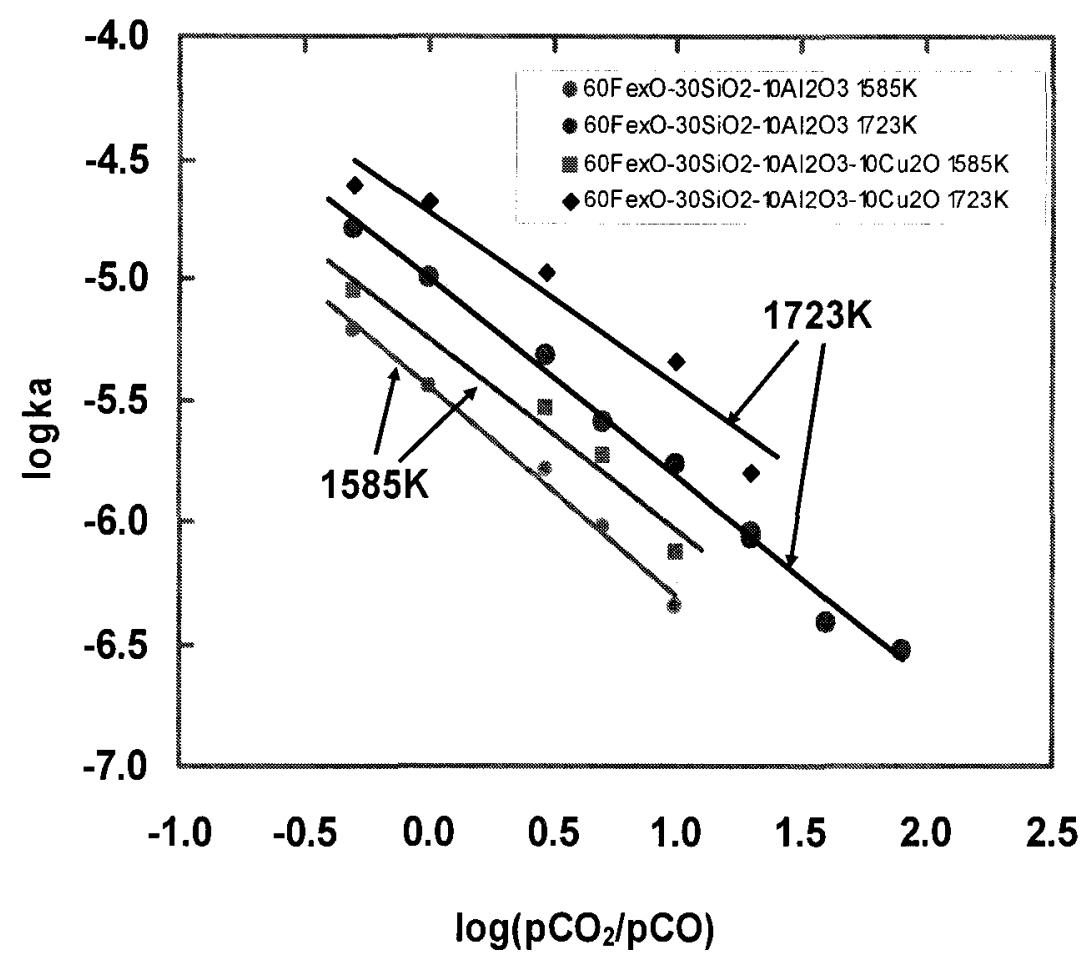

Figure (4.7): Apparent rate constants $\left(\mathrm{mol} \mathrm{cm}^{-2} \mathrm{~s}^{-1} \mathrm{~atm}^{-1}\right)$ for the dissociation of $\mathrm{CO}_{2}$ on slag of $60 \mathrm{Fe} \mathrm{x}_{\mathrm{x}} \mathrm{O}-30 \mathrm{SiO}_{2}-10 \mathrm{Al}_{2} \mathrm{O}_{3}$ and $60 \mathrm{Fe}_{x} \mathrm{O}-30 \mathrm{SiO}_{2}-10 \mathrm{Al}_{2} \mathrm{O}_{3}$ $10 \mathrm{Cu}_{2} \mathrm{O}$ at $1585 \mathrm{~K}$ and $1723 \mathrm{~K}$ as a function of the equilibrium $\mathrm{CO}_{2} / \mathrm{CO}$ ratio.

The dependence of rate constant on temperature after adding $10 \% \mathrm{Cu}_{2} \mathrm{O}$ is expressed by the following equation, the activation energy is $122 \mathrm{~kJ} / \mathrm{mole}$.

$$
\log k_{a}^{0}=-6384 / \mathrm{T}-1.065
$$




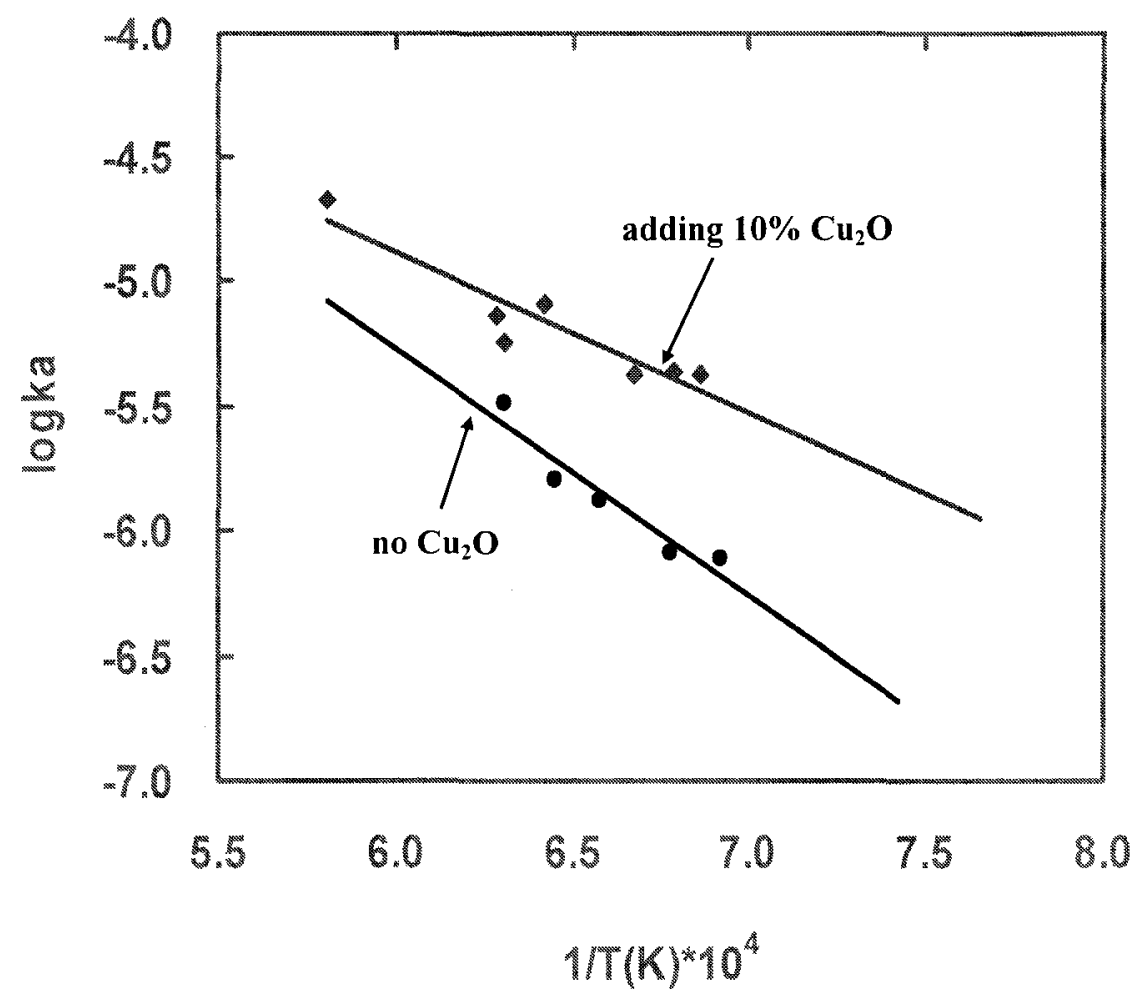

Figure (4.8): Arrhenius plot of the apparent rate constants for slag of $60 \mathrm{Fe}_{\mathrm{x}} \mathrm{O}$ $30 \mathrm{SiO}_{2}-10 \mathrm{Al}_{2} \mathrm{O}_{3}$ and $60 \mathrm{Fe}_{\mathrm{x}} \mathrm{O}-30 \mathrm{SiO}_{2}-10 \mathrm{Al}_{2} \mathrm{O}_{3}-10 \mathrm{Cu}_{2} \mathrm{O}$ at an equilibrium $\mathrm{CO}_{2}$ /CO ratio of 1 .

In summary, the rate constant increased after adding $10 \% \mathrm{Cu}_{2} \mathrm{O}$ into the slag within the restricted oxygen potentials within which metallic copper was reduced. (see Figure 4.8).

\subsubsection{The effect of cuprous oxide on the rate constants}

The oxygen potential was controlled so that no metallic copper was reduced from the slag in order to see the effect of cuprous oxide on the dissociation rate of $\mathrm{CO}_{2}$ on the 
slag surface. Different oxygen potentials should be applied because the activity of $\mathrm{Cu}_{2} \mathrm{O}$ changed with the content of $\mathrm{Cu}_{2} \mathrm{O}$ in the slag. See table 4.1.

\begin{tabular}{|l|l|}
\hline Content of $\mathrm{Cu}_{2} \mathbf{O}(\%)$ & $p_{C^{(O)}} / p_{C O}$ \\
\hline 1 & 3 \\
\hline 3 & 8 \\
\hline 7 & 23 \\
\hline 10 & 40 \\
\hline
\end{tabular}

Table (4.1): The control of oxygen potentials.

The rate constant was measured after adding $1,3,7,10 \% \mathrm{Cu}_{2} \mathrm{O}$ into the slag , meanwhile keeping the ratio of $\mathrm{Fe}_{2} \mathrm{O}_{3} / \mathrm{SiO}_{2} / \mathrm{Al}_{2} \mathrm{O}_{3}$ fixed. The experimental results are shown in Figure 4.9. It can be seen that the rate constant was independent of cuprous oxide even adding up to $10 \%$ into the slag. An attempt will be made to explain this result in detail in next chapter. 


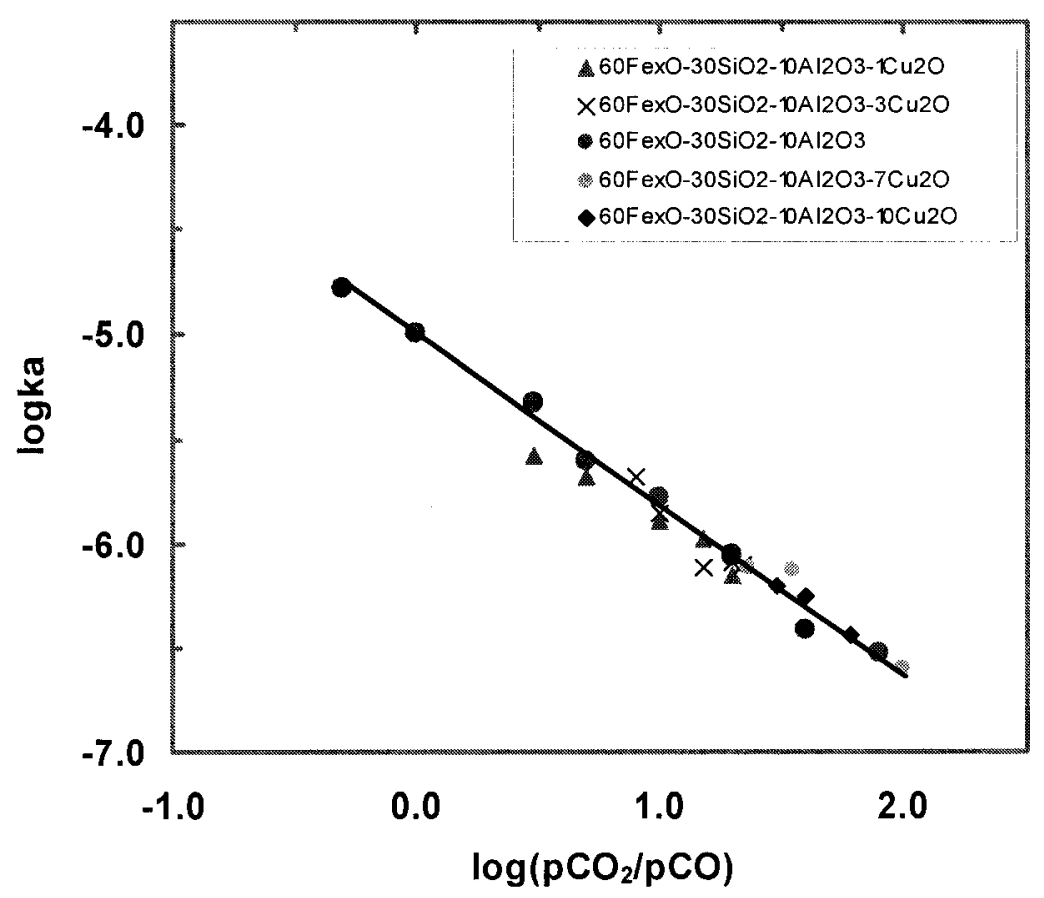

Figure (4.9): Apparent rate constants $\left(\mathrm{mol} \mathrm{cm} \mathrm{cm}^{-2} \mathrm{stm}^{-1}\right)$ for the dissociation of $\mathrm{CO}_{2}$ on slag of different percentages of $\mathrm{Cu}_{2} \mathrm{O}$ based on liquid aluminum iron silicates at $1723 \mathrm{~K}$ as a function of the equilibrium $\mathrm{CO}_{2} / \mathrm{CO}$ ratio. 


\section{Chapter Five:}

\section{Discussion of experimental results}

The experimental results given in Chapter 4 show that $\mathrm{Cu}_{2} \mathrm{O}$ has no remarkable effect on the rate constants under conditions where no metallic copper is reduced from the slag. However, the rate constant becomes 2 times higher than those for liquid aluminum iron silicates after metallic copper is reduced from the slag. The reason for this appears to be the presence of small metal particles at the slag/gas interface. In this chapter, an attempt will be made to explain all the results in terms of a charge transfer model $[11][17][18][51][] 67]$. 


\subsection{The effect of $\mathrm{Cu}_{2} \mathrm{O}$ on the dissociation rate of $\mathrm{CO}_{2}$}

Several researchers have studied the effect of different oxides on the $\mathrm{CO}_{2}$ dissociation rate on the surface of iron oxide containing slags [11][17][18][45]. Nagasaka et al. [45] studied the effect in simple binary slag systems, they found that the addition of strong basic oxides such as $\mathrm{Na}_{2} \mathrm{O}$ and $\mathrm{CaO}$ increased the apparent rate constant, and acidic oxides such as $\mathrm{TiO}_{2}, \mathrm{SiO}_{2}$, and $\mathrm{P}_{2} \mathrm{O}_{5}$ decreased it. $\mathrm{Al}_{2} \mathrm{O}_{3}, \mathrm{MgO}$, and $\mathrm{MnO}$ had no remarkable effect on it. Li et al. [12] also studied these effects, and their results supported Nagasaka's findings.

The experimental results obtained in this study are shown in Figure (5.1). All of the data are located on the same line with liquid aluminum iron silicates at $T=1723 \mathrm{~K}$ if the $\mathrm{CO}_{2} / \mathrm{CO}$ ratio is controlled such that no metallic copper is reduced. The rate constants were kept the same even after $10 \%$ of $\mathrm{Cu}_{2} \mathrm{O}$ was added to the slag. With this in mind, by decreasing the ratio of $\mathrm{pCO}_{2} / \mathrm{pCO}$ to less than 40 , according thermodynamic calculations, metallic copper will be reduced from the slag. The rate constants increase to 2 times higher than those for liquid aluminum iron silicates.

The experimental results for the $60 \mathrm{Fe}_{\mathrm{x}} \mathrm{O}-30 \mathrm{SiO}_{2}-10 \mathrm{Al}_{2} \mathrm{O}_{3}$ slag system at $1723 \mathrm{~K}$ agrees with those of other workers very well under similar conditions, [1][11][18] except for Mori's results [25], which used an equation to calculate $k_{a}$ that did not take full account of the natural abundance of ${ }^{13} \mathrm{C}$, see Figure (5.2). Y. Li's results are highest 
because of the higher basicity and temperature (1773K). Keeping the same basicity $\left(\mathrm{CaO} / \mathrm{SiO}_{2}=1\right)$, Barati's results seem reasonable due to the lower temperature $(1723 \mathrm{~K})$. El-Rahaiby's results obtained at a lower temperature (1673K) are on the same line as those in the present study because the basicity of the slag in their experiment is higher.

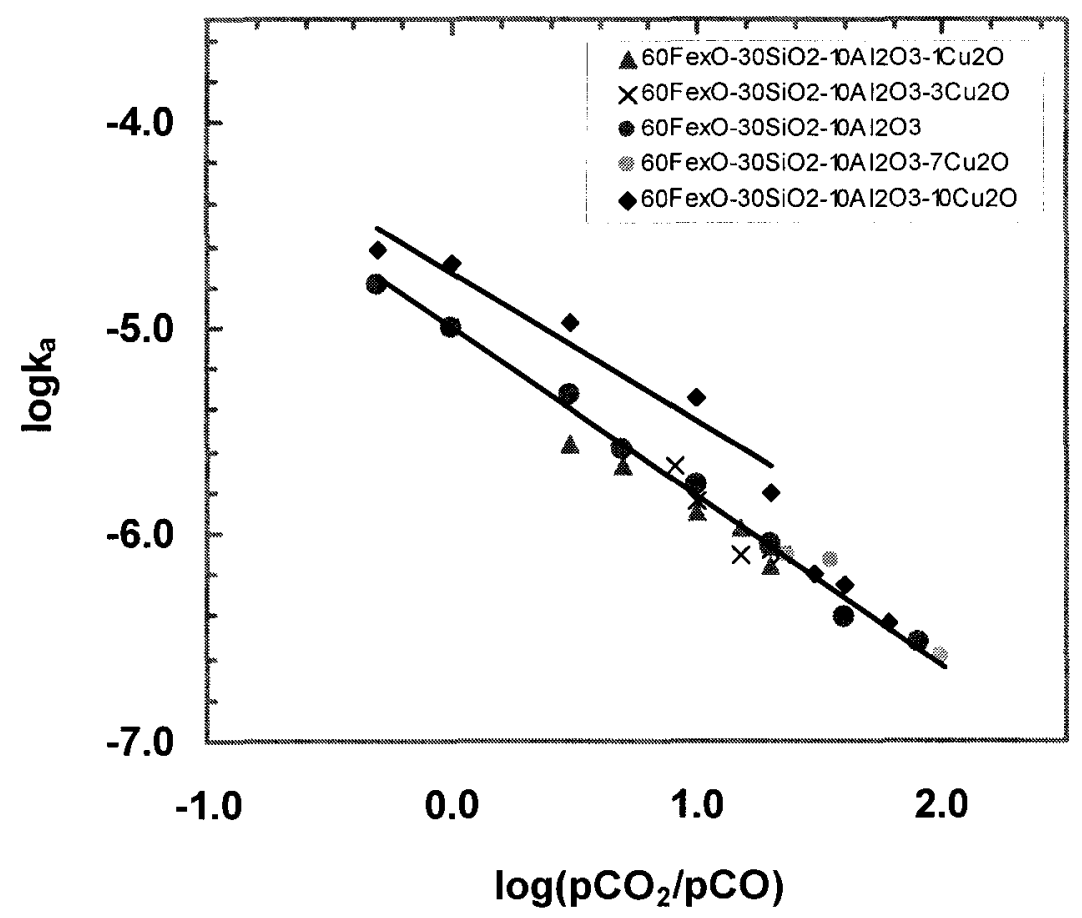

Figure (5.1): The apparent first order rate constants for slag of different percentages of $\mathrm{Cu}_{2} \mathrm{O}$ at $1723 \mathrm{~K}$ as a function of the equilibrium $\mathrm{CO}_{2} / \mathrm{CO}$ ratio. 


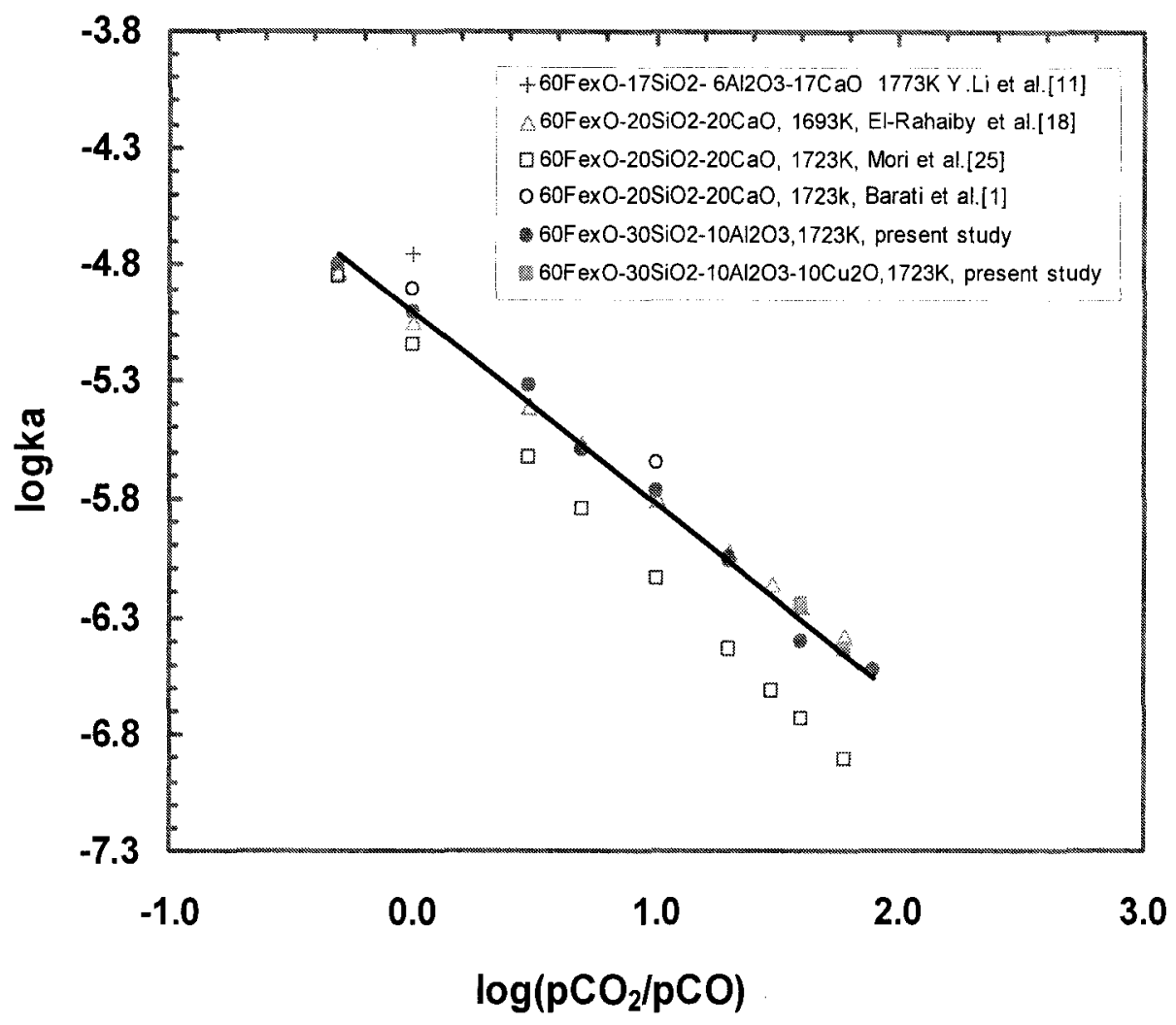

Figure (5.2): The dependence of the apparent rate constants on oxygen potential at 1723K.

The reasons that the effects of these oxides on the rate constants are not very clear until now. However, the possible reasons are discussed as follows. 


\subsubsection{Site blockage model}

Cramb [16][26], Sasaki [17][47] and Sun [31][51] et al. studied the dissociation rate of $\mathrm{CO}_{2}$ on the surface of liquid iron and copper. They found that the rate constants decreased with oxygen potential. These workers used the depression of surface tension by oxygen to determine the adsorption coefficient of oxygen. And found this to be in accord with the kinetic measurements. They also found that sulfur has a similar effect to oxygen, and explained this by a simple site blockage model. $\mathrm{O}$ and $\mathrm{S}$ are surface active elements [65], segregate on the surface, which leads to poisoning of the reaction. They decrease the fraction of free reaction sites, and thus decrease the $\mathrm{CO}_{2}$ dissociation rate.

Depression of surface tension is often considered an indicator of surface activity. Equations have been developed to calculate the partial molar surface tension for surfaceactive slag constituents, such as, $\mathrm{B}_{2} \mathrm{O}_{3}, \mathrm{CaF}_{2}, \mathrm{CaO}, \mathrm{Cr}_{2} \mathrm{O}_{3}, \mathrm{Fe}_{2} \mathrm{O}_{3}, \mathrm{~K}_{2} \mathrm{O}, \mathrm{Na}_{2} \mathrm{O}, \mathrm{P}_{2} \mathrm{O}_{5}, \mathrm{SiO}_{2}$ [59]. Sakai et al. [48] studied the surface tension of copper calcium ferrite slag, and found that the presence of copper oxide in the slag reduces the surface tension slightly. By the same logic, the rate constant should decrease with the addition of all of these surface active compounds. However, some researchers' experimental results [1][12][25][35][45] showed that not all of these surface active oxides decrease the rate constant. The addition of acidic surface active oxides, such as $\mathrm{SiO}_{2}$, and $\mathrm{P}_{2} \mathrm{O}_{5}$, decreased the apparent rate constant, basic surface active oxides such as $\mathrm{Na}_{2} \mathrm{O}$ and $\mathrm{CaO}$ increased it. Thus the effects 
of these basic surface active oxides on the rate constant could not be explained by the simple site blockage model.

\subsubsection{The apparent rate constants as a function of $\mathrm{Fe}^{+3} / \mathrm{Fe}^{+2}$ ratio}

It should also be noticed that these oxides change the $\mathrm{Fe}^{+3} / \mathrm{Fe}^{+2}$ ratio in the liquid slag. Studying the apparent first order rate constant for calcium ferrite slag, Sun et al. [35] gave a simple relationship for the oxidation rate dependence on the $\mathrm{Fe}^{+3} / \mathrm{Fe}^{+2}$ ratio through the following reaction,

$$
\mathrm{CO}_{2}+2 \mathrm{Fe}^{2+}=\mathrm{CO}_{2}^{2-}(\mathrm{ad})+2 \mathrm{Fe}^{3+}
$$

The forward rate of the above reaction may be written in the form,

$$
v=k_{u} p \mathrm{CO}_{2}\left(\mathrm{Fe}^{3+} / \mathrm{Fe}^{2+}\right)^{-2}
$$

where $k_{a}$ is the rate constant for the forward reaction.

Sun et al. [35] found that $\mathrm{ZnO}$, unlike those strong basic oxides, does not affect the $\mathrm{Fe}^{+3} / \mathrm{Fe}^{+2}$ ratio in the melt or at the interface, and thus, does not have a significant effect on the rate constants. Some researchers [46] [50] found that the presence of copper in the slag had no measurable effect on the $\mathrm{Fe}^{+3} /$ total $\mathrm{Fe}$ ratio. However, it is still questionable that this is the reason for $\mathrm{Cu}_{2} \mathrm{O}$ having no remarkable effect because equation (5.2) failed to explain the increase of the apparent rate constants with the addition of basic oxides, such as $\mathrm{Na}_{2} \mathrm{O}, \mathrm{CaO}$, etc. Some experimental results [25] [30] 
[35] show that the basicity increases the $\mathrm{Fe}^{+3} / \mathrm{Fe}^{+2}$ ratio in the slag, whilst according to equation (5.2), the reaction rate should decrease. The fact is the rate increases. So, the effects of these oxides on the rate constant are not due to the change of the ratio of $\mathrm{Fe}^{+3} / \mathrm{Fe}^{+2}$ in the melt.

\subsubsection{The charge transfer model}

Grabke [67] studied the kinetics of oxygen transfer to wustite by measuring the isotope exchange reaction,

$$
{ }^{14} \mathrm{CO}_{2}(\mathrm{~g})+{ }^{12} \mathrm{CO}(\mathrm{g})={ }^{14} \mathrm{CO}(\mathrm{g})+{ }^{12} \mathrm{CO}_{2}(\mathrm{~g})
$$

In which the oxygen transfer (5.3) occurs as a partial reaction step.

$$
\mathrm{CO}_{2}=\mathrm{CO}+\mathrm{O}_{(\mathrm{ads})}
$$

This inevitably involves the transfer of charge. Assuming two charges transferred:

$$
\begin{aligned}
& \mathrm{CO}_{2}(\mathrm{~g})+\mathrm{e}^{-}=\mathrm{CO}_{2}^{-}(\mathrm{ad}) \\
& \mathrm{CO}_{2}^{-}(\mathrm{ad})+\mathrm{e}^{-}=\mathrm{CO}(\mathrm{ad})+\mathrm{O}^{2-}(\mathrm{ad})
\end{aligned}
$$


The transfer rate could be calculated by the empirical equation, [24][67]

$$
v=k_{a}^{0}\left[a_{0}^{-n} p C O_{2}-a_{0}^{1-n} p C O\right]
$$

Equation (5.6) consists of two reaction rates, the dissociation of $\mathrm{CO}_{2}$ :

$$
v=k_{a}^{0} a_{0}^{-n} p C O_{2}
$$

the corresponding back reaction:

$$
v=k_{a}^{0} a_{0}^{1-n} p C O
$$

The dependence of the oxygen transfer rate on the oxygen activity, equation (5.6) may include two influences: [67]

1. Fraction of free reaction site;

2. Free ion or electron concentration.

As discussed in section 5.1.1, the site blockage model could not explain the increase of the rate constant with the addition of basic surface active oxides, such as $\mathrm{CaO}$, $\mathrm{Na}_{2} \mathrm{O}$. These basic surface active oxides do not lead to surface poisoning and therefore the explanation of the effects of both basic and acidic surface active oxides may lie 
elsewhere. $\mathrm{Cu}_{2} \mathrm{O}$, as a basic oxide would be expected to increase the rate but has a limited effect on the $\mathrm{CO}_{2}$ dissociation rate. Grabke [57] found that at temperatures $>800^{\circ} \mathrm{C}$, the dependence on the oxygen activity must be explained by the participation of electrons in the dissociation of the molecules on the wustite surface.

The rate constants for the dissociation of $\mathrm{CO}_{2}$ on liquid slag are described by the equation (5.9),

$$
k_{a}=k_{a}^{0}\left(p C \mathrm{O}_{2} / p C O\right)^{-n}
$$

where: $k_{a}^{0}$ is a temperature dependent constant, $\mathrm{n}$ depends on the slag and temperature. Barati et al. [65] has obtained a relationship between $\mathrm{n}$ and iron oxide content at unit $\mathrm{CaO} / \mathrm{SiO}_{2}$.

The dependence of $k_{a}^{0}$ on the temperature is expressed by the Arrhenius equation, as mentioned in Chapter 4,

$$
k_{a}^{0}=A \exp \left(\frac{-Q}{R T}\right)
$$

where:

Q: the activation energy;

$\mathrm{R}$ : the gas constant;

A: the Arrhenius pre-exponential and has the same dimension as the rate constant. 
Assuming that transfer of electrons via reaction (5.5) is the rate determining step, the activation energy will be related to the energy change for the transfer of electrons to the reactants. This is given by the difference between the energy of the electrons in the bottom of the conduction band at the surface and the Fermi energy, i.e. the electrochemical potential of the electrons [11] [51] [69]. It has been found that the higher the Fermi energy, the more basic the oxide [63]. Thus, basic oxides make a contribution towards ease of charge transfer.

Sun et al. found that [35], unlike the basic oxides, such as $\mathrm{CaO}\left(\Lambda_{(\mathrm{a})}=1\right.$ $[59][60][61]), \mathrm{PbO}\left(\Lambda_{P h O}=1.15\right)$ and $\mathrm{Na}_{2} \mathrm{O}\left(\Lambda_{\mathrm{Na}_{2} \mathrm{O}}=1.15\right)$, the effect of $\mathrm{ZnO}$ $\left(\Lambda_{Z n)}=0.9\right)$ on the rate constant is negligibly small. The optical basicity of $\mathrm{Cu}_{2} \mathrm{O}$ is estimated $\Lambda_{\mathrm{Cu}_{2} \mathrm{O}}=1.0$ according to Mills' model [61] [67], almost equals to that of $\mathrm{CaO}$. However, the experimental results showed that $\mathrm{Cu}_{2} \mathrm{O}$ has no remarkable effect on the rate constant. The explanation may lie in the quantity of $\mathrm{Cu}_{2} \mathrm{O}$ in the slag.

The optical basicity of any system comprised of oxides can be calculated by considering the proportion of each type of oxygen atom and its individual optical basicity value, [60]

$$
\Lambda=\frac{\left[a N_{A} \Lambda_{\left(A_{x} O_{a}\right)}+b N_{B} \Lambda_{\left(B_{x} O_{b}\right)}+\cdots\right]}{a N_{A}+b N_{B}+\cdots}
$$


where: $a$ is the number of oxygen ions in a mole in component $A_{x} O_{a}, N_{A}$ is the mole ratio, $\Lambda_{A_{x} O_{a}}$ is the individual optical basicity.

Based on equation (5.11), the optical basicity for the slag of $60 \mathrm{Fe}_{\mathrm{x}} \mathrm{O}-30 \mathrm{SiO}_{2}$ $10 \mathrm{Al}_{2} \mathrm{O}_{3}$ is $0.688, \Lambda_{\text {ree }}=1.0, \Lambda_{\mathrm{SiO}_{2}}=0.48, \Lambda_{\mathrm{Al}_{2} \mathrm{O}_{3}}=0.6$ [60][61][62]. Adding $10 \mathrm{wt}$ pct $\mathrm{Cu}_{2} \mathrm{O}$ to the slag, which does not represent much in terms of mole percent, the optical basicity becomes 0.699 . The small difference of the optical basicity between these two slag systems would not make any contribution to the rate constant. In the case of the addition of small molecular weight basic oxides, the optical basicity of the slag system can change greatly for a similar wt $\%$ so that the rate constant could be changed. For example, with the addition of $10 \mathrm{wt} \% \mathrm{Na}_{2} \mathrm{O}$ to the above slag, the slag optical basicity increases from 0.688 to 0.722 .

In summary, $\mathrm{Cu}_{2} \mathrm{O}$ has no effect on the $\mathrm{CO}_{2}$ dissociation rate is because the addition of $10 \mathrm{wt}$ pct of $\mathrm{Cu}_{2} \mathrm{O}$ to the slag does not change significantly the basicity of the slag system, and thus can not make a contribution towards ease of charge transfer.

\subsection{The effect of metallic $\mathrm{Cu}$ on the rate constant}

$\mathrm{Cu}_{2} \mathrm{O}$ has no remarkable effect on the apparent first order rate constant as discussed in section 5.1, but, with the decrease of oxygen potential so that copper metal is 
reduced from the slag, the rate constant becomes 2 times higher. The increase of rate constant with the content of reduced metal is shown in Figure (5.3).

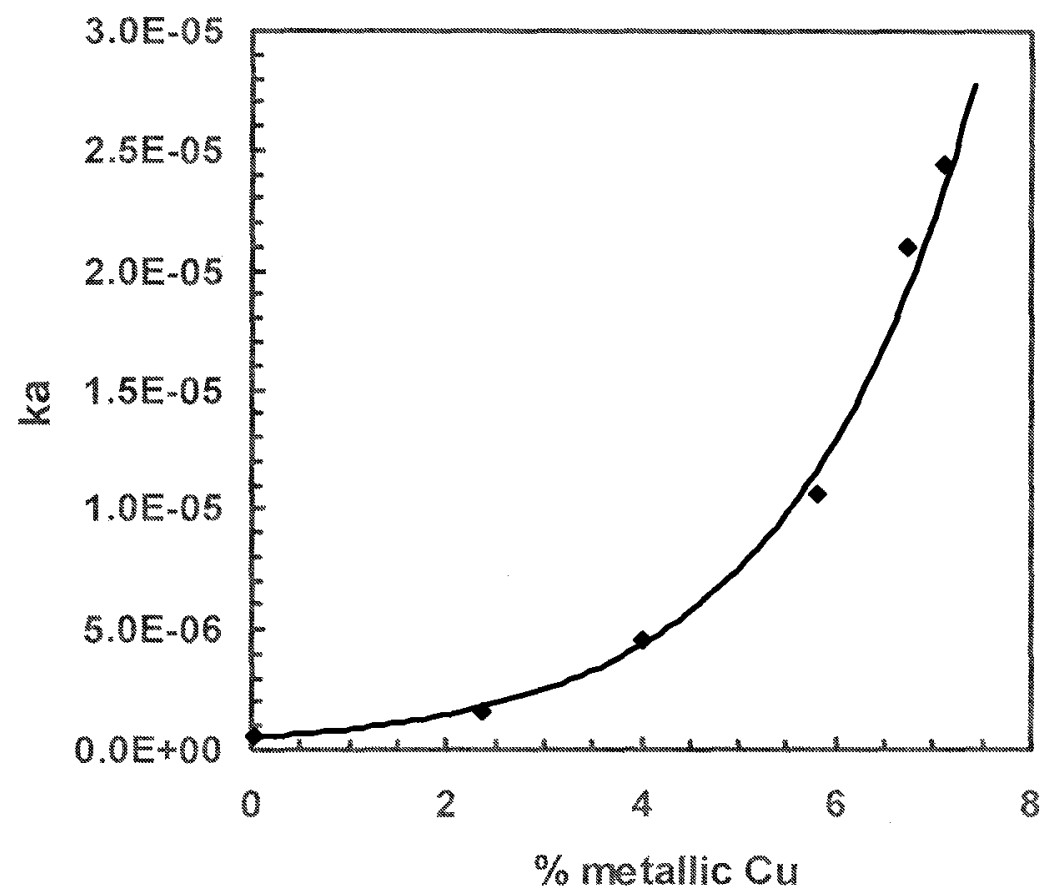

Figure (5.3): The effect of metallic copper on the rate constants.

In order to gain further insight into the effect of metallic copper, experiments were carried on the binary system $\mathrm{Cu}_{2} \mathrm{O}-\mathrm{SiO}_{2}$ using the $\mathrm{CO}$ method. In this binary slag system, metallic copper can be reduced even at very high oxygen potentials. It is noticed that within the whole range of oxygen potentials, the rate constants are almost one order higher than for the $60 \mathrm{Fe}_{\mathrm{x}} \mathrm{O}-30 \mathrm{SiO}_{2}-10 \mathrm{Al}_{2} \mathrm{O}_{3}$ slag system, see Figure (5.4). 


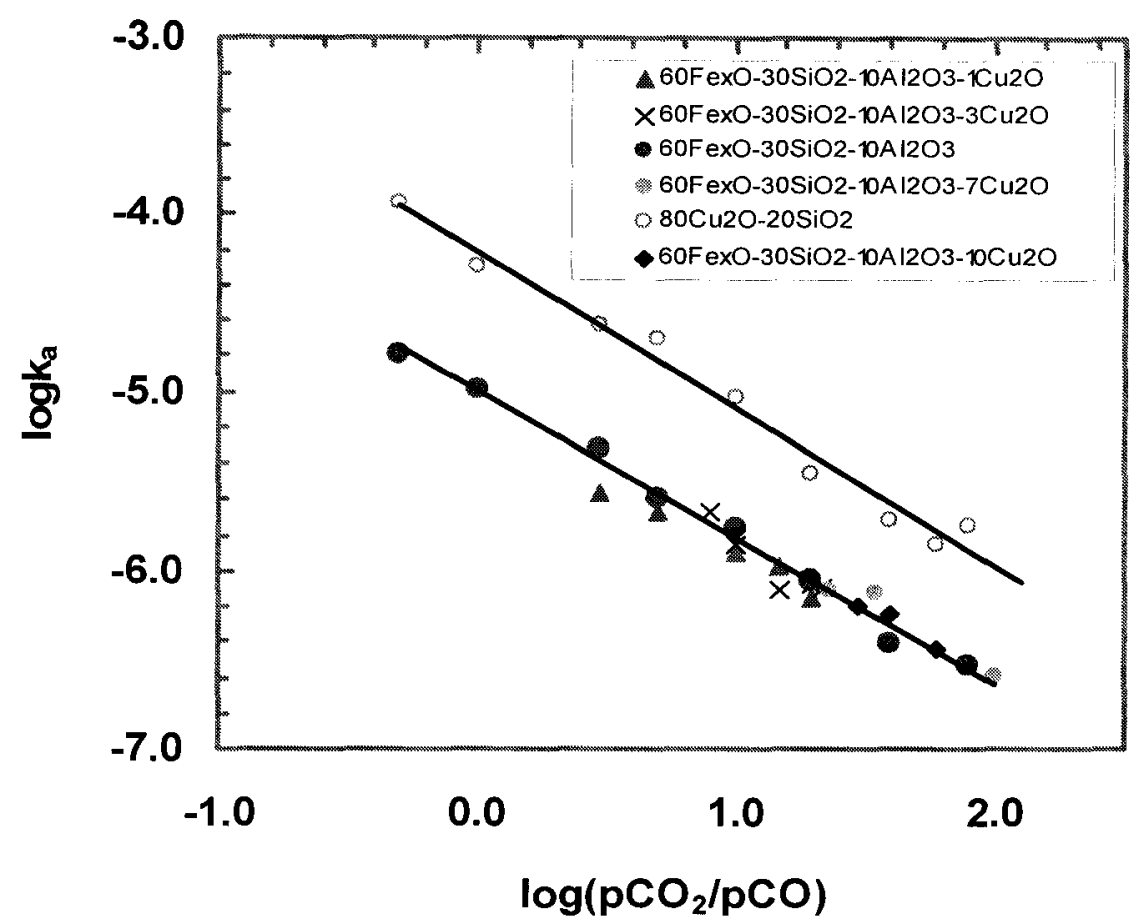

\section{Figure (5.4): Dependence of the apparent first order rate constant on oxygen potential.}

It is apparent that the rate constant increases when metallic copper is reduced from the slag. As mentioned in section 5.1, $\mathrm{Cu}_{2} \mathrm{O}$ has no remarkable effect, thus, the increase of rate constant is believed to be due to small droplets of copper remaining in suspension at the surface of the slag. Although much more dense metal should settle away from the gas/slag interface, it is always expected that some small droplets of metallic copper will stay in the slag.

The dependence of the apparent first order rate constant on temperature is also discussed in Figure 5.5. The activation energy for copper free slag in this study is 190 
$\mathrm{kJ} / \mathrm{mole}$, very close to EL-Rahaiby's result $(196 \mathrm{~kJ} / \mathrm{mol})$ for similar slag compositions. Compared with Utigard's results, the big different might be due to sulfur in his slag.

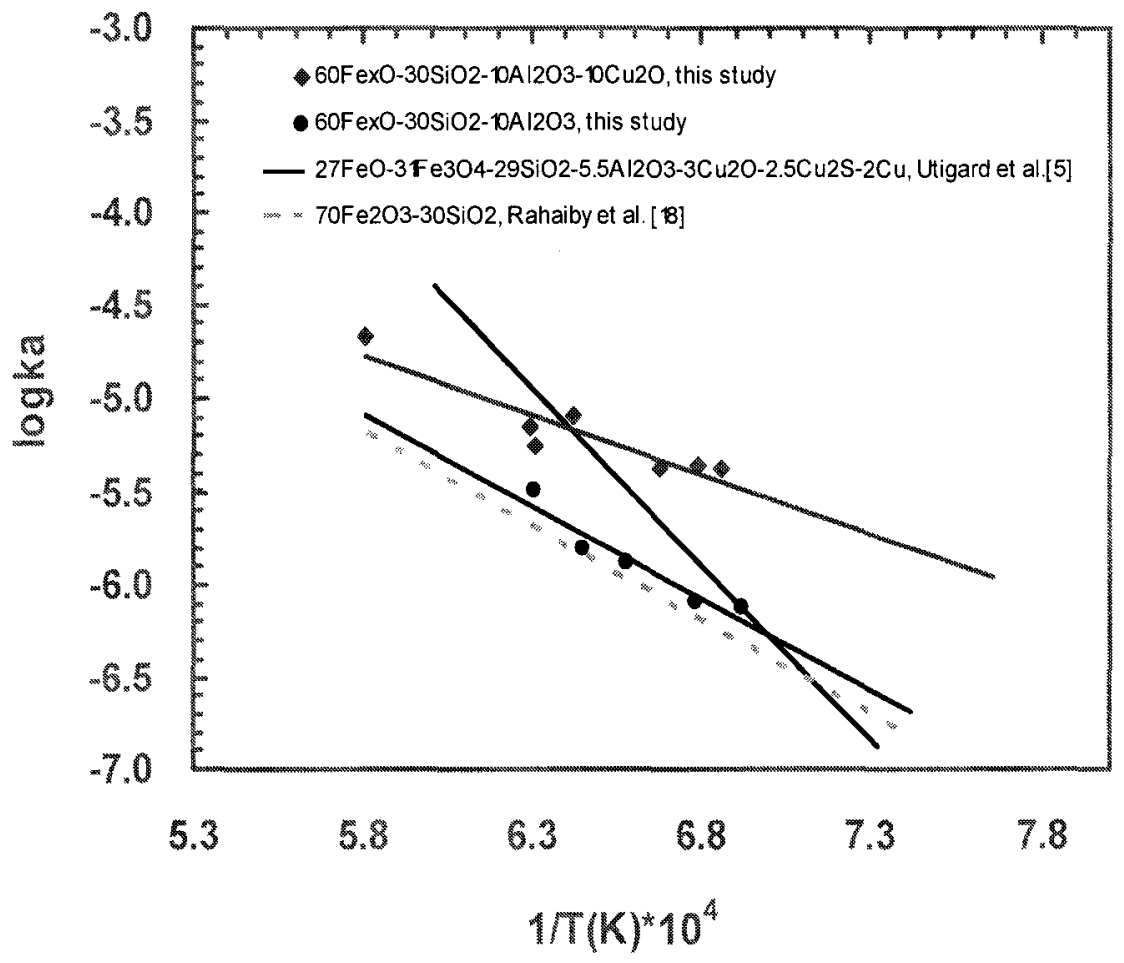

Figure (5.5): The rate constants as a function of temperatures at $\mathrm{pCO}_{2} / \mathrm{pCO}=1$.

The effect of metallic copper on the rate constants can be explained in terms of free electron concentration. As mentioned in section 5.1.3, two factors affect the $\mathrm{CO}_{2}$ dissociation rate. The presence of metallic copper definitely increases free electron concentration, and thus leads to the increase of the rate constant. If we consider the presence of copper to provide a surface of a very different nature we can write an equation for the composite rate constant: 


$$
k_{\text {total }}=k_{\text {slag }} f_{\text {slag }}+k_{C u} f_{C u}
$$

where $f_{l}$ represents the fraction of surface area occupied by that phase. As we can determine $k_{C u}$ from the data of Sun [51] and we know $k_{\text {slag }}$ from the present work, we can estimate the area fraction from the measured values of $k_{\text {toral }}$. The area fraction values for copper are compared in Figure (5.6) with those predicted assuming all copper reduced distributes in the crucibles evenly. Based on this assumption, the area fraction of the metallic copper is equal to it's volume fraction.

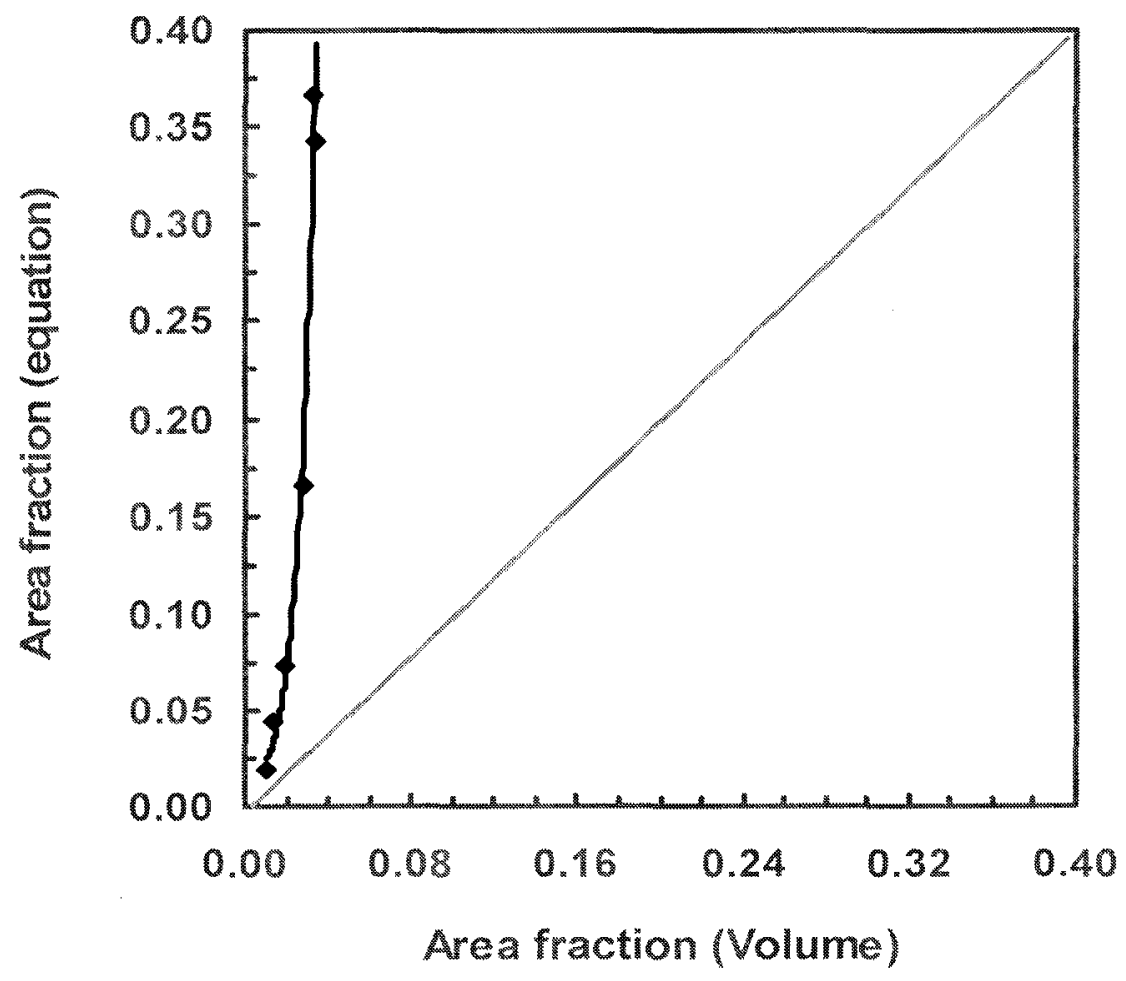

Figure (5.6): The comparison between the area fraction calculated from equation (5.11) and that assuming all reduced copper distributes in the crucible evenly. 
These results do not seem reasonable because even if all of the reduced copper is present in the slag, the rate constant could not be the same high as shown in Figure (5.5). As mentioned before, the assumption is that reduced metallic copper distributes in the crucible evenly, but according to the comparison in Figure (5.6), it might be possible that most of the small droplets of copper remaining in suspension at the surface of the slag and increase the rate greatly.

Once again, if we assume that the area fraction of liquid copper droplets were those calculated from the composite rate equation (5.11) and that all the copper occupies the surface as small droplets, we can calculate the radii of metallic droplets.

$$
\begin{aligned}
& \because \quad S_{\text {total }}=n \cdot \pi r^{2} \quad(5.12) \quad \text { and } \quad V_{\text {total }}=n \cdot \frac{4}{3} \pi r^{3} \\
& \therefore \quad r=\frac{3}{4} \frac{V}{S} \quad \text { (5.14) }
\end{aligned}
$$

where: $\mathrm{n}$ is the number of metal droplets, $\mathrm{r}$ is the radius of the metal droplet.

The calculated radii are $3-600 \mu \mathrm{m}$ (see Figure 5.7), which is a much wider range than the $1-25 \mu \mathrm{m}$ given by Warczok for the size range of the metallic copper inclusions in the slag [10][68][70], but consistent none the less. Their small range might be caused by the mechanical factors considering the practical situations. 


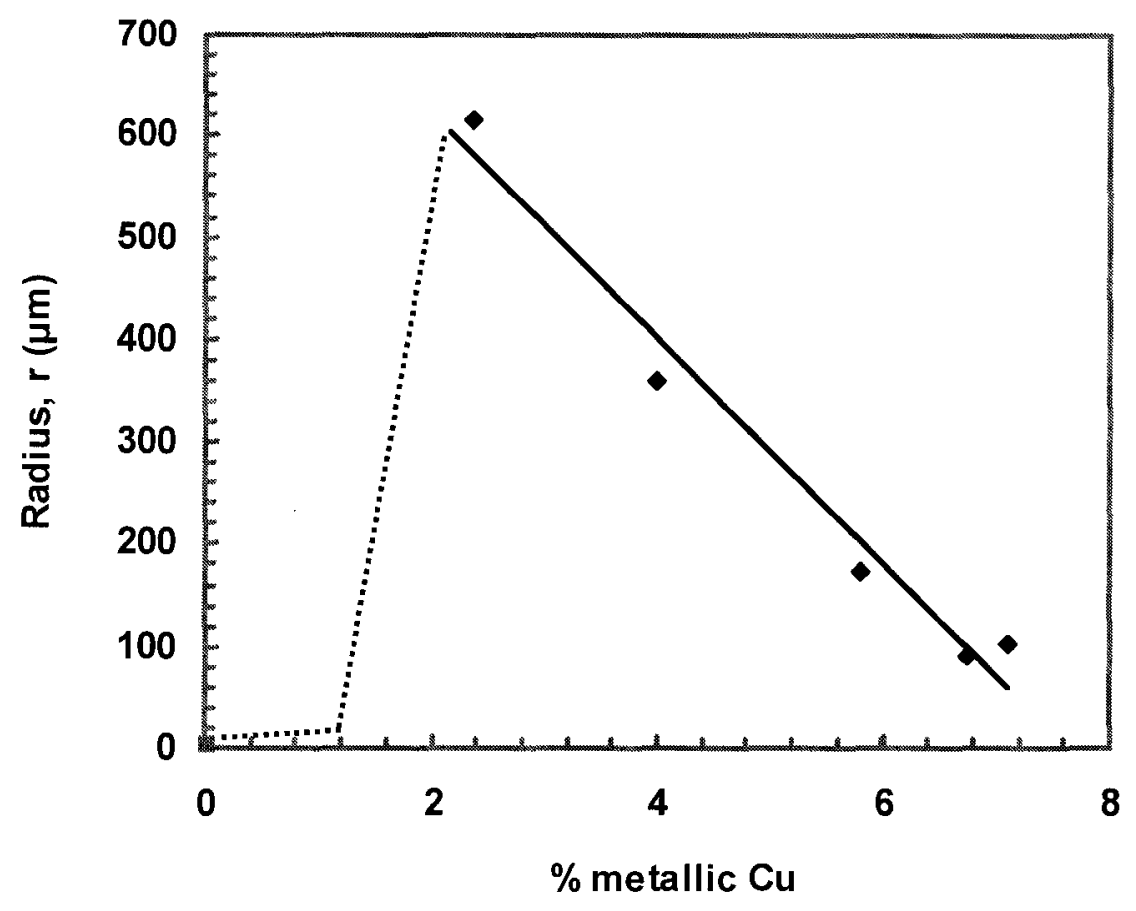

Figure (5.7): The change of the radii of the droplets calculated from kinetic measurements with the percentage of reduced metallic copper. 


\section{Chapter Six:}

\section{Conclusions}

The reaction between carbon and slags is of significant importance during direct smelting of iron ores, EAF slag foaming and copper slag cleaning processes. This reaction is known to occur via gaseous intermediates and it is important to have fundamental data to understand the relative importance of each reaction step. In this study, the rate constants of $\mathrm{CO}_{2}$ dissociation on the surface of copper making slag were measured using the isotope exchange technique. The relationship between rate constants, oxygen potential and temperature were determined. The effects of metallic copper and copper oxides on the rate constants were found. 


\subsection{Conclusions}

1. The apparent first order rate constants for the dissociation of $\mathrm{CO}_{2}$ on liquid copper making slag are described by the equation,

$$
k_{a}=k_{a}^{0}\left(p c o_{2} / p c o\right)^{-n}
$$

$\mathrm{n}$ depends on the slag composition and temperature.

2. $\mathrm{n}=-0.85$ for the slag of $60 \mathrm{Fe}_{\mathrm{x}} \mathrm{O}-30 \mathrm{SiO}_{2}-10 \mathrm{Al}_{2} \mathrm{O}_{3}$, at $\mathrm{T}=1585 \mathrm{~K}$, it changed to -0.82 at $\mathrm{T}=1723 \mathrm{~K} \cdot \mathrm{n}=-0.79$ for the slag of $60 \mathrm{Fe}_{\mathrm{x}} \mathrm{O}-30 \mathrm{SiO}_{2}-10 \mathrm{Al}_{2} \mathrm{O}_{3}-10 \mathrm{Cu}_{2} \mathrm{O}$, at $\mathrm{T}=1585 \mathrm{~K}$, it changed to -0.73 at $\mathrm{T}=1723 \mathrm{~K}$.

3. For slags of the $\mathrm{Fe}_{\mathrm{x}} \mathrm{O}-\mathrm{SiO}_{2}-\mathrm{Al}_{2} \mathrm{O}_{3}-\mathrm{Cu}_{2} \mathrm{O}$ system, the apparent rate constants remain fixed with $\mathrm{Cu}_{2} \mathrm{O}$ content from 1-10 wt pct at higher oxygen potentials under which no metallic copper reduced from the slag.

4. $\mathrm{Cu}_{2} \mathrm{O}$ has no remarkable effect on the rate constant because even at $10 \mathrm{wt} \%$, it makes little difference to the basicity. This is in contrast to oxides of similar basicity but much lower mole weight.

5. The rate constants increased by 2 times after metallic copper (2-7 \% in the slag) was reduced.

6. The increase with the presence of metallic copper in the slag is due to presence of metal droplets which have higher free electron concentrations.

7. The effect of temperatures in the range from $1200-1450^{\circ} \mathrm{C}$ on the rate constants was studied. The measured activation energy was $190 \mathrm{~kJ} /$ mole for slag $60 \mathrm{Fe}_{\mathrm{x}} \mathrm{O}$ - 
$30 \mathrm{SiO}_{2}-10 \mathrm{Al}_{2} \mathrm{O}_{3}$. In the presence of $\mathrm{Cu}$ metal in the slag, the activation energy was reduced to $122 \mathrm{~kJ} /$ mole ( $65 \mathrm{~kJ} /$ mole for pure copper according to Sun [29]).

8. Based on the two previous conclusions it is reasonable to conclude that the rate determining step in the current work involves the transfer of electrons to adsorbed $\mathrm{CO}_{2}^{-}$, i.e. reaction $(5.5)$,

$$
\mathrm{CO}_{2}^{-}(\mathrm{ad})+\mathrm{e}^{-}=\mathrm{CO}(\mathrm{ad})+\mathrm{O}^{2-}(\mathrm{ad})
$$

\subsection{Future work}

Sulfur is a typical surface active element, which decreases the apparent rate constant by a factor of about 30 when its content is $0.3 \mathrm{~mol}$ pet in liquid copper at $1458 \mathrm{~K}$, $\mathrm{pCO}_{2} / \mathrm{pCO}=10$ according to Sun and Belton. [51] However, there have been few studies relating this effect of sulfur on the interfacial rates of reaction of $\mathrm{CO}_{2}$ and $\mathrm{CO}$ with liquid copper.

In addition, $\mathrm{H}_{2}$ is another important reductant in the production of iron oxide from liquid slag. [53]-[57] Nagasaka and Fruehan [53][54] measured the rate of decarburization of iron by $\mathrm{H}_{2} \mathrm{O}$. The rate for $\mathrm{H}_{2} \mathrm{O}$ behaved similarly to that for $\mathrm{CO}_{2}$ but 
was an order of magnitude faster than for $\mathrm{CO}_{2}$. It is necessary to measure the reduction rate of iron oxides containing slags when hydrogen is a reductant.

Further study would be very helpful for enhancing the bath smelting, EAF and copper slag cleaning processes, because $\mathrm{H}_{2}$ occurs inevitably as a strong reductant in all of the above process. 


\section{References:}

1. M. Barati, E. Chen, and K.Coley, VII International Conference on Molten Slags Fluxes and Salts, (2004): 393

2. A.K.Biswas and W.G.Davenport, Extractive Metallurgy of Copper, Oxford; New York: Pergamon Press, 1980

3. Hang Goo Kim and H.Y.Sohn, Metallurgical and Materials Transactions B, 29B, (1998): 583

4. A.Warczok, G.Riveros and C.Diaz, in J.M.Toguri Symposium, Fundamentals of Metallurgical Processing, ed.G. Kaiura, C. Pickles, T. Utigard, A.Vahed, Canadian Institute of Mining, Metallurgy and Petroleum, (2000): 481

5. T. Utigard, G.Sanchez, J.Manriquez, A.Luraschi, C.Diaz, D.Cordero, and E.Almendras, Metallurgical and Materials Transactions B, 28B, (1997): 821

6. D.J.Min, J.W.Han and W.S.Chung, Metallurgical and Materials Transactions B: 30B, (1999): 215

7. D.J.Min and R.J.Fruehan, Metallurgical and Materials Transactions B: 23B, (1992): 29

8. Amitava Paul, Brahma Deo and Narayanasami Sathyamurthy, Steel Research, No.10, (1994): 414

9. A.Warczok and T.A.Utigard, Canadian Metallurgical Quarterly, 37, (1998): 27

10. A.Warczok, G.Riveros, P.Echeverria, C.Diaz, H.Schwarze and G.Sanchez Canadian Metallurgical Quarterly, 41, (2002): 465

11. Y.Li and I.P.Ratchev, Metallurgical and Materials Transactions B, 33B, (2002): 651

12. Y.Li, I.P.Ratchev, J.A.Lucas, G.M.Evans, and the late G.R.Belton Metallurgical and Materials Transactions B, 31B, (2000): 1049 
13. S.R.Story, B.Sarma, R.J.Fruhan, A.W.Cramb and G.R.Belton, Metallurgical and Materials Transactions B, 29B, (1998): 929

14. B.Sarma, A.W.Cramb, and R.J.Fruehan, Metallurgical and Materials Transactions B, 27B, (1996): 717

15. D.Xie and G.R.Belton, Metallurgical and Materials Transactions B, 34B, (2003): 225

16. A.W.Cramb and G.R.Belton, Metallurgical Transactions B, 12B, (1981):699

17. Y.Sasaki, S.Hara, D.R.Gaskell and G.R.Belton, Metallurgical Transactions B, 15B, (1984):563

18. S.K.EL-Rahaiby, Y.Sakaki, D.R.Gaskell, and G.R.Belton,. Metallurgical Transactions B, 17B, (1986): 307

19. S.Sun, Y.Sakaki and G.R.Belton, Metallurgical Transactions B, 19B, (1988): 959

20. J.R.Taylor and J.H.E.Jeffes, Transactions of the Institution of Mining and Metallurgy, (Section C: Mineral Processing and Extractive Metallurgy), 84, (1975): C18

21. R.J.Fruehan, The Making, Shaping and Treating of Steel, AISE Foundation, Steelmaking Volume, $11^{\text {th }}$ Ed. 1998

22. Atsumu Ozaki, Isotopic Studies of Heterogeneous Catalysis, Tokyo: Kodansha ; New York : Academic Press, 1977

23. C.Borgianni, Ironmaking and steelmaking, No.2, (1978): 61

24. Carl Wagner, Advances in Catalysis, Adsorbed Atomic Species as Intermediates in Heterogeneous Catalysis, 21, (1970): 323

25. Mamiko MORI, Kazuki MORITA and Nobuo SANO, ISIJ International,(1996): 624

26. A.W.Cramb,W.R.Graham and G.R.Belton, Metallurgical Transactions B, 9B (1978): 623

27. H.J.Grabke, 3rd International Congress on Catalysis, Amsterdam (1964): 928 
28. Hiroyuki Matsuura and Fumitaka Tsukihashi, in Yazawa International Symposium, Metallurgical and Materials Processing Fundamentals and New Technology, ed. F.Kongoli, K.Itagaki, C.Yamauchi and H.Y.Sohn, TMS, vol.1, (2003): 107

29. S. Sun and G.R.Belton, Mineral Processing and Extractive Metallurgy Review, 10, (1992): 291

30. LiXiang Yang and G.R.Belton, Metallurgical Transactions B, 29B, (1998): 837

31. S. Sun and G.R.Belton, Metallurgical and Materials Transactions B, 29B, (1998): 137

32. M.Nagamori and P.J.Mackey, Metallurgical Transactions B, 8B, (1977):39

33. Roger Altman and H.H.Kellogg, Transactions of the Institution of Mining and Metallurgy, (Section C: Mineral Processing and Extractive Metallurgy), 81, (1972): C163

34. J.M.Toguri and N.H.Santander, Canadian Metallurgical Quarterly, 8, (1969):167

35. S. Sun and Sharif Jahanshaih, Metallurgical and Materials Transactions B, 31B, (2000): 937

36. F.J.Mannion and R.J.Fruehan, Metallurgical and Materials Transactions B, 20B, (1989): 853

37. D.R.Sain and G.R.Belton, Metallurgical and Materials Transactions B, 7B,(1976): 235

38. R.J.Fruehan, D.Goldstein, B.Sarma, S.R.Story, P.C.Glaws and H.U.Pasewicz, Metallurgical and Materials Transactions B, 31B, (2000): 891

39. D.R. Sain and G.R.Belton, Metallurgical and Materials Transactions B, 9B, (1978): 403

40. S.R.Story and R.J.Fruehan, Metallurgical and Materials Transactions B, 31B, (2000): 43

41. Jae-Cheol Lee, Dong-Joon Min, and Sung-Soo Kim, Metallurgical and Materials Transactions B, 28B, (1997): 1019 
42. K.P.EI-Rassi and T.A.Utigard, Metallurgical and Materials Transactions B, 31B, (2000): 1187

43. M.Nagamori, P.J.Machey and P.Tarassoff, Metallurgical and Materials Transactions B, 6B, (1975): 295

44. I.Imris, S.Rebolledo, M.Sanchez, G.Castro, G.Achurra and F.Hernandez, Canadian Metallurgical Quarterly, Vol.39, No.3, (2000): 281

45. T.Nagasaka, Mitsutaka Hino and Shiro Ban-Ya, Metallurgical and Materials Transactions B, 31B, (2000): 945

46. Toshio Oishi, Morinori Kamuo, Katsutoshi Ono, and Joichiro Moriyama, Metallurgical and Materials Transactions B, 14B, (1983):101

47. Y.Sasaki and G.R.Belton, Metallurgical and Materials Transactions B, 11B, (1980): 221

48. T. Sakai, S.W.IP and J.M.Toguri, Metallurgical and Materials Transactions B, 28B, (1997): 401

49. R.J.Hundermark, S.Jahanshahi, and S.Sun, VII International Conference on Molten Slags Fluxes and Salts, (2004): 487

50. Akira Yazawa and Yoichi Takeda, Transactions of the Japan Institute of Metals, Vol.23, No.6 (1982):328

51. S. Sun and G.R. Belton, Metallurgical and Materials Transactions B, 29B, (1998): 296

52. R.J.Fruehan and L.J.Martonik, Metallurgical Transactions, Vol.5,(1974):1027

53. R.J.Fruehan, G.R.Belton, F.J.Mannion, and Y.Sasaki, Metallurgical and Materials Transactions B, 23B, (1992): 45

54. T.Nagasaka and R.J.Fruehan, Metallurgical and Materials Transactions B, 23B, (1994): 245

55. P.C.Glaws and G.R.Belton, Metallurgical and Materials Transactions B, 21B, (1990): 511

56. C.F.Acton and G.R.Belton, Metallurgical and Materials Transactions B, 7B, (1976): 693 
57. Y.Sasaki and G.R.Belton, Metallurgical and Materials Transactions B, 14B, (1983): 267

58. R.K.Paramguru, R.K.Galgali and H.S.Ray, Metallurgical and Materials Transactions B, 28B, (1997): 805

59. K.C.Mills and B.J.Keene, International Materials Reviews, Vol.32, No.1-2, (1987): 55

60. J.A.Duffy, Ironmaking and steelmaking, Vol.17, No.6, (1990): 410

61. K.C.Mills, ISIJ International, Vol.33, No.1, (1993): 624

62. D.R.Gaskell, Metallurgical and Materials Transactions B, 20B, (1989):113

63. W.M.Mullins, Surface Science Letter, 262, (1992): L144

64. H.J.Grabke, ISIJ International, Vol.29, No.7, (1989): 529

65. Private communication, to be published

66. H.J.Grabke and H.Viefhaus, Ber.Bunsenges. Physical Chemistry, 84, (1980):152

67. A.Lebouteiller and P.Courtine, Journal of Solid State Chemistry, Vol.137, (1998): 94

68. A.Warczok and T.A.Utigard, Metallurgical and Materials Transactions B, 26B, (1995): 1165

69. H. Reiss, Journal of Physical chemistry, 89, (1985): 3783

70. P.Spira and N.J.Themelis, Journal of Metals, (1969): 35 